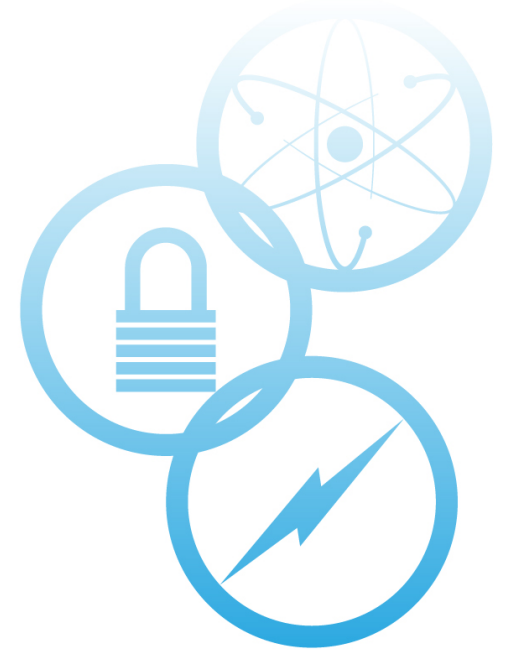

\title{
An Investigation of Liquefaction in Irradiated TRIGA Fuel Exposed to Relatively High Temperatures
}

Dennis D. Keiser, Jr.,

Francine J. Rice

David A. Sell

Jan-Fong Jue

Emmanuel Perez

Bryan L. Forsmann

Eric C. Woolstenhulme

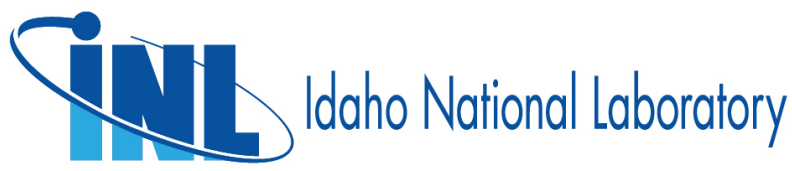




\section{DISCLAIMER}

This information was prepared as an account of work sponsored by an agency of the U.S. Government. Neither the U.S. Government nor any agency thereof, nor any of their employees, makes any warranty, expressed or implied, or assumes any legal liability or responsibility for the accuracy, completeness, or usefulness, of any information, apparatus, product, or process disclosed, or represents that its use would not infringe privately owned rights. References herein to any specific commercial product, process, or service by trade name, trademark, manufacturer, or otherwise, does not necessarily constitute or imply its endorsement, recommendation, or favoring by the U.S. Government or any agency thereof. The views and opinions of authors expressed herein do not necessarily state or reflect those of the U.S. Government or any agency thereof. 


\title{
An Investigation of Liquefaction in Irradiated TRIGA Fuel Exposed to Relatively High Temperatures
}

November 2020

\author{
Idaho National Laboratory \\ Idaho Falls, Idaho 83415
}

http://www.inl.gov

\author{
Prepared for the \\ U.S. Department of Energy \\ NNSA Office of Material Management and Minimization \\ Under DOE Idaho Operations Office \\ Contract DE-AC07-05ID14517
}


Page intentionally left blank 


\begin{abstract}
This report presents the findings of an investigation into high-temperature fuel cladding chemical interactions (FCCI) in Training, Research, Isotopes, General Atomics (TRIGA) fuel rods. A TRIGA fuel-rod core or meat is principally composed of uranium (U) particles dispersed in a zirconium-hydride $(\mathrm{Zr}-\mathrm{H})$ matrix. The fuel is clad in sealed 304SS or Incoloy 800 tubes. At high temperatures, the fuel will interact with the cladding, resulting in FCCI.

To investigate the FCCI (in this case, liquefaction), irradiated TRIGA fuel rods were exposed to relatively high temperatures in furnace tests. The tests were performed at different temperatures using segments from an irradiated TRIGA fuel rod at the Hot Fuel Examination Facility located at Idaho National Laboratory (INL). The data from this study is important for developing a better understanding of the performance of $\mathrm{U}-\mathrm{ZrH}$ fuel type during transient events (e.g., a Loss of Coolant Accident [LOCA] event) that may result in high temperatures while operating a TRIGA reactor. Furnace tests were run for $6 \mathrm{hr}$ at $730,800,900,950$, and $1,000^{\circ} \mathrm{C}$. One test was run for $12 \mathrm{hr}$ at $950^{\circ} \mathrm{C}$. Post-test microstructural characterization was performed on the heat-treated specimens using optical metallography to look for evidence of liquefaction. Additionally, microstructural characterization was performed using scanning electron microscopy to investigate the microstructure of the as-irradiated fuel before heat treatment and the microstructural changes that occurred after heat treating at 730 and $950^{\circ} \mathrm{C}$ for $6 \mathrm{hr}$. Results of the analysis were compared to those produced during diffusion studies performed using unirradiated TRIGA fuel meat and Type 304 stainless steel. A gap is typically present in as-irradiated fuel that limits any possibility for chemical interaction between the fuel and cladding. Optical metallography $(\mathrm{OM})$ was used to identify areas in the specimens that were heat treated at 950 and $1000^{\circ} \mathrm{C}$ where fuel and cladding contact was satisfactory for the FCCI to transpire. The bulk of the interaction zones that form due to FCCI developed in the fuel meat and not as much in the cladding. Even in the specimen heated to $1,000^{\circ} \mathrm{C}$, no evidence was found that gross fuel meat or cladding melting had occurred. Only limited porosity was found in the fuel meat, which possibly was from melting of a particular precipitate phase or phases that had formed during FCCI. These results agreed with those reported for the unirradiated diffusion couple studies.
\end{abstract}


Page intentionally left blank 


\section{CONTENTS}

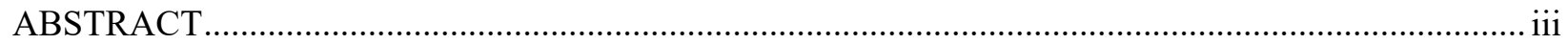

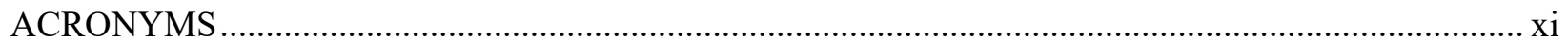

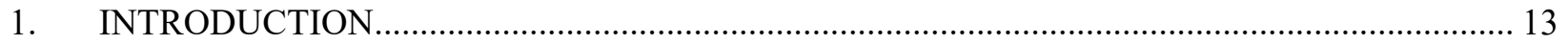

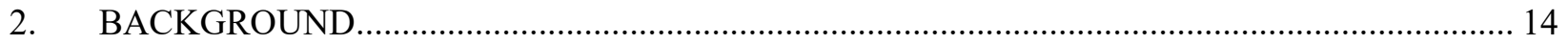

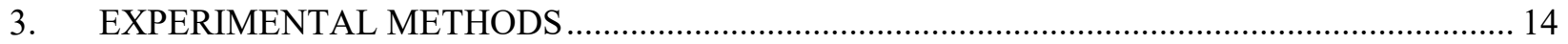

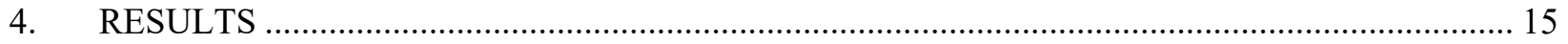

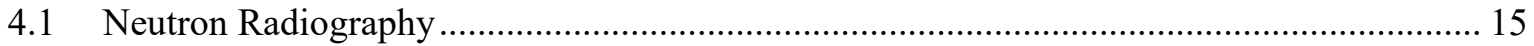

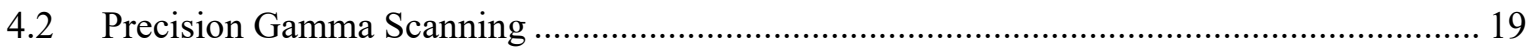

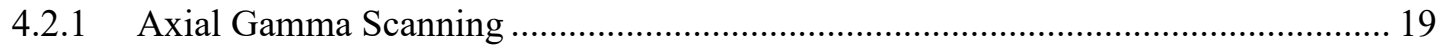

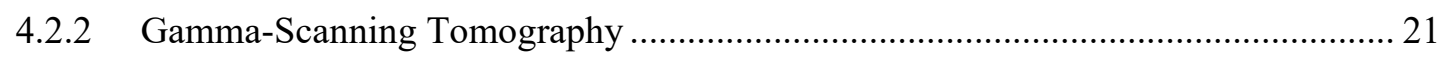

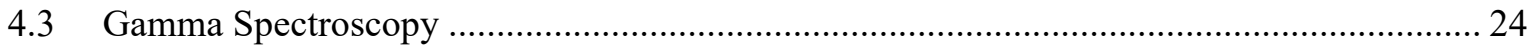

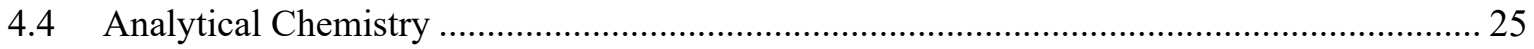

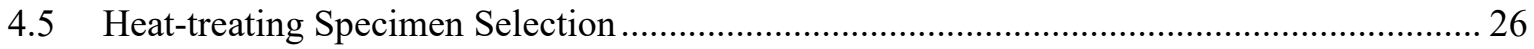

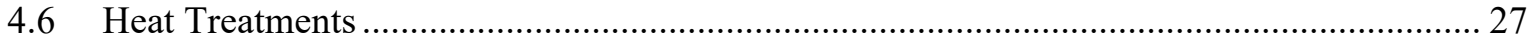

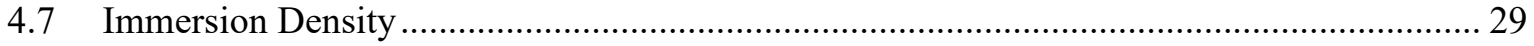

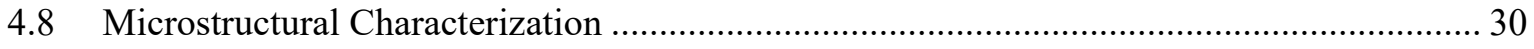

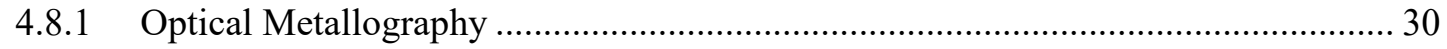

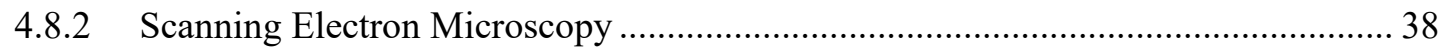

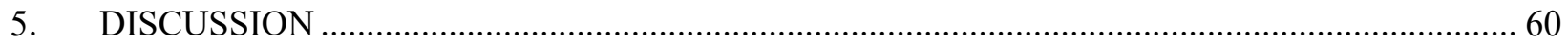

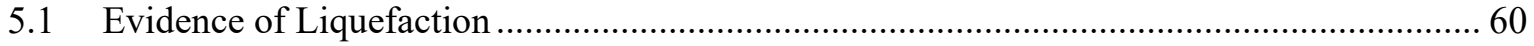

5.1.1 Comparison to Out-of-Pile Diffusion Studies Using Unirradiated TRIGA Fuel and

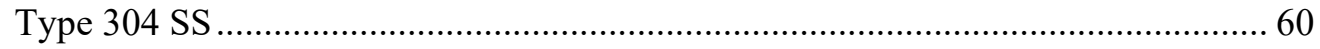

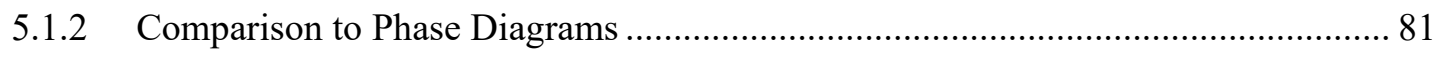

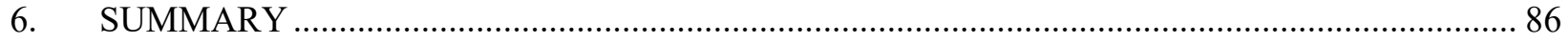

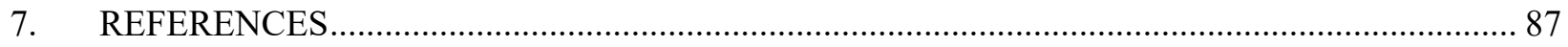

\section{FIGURES}

Figure 1. TRIGA fuel rod and components. The zirconium rods run through holes present in the fuel-meat sections.

Figure 2. Dysprosium exposure for Fuel Rods 10172 and 10172 for the 0, 60- and 120-degree rotations.

Figure 3. Fuel Rods 10170 and 10172 shown for the 120-degree view. The circled regions are dehydride locations in the fuel meat.

Figure 4. Example of fuel meat to cladding interface for Fuel Rod 10172 


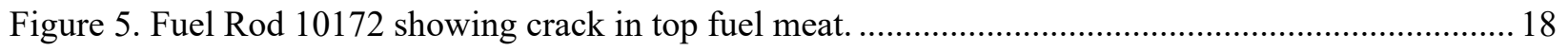

Figure 6. Isotopic gamma-scan profile for TRIGA Fuel Rod 10170 ................................................... 20

Figure 7. Isotopic gamma-scan profile for TRIGA Fuel Rod 10172. Y-axis in in Cs-137 counts. ............ 20

Figure 8. (a) initial fuel-rod sectioning diagrams for Fuel Rod 10172 showing where the ends were removed and (b) where the fuel meat was cut into sections. Y-axis is in Cs-137 counts.

Figure 9. Fuel Slug 1 from Fuel Rod 10172, showing chemistry specimen. Y-axis is in Cs-137 counts. 22

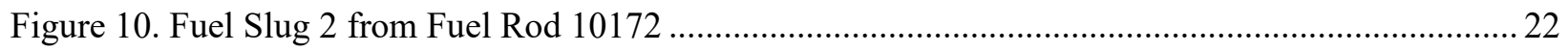

Figure 11. Fuel Slug 3 from Fuel Rod 10172, showing chemistry specimen, anneal specimen, and non-annealed specimen. Y-axis is in Cs-137 counts.

Figure 12. BOT217 137Cs (a), 60Co (b) and 154Eu (c) tomographic maps.

Figure 13. Chemistry sample-sectioning diagrams from Specimen BOT215 from Fuel Rod 10172, fuel pieces -2 (a) and -1 (b)...

Figure 14. BOT215 134Cs (a), and 154Eu (b) gamma spectroscopy results as measured as a solid and $134 \mathrm{Cs}(\mathrm{c})$, and 154Eu (d) as measured in solution.

Figure 15. Plotted burnup values calculated via fission product measured using chemistry and ICP-MS. 26

Figure 16. Experiment furnace configuration for the TRIGA fuel heat-treating experiments. (a) Photo of sealed furnace insert assembly, and (b) the inside of the insert assembly where the samples reside in alumina crucibles. 28

Figure 17. Tantalum wrap for Specimen BOT223 heat treated at $800^{\circ} \mathrm{C}$ for $6 \mathrm{hr}$ with first layer of Ta reacted, as shown in (a), and the final layer of Ta in pristine condition, as shown in (b).

Figure 18. Specimen BOT221 showing fuel bulging near the cladding following a heat treatment at $950^{\circ} \mathrm{C}$ for $6 \mathrm{hr}$.

Figure 19. Pre-anneal image of BOT224 (a) and the post-anneal swelling shown for Specimen BOT224 (b).

Figure 20. BOT229/MNT56Y non-heat-treated as-received specimen full montage at 31.5× magnification.

Figure 21. BOT229/MNT56Y non-heat-treated as-received specimen at 200× magnification, showing a fuel to cladding region with the best signs of potential fuel and cladding contact.

Figure 22. BOT228/MNT55Y $730^{\circ} \mathrm{C}$-heat-treated specimen full montage at $31.5 \times$ magnification. The white rectangle is a missing image in the montage.

Figure 23. BOT228/MNT55Y $730^{\circ} \mathrm{C}$-heat-treated specimen partial montage at $100 \times$ magnification, showing a fuel to cladding region with the best signs of good contact.

Figure 24. BOT223/MNT94Y $800^{\circ} \mathrm{C}$ heat-treated specimen full montage at $31.5 \times$ magnification. A crack is running down the center of the specimen..... 32

Figure 25. BOT223/MNT94Y $800^{\circ} \mathrm{C}$ heat-treated specimen partial montage at $200 \times$ magnification showing a fuel to cladding region with the best signs of good contact. .32 
Figure 26. BOT222/MNT91Y $900^{\circ} \mathrm{C}$ heat-treated specimen full montage at $31.5 \times$ magnification.

Dark regions toward center of specimen are $\mathrm{Zr}-\mathrm{H}$ phase.

Figure 27. BOT222/MNT91Y $900^{\circ} \mathrm{C}$ heat-treated specimen partial montage at $200 \times$ magnification showing a fuel to cladding contact region. 33

Figure 28. BOT221/MNT92Y $950^{\circ} \mathrm{C}$ heat-treated specimen full montage at $31.5 \times$ magnification. 34

Figure 29. BOT221/MNT92Y $950^{\circ} \mathrm{C}$ heat-treated specimen partial montage at $200 \times$ magnification showing observed FCCI that resulted in the formation of a layer at the fuel and cladding interface.

Figure 30. BOT224/MNT99Y $950^{\circ} \mathrm{C}$ heat-treated specimen full montage at $31.5 \times$ magnification. Dark regions toward center of specimen are $\mathrm{Zr}-\mathrm{H}$ phase. 34

Figure 31 . BOT224/MNT99Y $950^{\circ} \mathrm{C}$ heat-treated specimen partial montage at $200 \times$ magnification showing observed FCCI at the fuel and cladding interface.

Figure 32. A full montage at $31.5 \times$ magnification of the BOT225/MNT01Z specimen heat treated at $950^{\circ} \mathrm{C}$ for $12 \mathrm{hr}$.

Figure 33. BOT225MNT01Z $950^{\circ} \mathrm{C} 12$-hr heat-treated specimen partial montage at $200 \times$ magnification showing observed FCCI at the fuel and cladding interface and the resulting development of an interaction layer.

Figure 34. BOT220/MNT93Y $1000^{\circ} \mathrm{C}$ heat-treated specimen full montage at $31.5 \times$ magnification. Dark regions toward center of specimen are $\mathrm{Zr}-\mathrm{H}$ phase or sample damage during polishing. 36

Figure 35 . BOT220/MNT93Y $1000^{\circ} \mathrm{C}$ heat-treated specimen partial montage at $200 \times$ magnification showing the fuel to cladding contact region.

Figure 36. A plot of the thickness of the cladding not impacted by FCCI at different locations for the different annealed specimens.

Figure 37. Backscattered electron images (a-c) showing the as-irradiated TRIGA fuel microstructure (a) and a gap (b,c) that was observed at the fuel and cladding interface. 38

Figure 38. A BSE image of the irradiated fuel specimen microstructure (a) and WDS x-ray maps for (b) U and (c) Zr. Hydrogen cannot be detected using WDS. 39

Figure 39. Montage of optical images showing as-fabricated TRIGA fuel. 40

Figure 40. BSE images $(a, b)$ of the microstructure for as-fabricated TRIGA fuel [2]. .40

Figure 41. XRD pattern obtained from as-fabricated TRIGA fuel. 41

Figure 42. Montage of OM images showing location where SEM sample was taken (area in dashed line box). 42

Figure 43. Photographs of the as-mounted samples from the TRIGA fuel that was heat treated at $730^{\circ} \mathrm{C}$ for $6 \mathrm{hr}$ that were generated for SEM analysis. .42

Figure 44. BSE image of the fuel and cladding interface for Sample 03A. A gap was observed. .43

Figure 45. BSE image (a) and WDS x-ray maps for (b) Zr, (c) Er, and (d) U in the TRIGA fuel for Specimen 03A after the heat treatment at $730^{\circ} \mathrm{C}$ for $6 \mathrm{hr}$. .43

Figure 46. BSE image (a) showing location of EDS line scan (dashed line), and (b) variations of $\mathrm{Fe}, \mathrm{Cr}, \mathrm{Ni}, \mathrm{Zr}$, and $\mathrm{U}$ concentrations along line scan for Sample 03A. 44 
Figure 47. BSE micrographs of Sample 05A. A gap was observed at the fuel and cladding interface.

Figure 48. Montage of OM images showing location where SEM sample was taken (area in dashed line box). Isolated dark areas are $\mathrm{Zr}-\mathrm{H}$ phase. 46

Figure 49. Photograph of the as-mounted sample that was generated for SEM analysis. 46

Figure 50. BSE images $(\mathrm{a}-\mathrm{b})$ The microstructure at the fuel and cladding interface for Sample 02A (annealed at $950^{\circ} \mathrm{C}$ for $6 \mathrm{hr}$ ).

Figure 51. SE images (a-d) and BSE image (e-f) showing porosity that can be observed in the interaction zone.

Figure 52. BSE image of interdiffusion zone (a) and WDS x-ray maps (b-i) for $\mathrm{Cr}, \mathrm{Fe}, \mathrm{Ni}, \mathrm{Mn}, \mathrm{U}$, $\mathrm{Zr}, \mathrm{Nd}$, and $\mathrm{Pu}$, respectively.

Figure 53. BSE image of interdiffusion zone (a) and WDS x-ray maps (b-h) for Fe, Cr, U, Zr, Ce, $\mathrm{Nd}$, and Er, respectively.

Figure 54. BSE image of interdiffusion zone (a) and WDS x-ray maps for (b) Er, (c) Fe, (d) U, and (e) $\mathrm{Zr}$.

Figure 55. BSE image (a) showing where a WDS line scan was performed at the fuel and cladding interface for Sample 02A, and the results for $\mathrm{Cr}, \mathrm{Fe}, \mathrm{Ni}$, and $\mathrm{U}$ are shown in (b), (c), (d), and (e), respectively. The y-axis is in counts. 52

Figure 56. BSE image (a) and WDS x-ray maps for (b) Fe, (c) U, (d) Zr, (e) Er, and (f) Ni. .53

Figure 57. (a) BSE image showing a line of EDS composition measurements (in wt.\%) taken through the interdiffusion zone; (b) a plot of the results for $\mathrm{Fe}, \mathrm{Zr}$, and $\mathrm{U}$; and (c) a plot of the results for $\mathrm{Cr}, \mathrm{Nd}, \mathrm{Ni}, \mathrm{Er}$, and $\mathrm{Fe}$.

Figure 58. BSE image (a) and WDS x-ray maps for (b) Fe, (c) Zr, (d) U, (e) Er, (f) Nd, and (g) Ce.

Figure 59. BSE images $(\mathrm{a}-\mathrm{c})$ showing fine phases present in the interdiffusion zone nearest the unreacted cladding. .56

Figure 60. BSE image (a) at location of interdiffusion zone nearest the unreacted cladding. .57

Figure 61. OM image (100x magnification) showing the location of possible grain boundary phase(s) present on the unreacted cladding side of the interdiffusion zone for the specimen annealed at $950^{\circ} \mathrm{C}$ for $6 \mathrm{hr}$. .58

Figure 62. BSE image (a) showing microstructure of fuel and cladding interaction zone.

Figure 63. (a) is a schematic diagram of a diffusion couple jig employed for the diffusion couple experiments described in [5] and (b) shows a standard jig used for experiments performed by [2].

Figure 64. Fuel and cladding interface for a diffusion couple annealed at (a) $730^{\circ} \mathrm{C}$ for $1 \mathrm{hr}$ and (b) $800^{\circ} \mathrm{C}$ for $1 \mathrm{hr}[5]$

Figure 65 . Temperature profiles generated from the TRIGA fuel heat-treating process at $950^{\circ} \mathrm{C}$ for (a) 5, (b) 16, and (c) $24 \mathrm{hr}$.

Figure 66. TRIGA fuel microstructure after heat treating at $950^{\circ} \mathrm{C}$ for $5 \mathrm{hr}$ : (a) low and (b) higher magnification BSE micrographs. 
Figure 67. (a) BSE micrograph of a selected microstructural area of unirradiated TRIGA fuel annealed at $950^{\circ} \mathrm{C}$ for $5 \mathrm{hr}$. EDS x-ray maps are shown for (b) $\mathrm{Zr}$, (c) U, and (d) Er.

Figure 68. TRIGA fuel microstructure after heat treating at $950^{\circ} \mathrm{C}$ for $16 \mathrm{hr}$ : (a) low and (b) higher magnification BSE micrographs.

Figure 69. TRIGA fuel microstructure after heat treating at $950^{\circ} \mathrm{C}$ for $24 \mathrm{hr}$ : (a) low and (b) higher magnification BSE micrographs.

Figure 70. XRD pattern obtained from the TRIGA fuel annealed at $1000^{\circ} \mathrm{C}$ for $24 \mathrm{hr}$.

Figure 71 . BSE image (a) of a diffusion couple annealed at $1000^{\circ} \mathrm{C}$ for $5 \mathrm{hr}$ where a gap near the fuel and cladding interface is present, along with the presence of a microns-thick FCCI zone that extends into the cladding, and (b) is a higher magnification image of this interaction zone, (c) is an SE image showing voids moving towards the TRIGA fuel.

Figure 72. High-angle annular dark-field micrograph of the TEM sample obtained from the interaction region of the diffusion couple of TRIGA fuel versus Type 304SS annealed at $1000^{\circ} \mathrm{C}$ for $5 \mathrm{hr}$.

Figure 73. Backscatter electron micrographs of (a) a selected region from the TRIGA fuel versus $304 \mathrm{SS}$ diffusion couple annealed at $1000^{\circ} \mathrm{C}$ for $24 \mathrm{hr}$, and (b) a detailed micrograph of the interaction region.

Figure 74. BSE image (a) of the interaction zone penetration into the cladding for the $1000^{\circ} \mathrm{C}$ diffusion couple annealed for $24 \mathrm{hr}$.

Figure 75 . Diffusion couple run at $1000^{\circ} \mathrm{C}$ for $24 \mathrm{hr}$ in the advanced diffusion jig (a) prior to heat treating and (b) post heat treating.

Figure 76. BSE micrograph of a selected area of a cross section of the Type 304SS that was in contact with the re-solidified TRIGA fuel material that was to the right.

Figure 77. XRD pattern of a selected area in the re-solidified material in a diffusion couple run at $1000^{\circ} \mathrm{C}$ for $24 \mathrm{hr}$ using the advanced diffusion couple jig.

Figure 78. Diffusion couple run at $900^{\circ} \mathrm{C}$ for $24 \mathrm{hr}$ in an advanced diffusion jig in the post heattreating condition.

Figure 79. BSE micrographs of the cross sections of the diffusion couple run at $900^{\circ} \mathrm{C}$ for 24 using the advanced diffusion couple jig. .73

Figure 80 . BSE micrograph of a selected region of the fuel and cladding interaction zone .74

Figure 81. Concentration profiles for $\mathrm{Zr}, \mathrm{Cr}, \mathrm{Fe}, \mathrm{Ni}$, and $\mathrm{U}$ generated from the interaction region of a diffusion couple annealed at $900^{\circ} \mathrm{C}$ for $24 \mathrm{hr}$ using the advanced diffusion couple jig.

Figure 82. SE image and EDS x-ray maps for $\mathrm{Fe}, \mathrm{Cr}, \mathrm{Mn}, \mathrm{Ni}, \mathrm{Er}, \mathrm{Si}, \mathrm{U}$, and $\mathrm{Zr}$ in the same region along the fuel and cladding interface that was selected for the concentration profile in Figure 81 .

Figure 83. (a) SE and (b) BSE micrographs of a selected region of the interaction zone where voids can be observed. 75

Figure 84. Higher magnification BSE micrographs of the interaction zone region that contains the $\mathrm{Zr}(\mathrm{C}, \mathrm{H})$ phase . 76

Figure 85. SE image and EDS x-ray maps for Fe, Cr, Mn, Er, Ni, Si, U, and $\mathrm{Zr}$ at a second selected area in the interaction region where a void is present. .76 
Figure 86. BSE micrograph showing the locations where the EDS compositional data enumerated in Table 9 were collected.

Figure 87. (a) a BSE image of the fuel and cladding interaction zone for the irradiated TRIGA fuel sample annealed at $950^{\circ} \mathrm{C}$ for $6 \mathrm{hr}$ 80

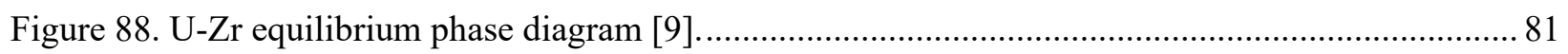

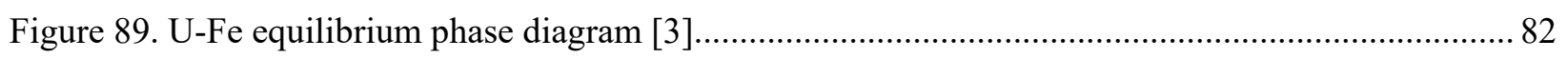

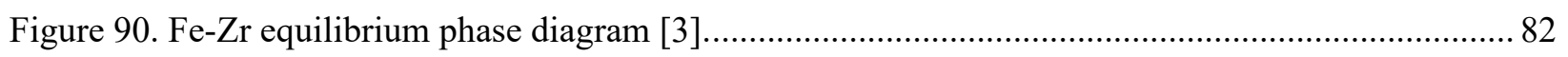

Figure 91. U-Zr-Fe ternary phase diagrams at (a) $730^{\circ} \mathrm{C}$ and (b) $800^{\circ} \mathrm{C}$. The dashed line in (b) shows in a general way how a diffusion path could move through the diagram and various phase regions for a diffusion couple going from the fuel with almost 80 at.\% $\mathrm{Zr}$ to the cladding [11].

Figure 92. (a) OM image of a FBTA test result showing an HT9-Clad U-10Zr fuel pin segment ( $\sim 3$ at. \% BU) after being heated at $750^{\circ} \mathrm{C}$ for $1 \mathrm{hr}$ and (b) OM image of a FBTA test result showing an HT9-Clad U-10Zr fuel pin segment ( $\sim 3$ at.\% BU) after being heated at $800^{\circ} \mathrm{C}$ for $1 \mathrm{hr}$.

\section{TABLES}

Table 1. Nominal composition of Type 304 stainless steel. 14

Table 2. Gamma-scanning specimen summary. 21

Table 3. Burnup percent calculated from select fission-product inventories. 26

Table 4. List of anneal, chemistry, and non-annealed specimens with analysis performed. .27

Table 5. Phase compositions, in at.\%, at Locations 1-4 depicted in Figure 60(b). .58

Table 6. EDS measurements for the concentrations of $\mathrm{Er}, \mathrm{U}$, and $\mathrm{Zr}$ in various observed phases in the unirradiated TRIGA fuel specimen annealed at $950^{\circ} \mathrm{C}$ for $5 \mathrm{hr}$.

Table 7. Measured concentrations using EDS of different observed features in fuel microstructure of sample annealed at $950^{\circ} \mathrm{C}$ for $16 \mathrm{hr}$.

Table 8. Measured concentrations using EDS of different observed features in fuel microstructure of sample annealed at $950^{\circ} \mathrm{C}$ for $24 \mathrm{hr}$.

Table 9. Compositional EDS data collected from the interaction region of a diffusion couple annealed at $900^{\circ} \mathrm{C}$ for $24 \mathrm{hr}$ where the locations are shown in Figure 87. 


\section{ACRONYMS}

BSE backscattered electrons

DOE Department of Energy

EDS Energy-dispersive spectroscopy

FBTA Fuel Behavior Test Apparatus

FCCI Fuel cladding chemical interactions

HFEF Hot Fuels Examination Facility

INL Idaho National Laboratory

LOCA Loss of Coolant Accident

OM Optical metallography

PGS Precision gamma scanning

QA Quality Assurance

RERTR Reduced Enrichment Research and Test Reactors

SE Secondary electrons

SEM Scanning electron microscopy

TEM Transmission electron microscope

TRIGA Training, Research, Isotopes, General Atomic

WDS Wavelength dispersive spectroscopy

XRD X-Ray diffraction

QA Quality Assurance

RERTR Reduced Enrichment Research and Test Reactors

SE Secondary electrons

SEM Scanning electron microscopy

TEM Transmission electron microscope

TRIGA Training, Research, Isotopes, General Atomic

WDS Wavelength dispersive spectroscopy

XRD X-ray diffraction 
Page intentionally left blank 


\section{INTRODUCTION}

Fuel element temperature is a safety parameter for Training, Research, Isotopes, General Atomic (TRIGA) reactors. High-temperature limits are established to mitigate loss of cladding confinement and the subsequent release of fission products. For some TRIGA reactors, a Loss of Coolant Accident (LOCA) is postulated where the fuel element temperatures could exceed safe levels. One of the postulations is that excessive temperatures could cause the cladding to fail by potential liquefaction, due to the formation of eutectic phases that result from interdiffusion between the uranium or fission products in the fuel meat and the iron, chromium, or nickel in the cladding [1].

The main objectives of this testing were to (1) identify the temperature for irradiated TRIGA fuel, as a function of burnup if possible, where liquid phases (i.e., eutectics) form at the fuel and cladding interface, and (2) determine how liquid phases propagate in the irradiated fuel microstructure (i.e., into the fuel or towards the outer surface of the cladding) at relatively high temperatures, and (3) provide data to improve understanding of how liquefaction might impact the confinement capabilities of the cladding.

The propensity for the formation of eutectic phases between the constituents of typical TRIGA fuel and cladding materials (fuel and cladding chemical interaction [FCCI]) has not been observed at the operating conditions that are characteristic of TRIGA reactors. However, it would be beneficial to evaluate this phenomenon using focused experiments under prototypic conditions. There is also interest from the Nuclear Regulatory Commission to assess the potential for the eutectic phase formation for very low probability, non-mechanistic accident conditions, primarily LOCA-type accidents. At these conditions, some calculations have shown that temperatures during latter stages of decay heating could exceed those for eutectic phase formation (based on available binary phase diagrams) between the constituents of the TRIGA fuel and cladding materials. Therefore, an experimental capability was established for testing irradiated fuel-rod sections to determine if eutectic phases can form between irradiated TRIGA fuel and cladding; this capability was employed to investigate the impact of liquefaction at relatively high temperatures on cladding integrity.

Two irradiated TRIGA rods, serial numbers 10170 and 10172, were selected from a batch of rods that were shipped to Idaho National Laboratory (INL) from General Atomics in San Diego, California. The rods were recovered from their storage location at the Irradiated Spent Fuel Storage facility and transported to the Hot Fuels Examination Facility (HFEF). Precision gamma scanning (PGS) and neutron radiography of the fuel rods were performed before cutting the rods into sections for heat treating. The sections were later cut into smaller "specimens" where required for special analyses. A series of heat treatments were then performed using rod sections taken from the highest-burnup regions of the fuel rod. The rod sections, or specimens from the sections, were characterized following the heat treatment to identify any evidence of liquefaction at the fuel and cladding interface.

Initial characterization was performed using optical metallography (OM). Follow-on characterization was performed using analytical chemistry and scanning electron microscopy (SEM) combined with energy-dispersive spectroscopy (EDS) for compositional measurements and wavelength dispersive spectroscopy (WDS) for x-ray mapping. This report discusses the results of the PGS, neutron radiography, analytical chemistry, OM, and SEM. Explanations are given pertaining to any indications that liquefaction has occurred at the fuel and cladding interface of the specimens. Comparisons are made to the results reported for the unirradiated TRIGA fuel-meat diffusion couple studies with Type 304 stainless steel (SS). The processes and findings are reported in the following sections.

The INL Quality Assurance (QA) Program and associated implementing procedures, as identified in LST-13040, "QA Program Implementing Documents," and LWP-13016, “Applying Quality Assurance

Requirements to Research and Development Activities," for an applied research and development activity, were followed, as applicable. Following the INL QA Program and implementing procedures assured that the testing was done in compliance with NQA-1 requirements. 
PLN-2078, "The Quality Assurance Program Plan for RERTR Fuel Development," was issued to identify the QA requirements unique to the Reduced Enrichment Research and Test Reactors (RERTR) program. PLN-2078 supplements PDD-13000, "INL Quality Assurance Program Description," and defines any deviations from the INL QA Program.

\section{BACKGROUND}

A TRIGA fuel-rod assembly with its components is shown in Figure 1. The fuel rod is axially centered in the Type 304 stainless-steel (SS) cladding tube with a graphite reflector slug at each end. Molybdenum discs are placed between the fuel meat and the graphite slug as shown in Figure 1 . There is no bonding material between the cladding and fuel meat. The fuel meats have a hole in the center where a solid zirconium rod is inserted in each fuel meat during assembly. The zirconium rod provides for increased hydrogen content in the fuel element. End fittings are heliarc welded to the top and bottom ends of the cladding tube, encapsulating all internal pieces.

The two TRIGA rods used for testing were discharged from service in the reactor on January 31, 1995, and stored at the storage pool at General Atomics until the fuel rods were shipped to the Hot Fuel Examination Facility in 2018 for characterization and furnace testing. The calculated physics data estimated the average-per rod burnup for 10170 and 10172 to be 20.72 and 21.81 mega-watt-days, respectively.

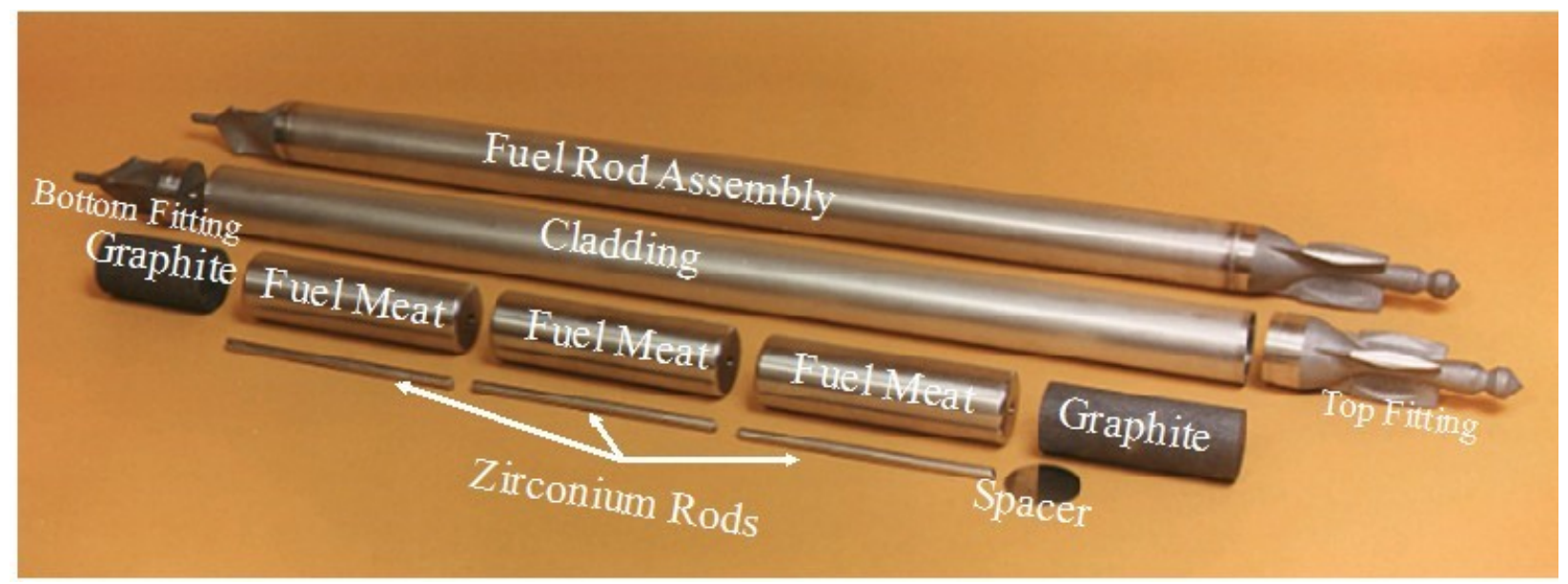

Figure 1. TRIGA fuel rod and components. The zirconium rods run through holes present in the fuel-meat sections.

Table 1. Nominal composition of Type 304 stainless steel.

$\begin{array}{lllllllll}\text { Element } & \mathrm{C}(\leq) & \mathrm{Si}(\leq) & \mathrm{Mn}(\leq) & \mathrm{P}(\leq) & \mathrm{S}(\leq) & \mathrm{Cr} & \mathrm{Ni} & \mathrm{Fe} \\ \text { Wt.\% } & 0.08 & 1.00 & 2.00 & 0.045 & 0.030 & 18-20 & 8-11 & \text { Bal. }\end{array}$

\section{EXPERIMENTAL METHODS}

Non-destructive visual examinations, neutron radiography, and PGS were performed on both rods upon reciept. This informed the investigators where to cut the rod so that sections could be produced for the best testing and characterization results. The PGS data showed the regions of higher burnup that were of greater interest due to the larger inventory of lanthanide fission products in the fuel meats. Lanthanides had been hypothesized to lower the melting point of the phases that develop during the FCCI. Neutronradiography images showed areas in the fuel meats that may have dehydrided or cracked; therefore, the fuel meats may not produce prototypical results during heat treating in the test furnace. These areas were avoided during the specimen selection process. 
Analytical chemistry was performed to benchmark the PGS data by establishing the local fissionproduct inventories for select test specimens. The fission-product inventory was coupled with the PGS data to determine the fission density, burnup, and fission-product inventories for the sections selected for heat treating.

OM images were to be used later to evaluate differences at the fuel and cladding interface between heat-treated, irradiated specimens, as-irradiated, non-heat-treated specimens, and non-irradiated specimens. OM images were also used to select the areas of interest in the fuel and cladding regions before heat treating. Those areas were used to make the smaller samples used for SEM characterization, WDS x-ray mapping, and EDS spot analysis.

Specimens cut from the fuel rods and were heated in a tube furnace isolated from the furnace body within an insert that was designed specifically for this test in the HFEF hot cell. The tube furnace insert was continuously purged with high-purity argon during heat treating to limit specimen oxidation. Additionally, the insert was positioned within the large, uniform, isothermal heating zone, which eliminated temperature gradients that could affect diffusion processes. Fuel-rod specimens were wrapped in three layers tantalum foil to prevent impurities and oxygen from reaching the argon, thus keeping the specimen from reacting within the test insert. Following completion of each test at the specified time at temperature, the specimens were cooled in the furnace. Gas flow of the high-purity argon was maintained until the furnace was at ambient temperature.

Immersion density measurements were taken (pre- and post-annealing) to provide volumetric change data for a $950^{\circ} \mathrm{C}$ test specimens. This characterization was performed to evaluate the observed dimensional changes for a $950^{\circ} \mathrm{C}$ heat-treated specimen that was later added to the specimen test matrix. This additional data was requested when it was noted during some post-test visual exams, that significant dimensional changes had occured for some previously annealed specimens tested at this temperature.

Following the heat treatments, pre-anneal and post-anneal optical microscopy data was used to inform the selection of the locations from the heat-treated specimens where samples would be cut for SEM characterization. SEM characterization was then performed on samples that were selected from the fuel and cladding regions that appeared (using the OM data) to have reacted during furnace testing. WDS x-ray mapping was used during the SEM characterization to determine the interaction behaviors of fuel, cladding, and fission-product constituents. EDS spot analysis was also used to obtain qualitative information on the phase compositions. Hydrogen concentrations could not be measured since neither EDS nor WDS can resolve this element.

\section{RESULTS}

The results of the various tests and examinations described in Section 3 above are given in the following sections.

\subsection{Neutron Radiography}

Neutron radiography is a non-destructive characterization method used to evaluate mechanical integrity and geometric stability prior to performing destructive examinations. A loss of integrity of geometric stability would be indicated by evidence of fuel cracking, fuel relocation, or significant fuel density variations throughout the element and rod. Radiographic images are also used to guide further post-irradiation examinations and to both benchmark and validate other non-destructive characterization data. All neutron-radiography activities were performed according to PLN-5059, "Neutron Radiography of TRIGA Fuel Pins for the TRIGA Eutectic Study," HFEF-OI-5810, "In-Cell Radiography," NRAD-OI-5550, "Photographic Laboratory," NRAD-OI-5560, "Neutron Radiography, East Radiography Station," a completed FRM-1411, "NRAD Request Sheet," and MCP-3948, "US HPRR Fuel Development Data Qualification." 
Neutron radiography was performed on two irradiated TRIGA fuel rods (10170 and 10172) to improve the likelihood of selecting regions of fuel to cladding contact for the TRIGA fuel heat-treating experiments. Radiography was also expected to reduce the likelihood of selecting areas for sectioning with higher levels of damage to the fuel meat and the fuel to cladding interface. A collimated neutron beam from the reactor penetrated the fuel. The beam was attenuated by the uranium zirconium hydride fuel in the rods. Attenuation is dependent on uranium density, thickness, and local neutron cross section; the remaining beam passed onto a foil made of a high-neutron cross-section material, which became activated. The activated foil was placed on industrial x-ray radiography film in a vacuum cassette and allowed to decay for a minimum of five half-lives. The activated foil subsequently decayed by beta emission, and the beta particles exposed the radiography film, thus transferring a latent image of the fuel rod from the foil to the film. The film was developed using an automatic film processor to obtain a finished neutron-radiography image.

The NRAD imaging of TRIGA Rods 10170 and 10172 was successful in providing data with which to assess the general condition of the fuel region of both rods. Both are shown in Figure 2 for the dysprosium exposure. Regions of dehydriding are observed in both rods (most pronounced in the 120-degree view) and are primarily located in the regions between the fuel meats. These areas were characterized by the circled darker regions on the fuel meats in the radiographs shown in Figure 3 for Fuel Rod 10170 and 10172. It is hypothesized that these were areas of higher temperatures during the operation of the reactor and the hydrogen diffused from these areas to cooler areas.

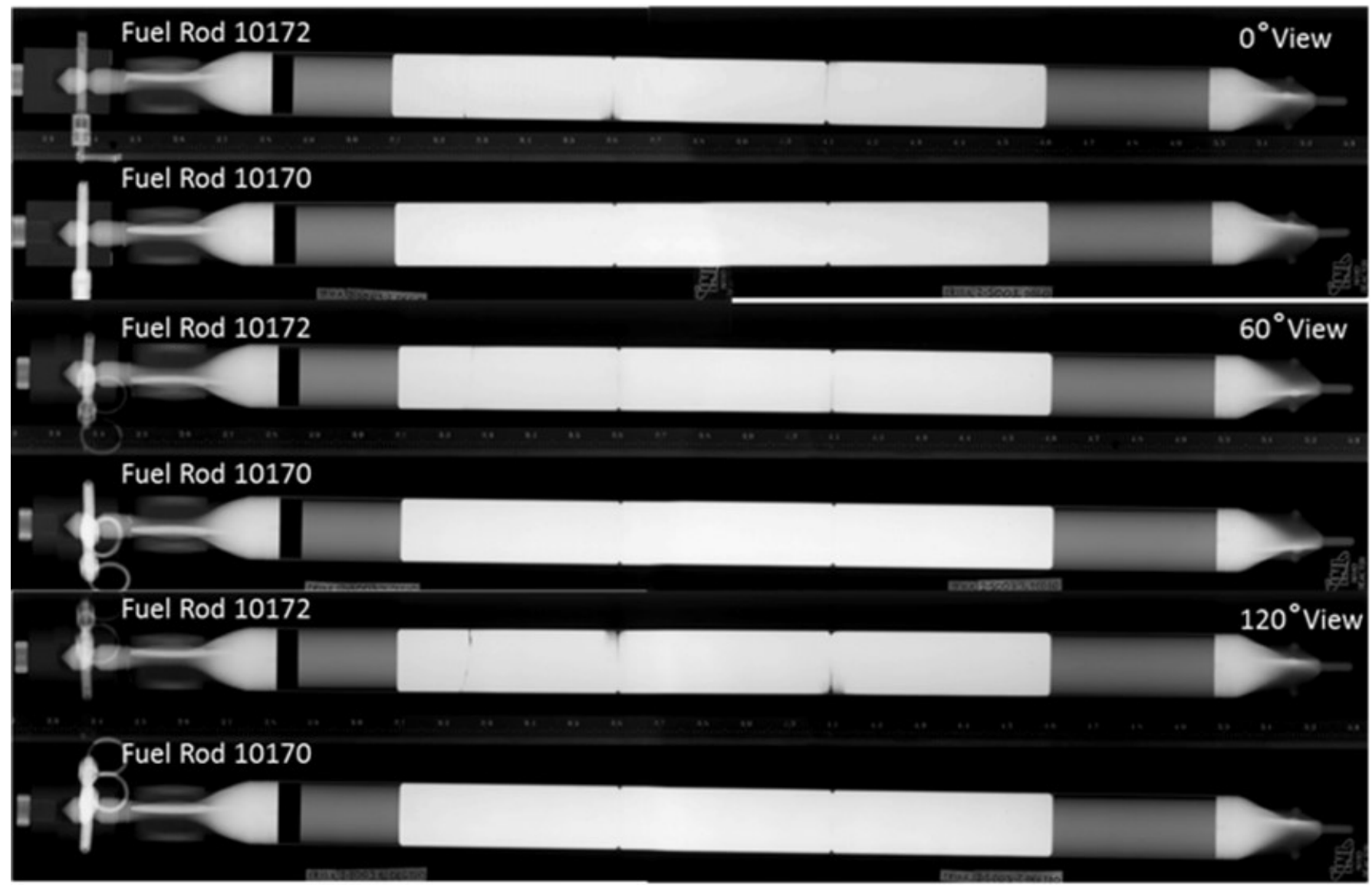

Figure 2. Dysprosium exposure for Fuel Rods 10172 and 10172 for the 0, 60- and 120-degree rotations. 


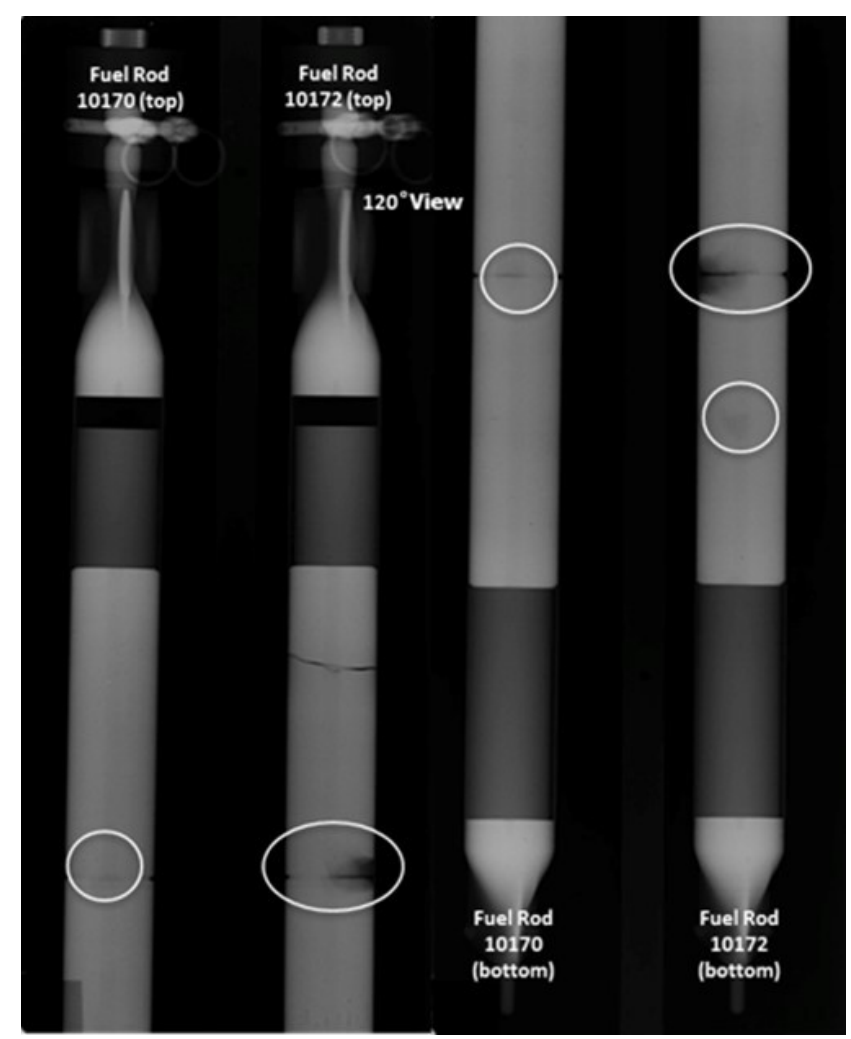

Figure 3. Fuel Rods 10170 and 10172 shown for the 120-degree view. The circled regions are dehydride locations in the fuel meat.

Due to irradiation-induced fuel swelling, the fuel meat expanded. Of interest was if this resulted in good contact between the fuel and the cladding. Figure 4 shows that there may be good fuel meat contact with the cladding for the higher burnup rod, Fuel Rod 10172, excluding the regions between the fuel meats where the fuel-meat ends are chamfered and do not contact the cladding. Once several variables were considered, Fuel Rod 10172 was selected for sectioning because it potentially had good fuel and cladding contact, was the highest-burnup rod, and contained the highest inventory of lanthanide fission products. 


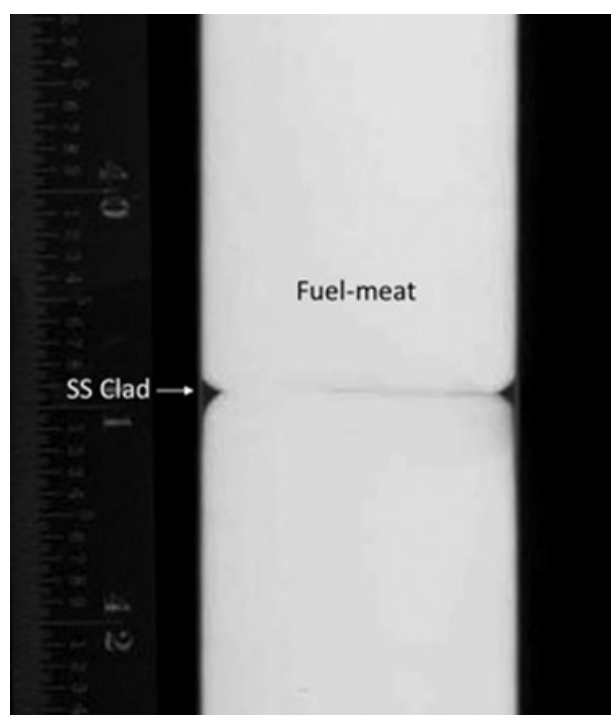

Figure 4. Example of fuel meat to cladding interface for Fuel Rod 10172.

All views (dysprosium exposure) shown in Figure 5 for Fuel Rod 10172 (higher burnup than Fuel Rod 10170) show a crack (labelled) in the top fuel meat with some dehydriding also visible in this location. There was no indication in the gamma-scan data or during the visual inspection of the exterior of the rods that would have indicated damage to the fuel in this region. An explanation for the crack in the fuel is not currently available. Subsequent sectioning of Fuel Rod 10172 revealed radial cracking in most regions of the fuel meat that were not resolvable in radiography. It is conceivable that cracking could have occurred during specimen sectioning. Sectioning is performed using a slow-speed saw with water cooling. A slightly smudged region just off-center in the middle fuel meat of Fuel Rod 10172 also indicates a dehydriding location. Based on radiography results, the cracked fuel and dehydride regions of the fuel were avoided during sectioning.

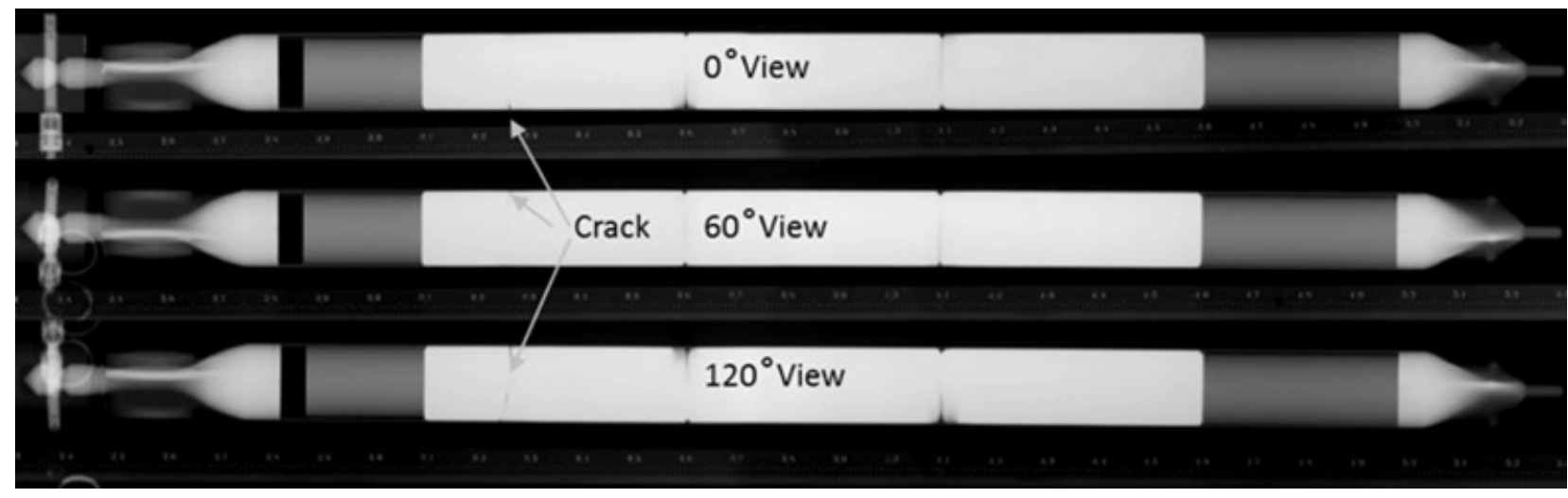

Figure 5. Fuel Rod 10172 showing crack in top fuel meat. 


\subsection{Precision Gamma Scanning}

PGS was performed to verify the burnup profile and relative burnup, using the ${ }^{137} \mathrm{Cs}$ spectra throughout the selected TRIGA rods prior to sectioning into specimens. PGS is a non-destructive examination method that records the gamma spectra emitted by irradiated items (for example, capsules, fuel elements, and waste forms) and is commonly used in post-irradiation characterization examinations. Typical application of PGS involves recording a gamma spectrum to determine relative axial and radial fuel-burnup profiles, identify radionuclide location, and generate other data to aid in evaluating the performance of irradiated fuels. For the TRIGA-rod liquefaction study, gamma scanning was required to verify the burnup profile and relative burnup using the ${ }^{137} \mathrm{Cs}$ spectra distribution in the rods prior to sectioning for heat treating.

Work associated with the PGS on the TRIGA rods was performed in accordance with PLN-5041, "Precision Gamma Scan of TRIGA Pins for Eutectic Study," FRM-1413, "PGS Process Operation Instructions," FRM-1687, "PGS QA and Source Checks," HFEF-OI-4352, "Precision Gamma Scanner" and MCP-3948, "US HPRR Fuel Development Data Qualification."

In conducting a PGS assay on the TRIGA fuel rods, gamma rays from the irradiated fuel rod were passed through a narrow variable slit and collimator so that photons from only a small and identifiable part of the rod were counted over a particular time interval. The gamma rays struck the high-purity germanium detector, which emitted a pulse of electric charge proportional to the energy of each individual event. The pulses, after shaping and amplification, were counted. The collected data were analyzed to provide information about the isotopic composition of the area analyzed.

A source scan of known isotopes spanning the energy range of the isotopes of interest was performed prior to each measurement campaign on each TRIGA rod. To reduce uncertainty while performing assays with the smallest step size, the fuel rod was oriented such that it was centered as closely as possible in front of the collimator. This was accomplished by incrementally moving the fuel rod horizontally across the slit of the collimator, thereby determining the relative edge locations (right and left) of the sample by observing the count rate and spectra collected; by this method, the center-line coordinate of the fuel rod was determined.

\subsubsection{Axial Gamma Scanning}

Gamma-scanning results are shown in Figure 6 and Figure 7, and ${ }^{137} \mathrm{Cs}$, which is a longer-lived fission product (half-life of 30.07 years), was selected to indicate burnup levels for the rods relative to each other. Spectral profiles of ${ }^{137} \mathrm{Cs}$ for both rods indicate the peak burnup location within each rod to be in the middle (center fuel meat) region of the rods. Also indicated in the ${ }^{137} \mathrm{Cs}$ spectra is a dip between each of the fuel meats (see Figure 6 and Figure 7). While both Fuel Rods 10170 and 10172 have a slight dip in the ${ }^{137} \mathrm{Cs}$ spectra located in the center fuel-meat region, neutron radiography of the fuel rods indicate that the fuel is intact. Also, the uncertainty in the data indicates that the dips are not statistically significant relative to other data points in this region. ${ }^{60} \mathrm{Co}$ (half-life 5.27 years) is an activation product from the SS cladding of the fuel rod and end fittings. ${ }^{154} \mathrm{Eu}$ (half-life 8.59 years) is another gamma-emitting fission product by which burnup can be benchmarked.

The top of the rods in the overlay on the plots are oriented toward the left side $(10,0)$ of the $\mathrm{x}$ and $\mathrm{y}$ axes. While absolute position on the plots is arbitrary, the relative position from point to point is absolute and measured in inches. As shown in Figure 6, Fuel Rod 10170 has a relatively flat profile in the center region as compared to the areas to the left and the right of the middle fuel meat. The peak net count for Fuel Rod 10170 is 152,602 , based on a 240 -second count time for each 0.100 -in. step down the length of the rod. The center fuel-meat region for Fuel Rod 10172, shown in Figure 7, has a less flat profile as compared to Fuel Rod 10170's profile in this location. Peak net count for Ruel Rod 10172 is 166,745 for the same count parameters. Therefore, Fuel Rod 10172 was selected for sectioning due to its higher relative burnup, as indicated by the higher gamma activity level for ${ }^{137} \mathrm{Cs}$. These data also confirm the 
calculated physics estimates for which of the two rods had a higher burnup. Additionally, because of its higher burnup, the middle fuel-meat region for Fuel Rod 10172 offers the highest fission-product inventories. This is desirable for the heat-treating experiments since it is of interest to investigate the role of fission products in forming phases during FCCI that may have relatively low-melting temperatures during an off-normal event during service.

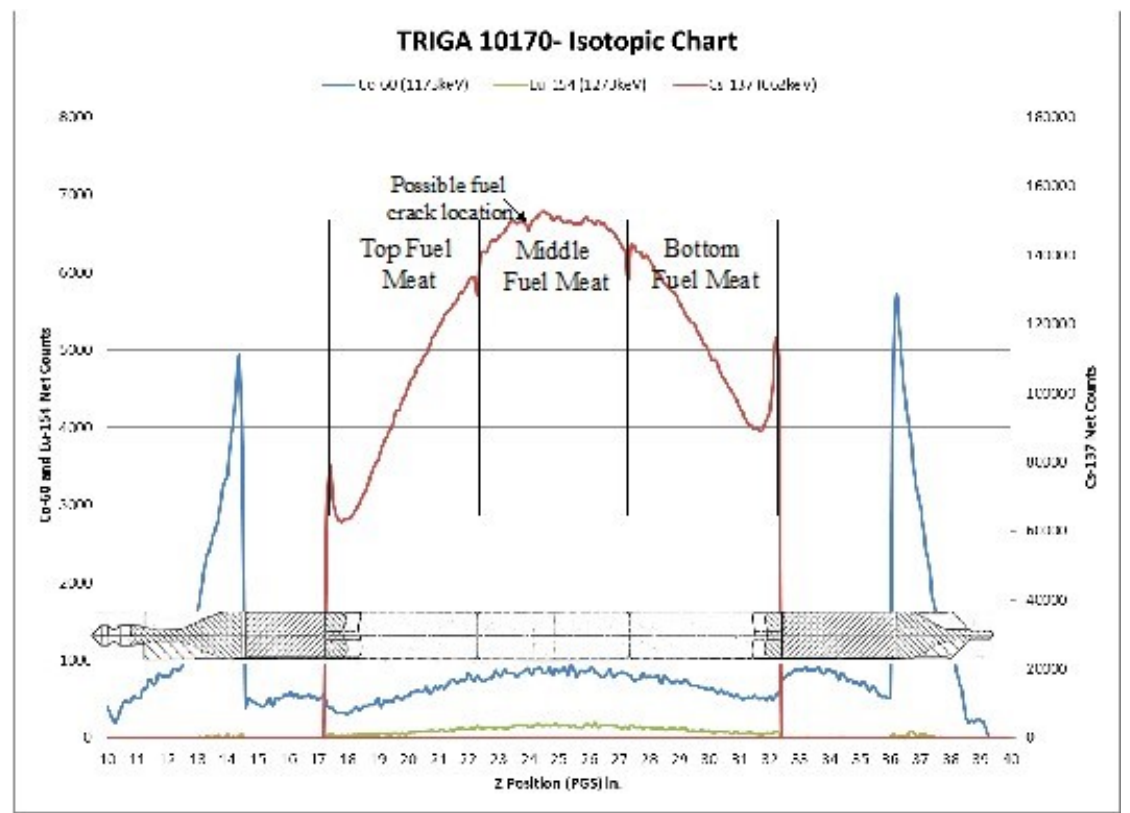

Figure 6. Isotopic gamma-scan profile for TRIGA Fuel Rod 10170.

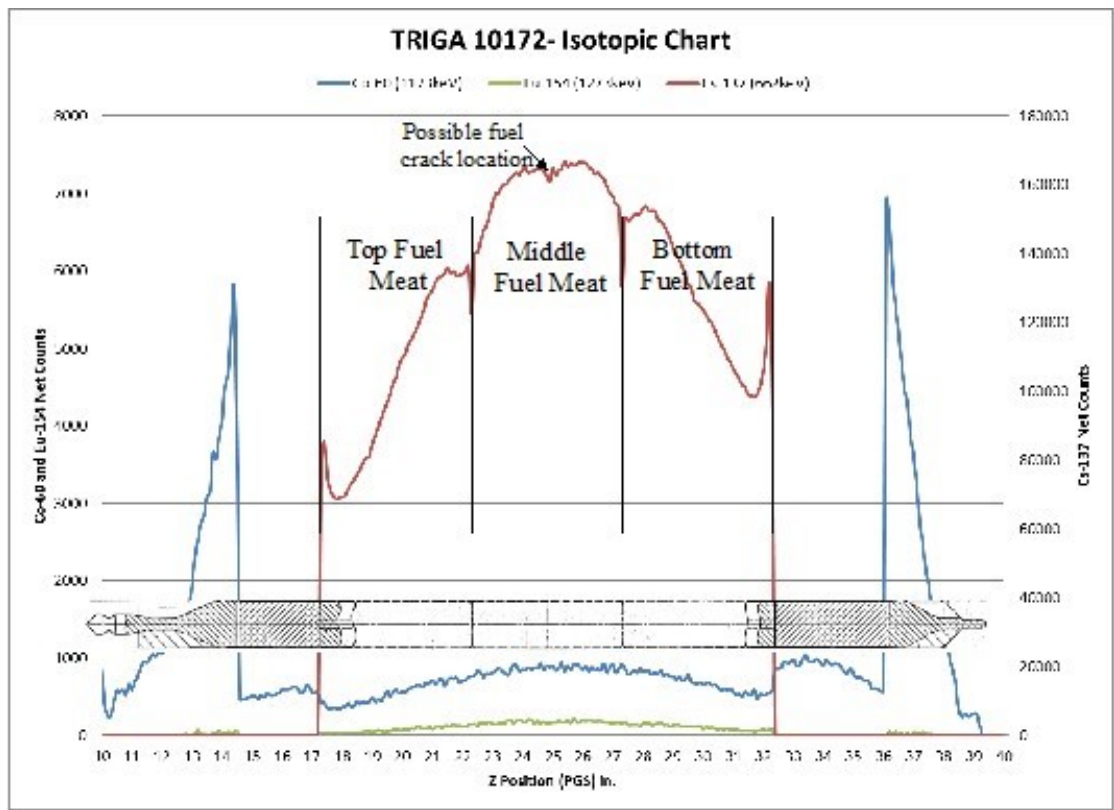

Figure 7. Isotopic gamma-scan profile for TRIGA Fuel Rod 10172. Y-axis in in Cs-137 counts. 


\subsubsection{Gamma-Scanning Tomography}

Gamma scans were performed on three cross sections that were adjacent to the chemistry sample taken from the middle fuel meat. Results for each specimen are presented in the following sections. Based on results for BOT217, the scans for BOT218 and BOT219 were changed to a step size of $0.02 \mathrm{in}$., and angles were increased to 16 to improve the statistical data for the lower activity and improve the resolution of the tomographic images. The three tomographic gamma scans (in-cell) and six analytical chemistry specimens (gamma scan and inductively coupled plasma mass spectroscopy [ICP-MS]) are listed in Table 2.

Table 2. Gamma-scanning specimen summary.

\begin{tabular}{|l|l|l|}
\hline Specimen & Sample Type (Approximate Geometry Mm) & Analysis Performed (Location/Method) \\
\hline BOT217 & $6.4 \mathrm{~L} \times 38.1$ dia. discs & HFEF/PGS Tomography \\
\hline BOT218 & $6.4 \mathrm{~L} \times 38.1$ dia. discs & HFEF/PGS Tomography \\
\hline BOT219 & $6.4 \mathrm{~L} \times 38.1$ dia. discs & HFEF/PGS Tomography \\
\hline KGT2265 & $2.0 \mathrm{~W} \times 3.0 \mathrm{~L} \times 3.2 \mathrm{H}$ & AL/Gamma Scan \\
\hline KGT2264 & $2.0 \mathrm{~W} \times 3.0 \mathrm{~L} \times 3.2 \mathrm{H}$ & AL/Gamma Scan \\
\hline KGT2263 & $2.0 \mathrm{~W} \times 3.0 \mathrm{~L} \times 3.2 \mathrm{H}$ & AL/Gamma Scan \\
\hline KGT2262 & $2.0 \mathrm{~W} \times 3.0 \mathrm{~L} \times 3.2 \mathrm{H}$ & AL/Gamma Scan \\
\hline KGT2261 & $2.0 \mathrm{~W} \times 3.0 \mathrm{~L} \times 3.2 \mathrm{H}$ & AL/Gamma Scan \\
\hline KGT2260 & $2.0 \mathrm{~W} \times 15.9 \mathrm{~L} \times 3.2 \mathrm{H}$ & AL/Gamma Scan \\
\hline KGT2259 & $2.0 \mathrm{~W} \times 15.9 \mathrm{~L} \times 3.2 \mathrm{H}$ & AL/Gamma Scan \\
\hline
\end{tabular}

Sectioning diagrams are provided in Figure 8, where the end fitting removal is shown in (a) and (b) shows the initial fuel-rod sectioning, 10172-1 top fuel meat, 10172-2 middle fuel meat, and 10172-3 bottom fuel meat.

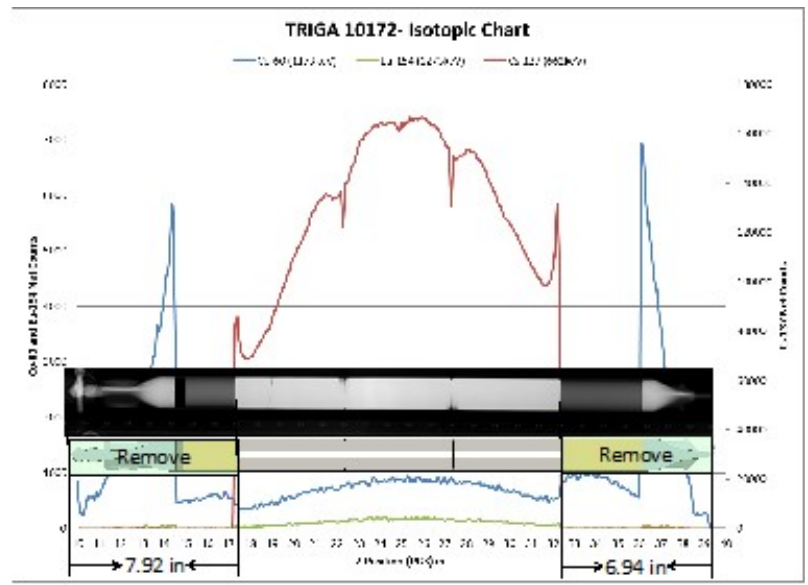

a.

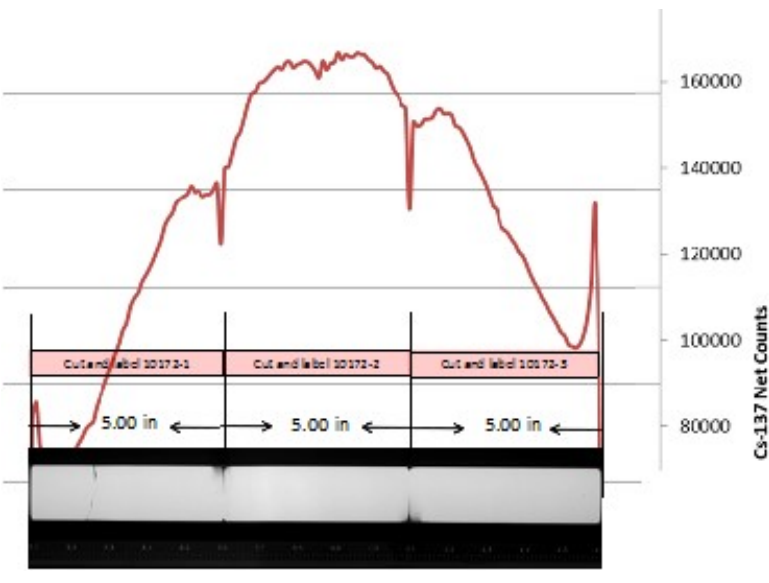

b.

Figure 8. (a) initial fuel-rod sectioning diagrams for Fuel Rod 10172 showing where the ends were removed and (b) where the fuel meat was cut into sections. Y-axis is in Cs-137 counts. 
Figure 9 shows the chemistry sample from Fuel Slug 1. Figure 10 shows Fuel Slug 2 and the chemistry specimen, heat treating experiment specimens, and the non-annealed specimen. Figure 11 shows Fuel Slug 3 and the chemistry specimen, heat treating experiment specimen, and non-annealed specimen.

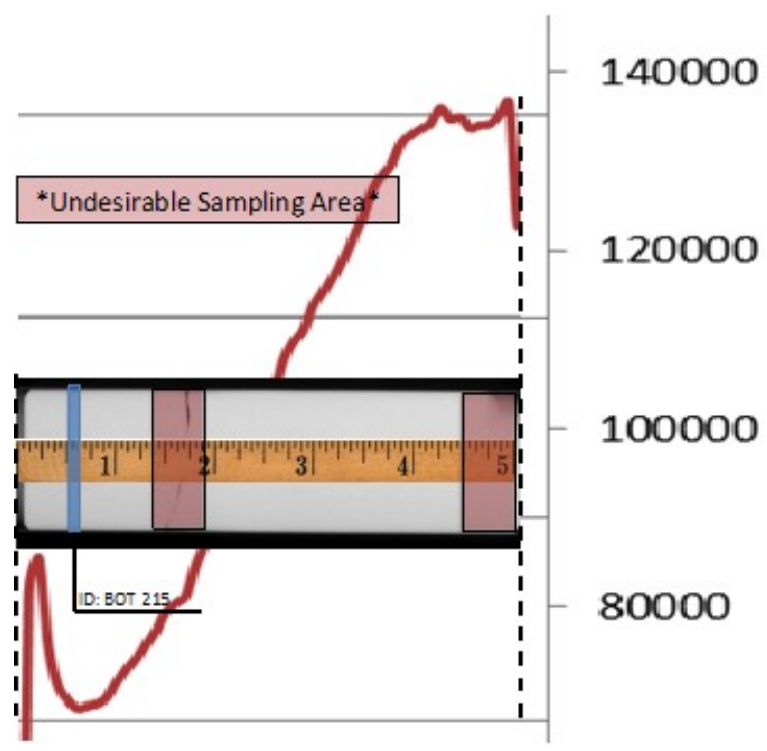

Figure 9. Fuel Slug 1 from Fuel Rod 10172, showing chemistry specimen. Y-axis is in Cs-137 counts.

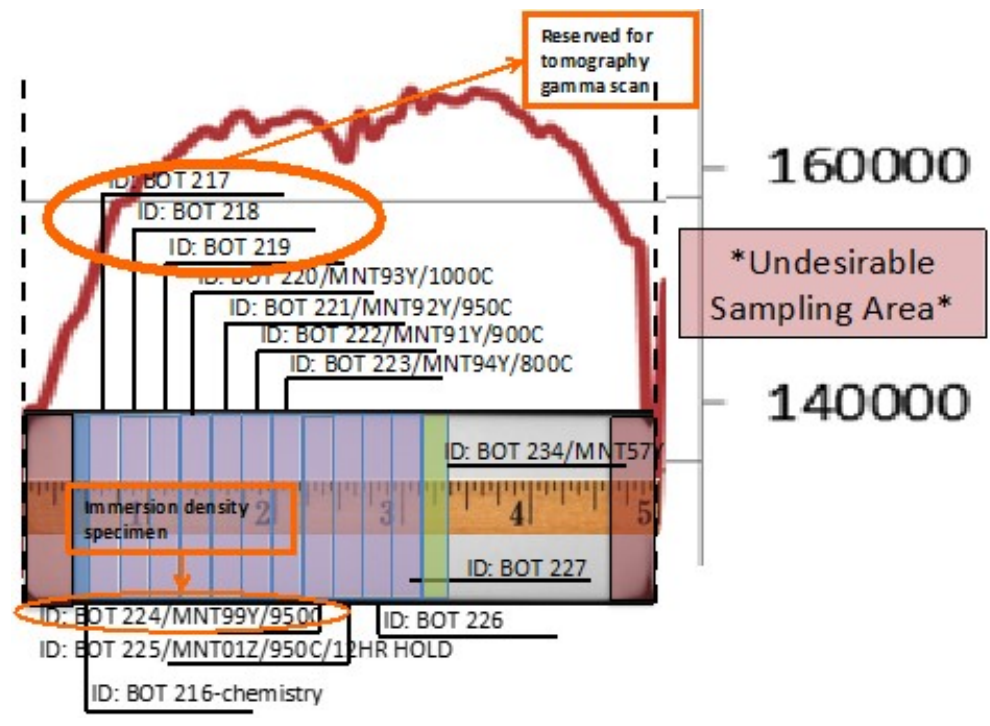

Figure 10. Fuel Slug 2 from Fuel Rod 10172 showing chemistry specimen, anneal specimens, and nonannealed specimen. Y-axis is in Cs-137 counts. 


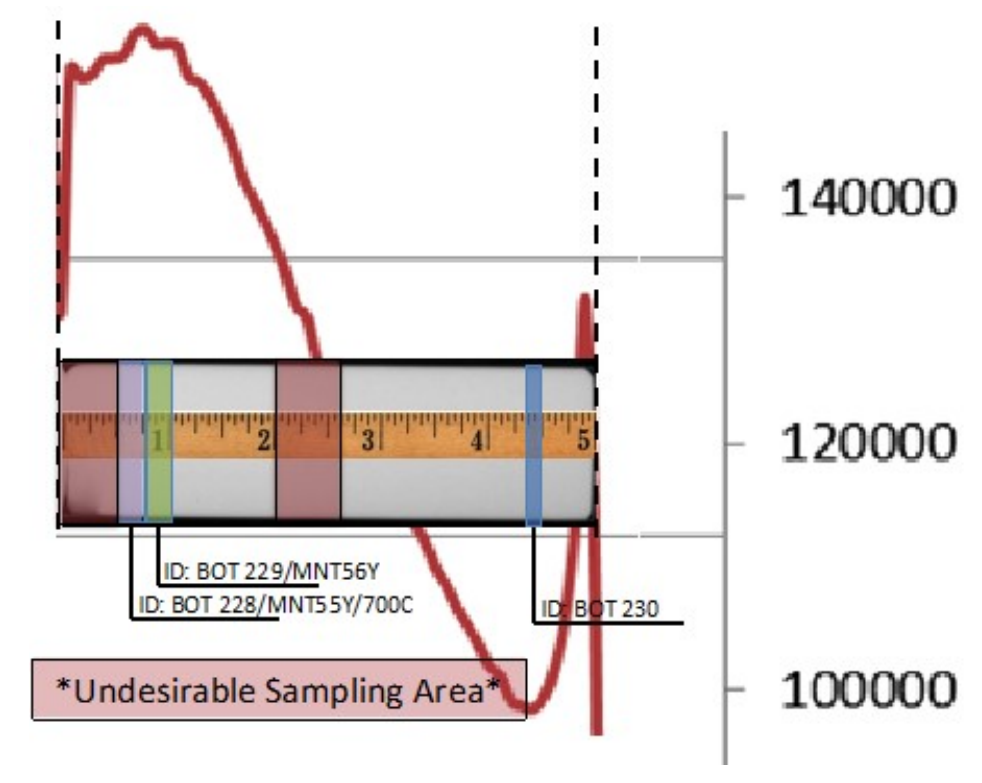

Figure 11. Fuel Slug 3 from Fuel Rod 10172, showing chemistry specimen, anneal specimen, and nonannealed specimen. Y-axis is in Cs-137 counts.

Scans were centered over the puck centerline and were taken in 0.01-in. steps at nine different angles for BOT217, 218, and 219. Decay counts were not high due to the long decay period of the fuel rod. Therefore, to improve the resolution of the plots and reduce statistical noise for ${ }^{137} \mathrm{Cs}$ and ${ }^{60} \mathrm{Co}$, data from two step locations were summed. Even lower counts for ${ }^{154} \mathrm{Eu}$ necessitated summing data from five step locations. The tomographic images of ${ }^{137} \mathrm{Cs},{ }^{60} \mathrm{Co}$, and ${ }^{154} \mathrm{Eu}$ from these data are shown in Figure 12 for the BOT217 specimen. Results from the tomographic reconstruction of the circumferential count locations indicate a radial gradient in the burnup in the fuel meat. The higher ${ }^{137} \mathrm{Cs}$ count data at the perimeter indicate greater burnup relative to the center of the fuel meat. Data for ${ }^{60} \mathrm{Co}$ are where they would be expected, at the fuel-perimeter and cladding region. The shape of the cobalt data is an artifact of the scanning method.

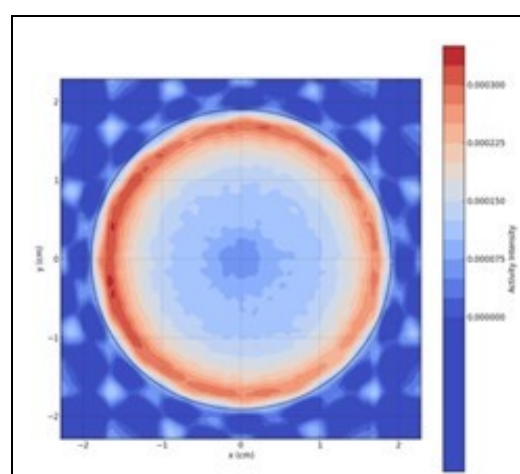

(a)

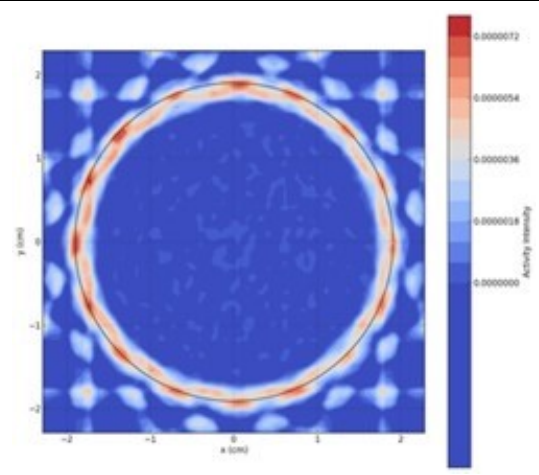

(b)

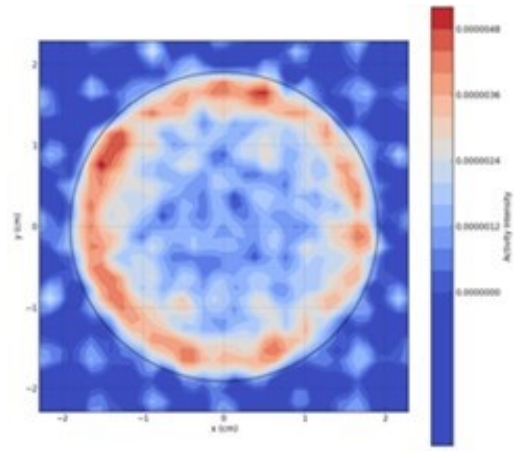

(c)

Figure 12. BOT217 137Cs (a), 60Co (b) and 154Eu (c) tomographic maps. 


\subsection{Gamma Spectroscopy}

Samples from BOT215 (see Figure 13) were used to confirm the radial burnup profile of the tomographic data compiled from the PGS both chemically and using gamma spectroscopy. Sample IDs are ordered left to right relative to the outside edge of the cross section, moving into the center of the cross section (see Figure 13). Results from gamma spectroscopy are shown in Figure 14 for ${ }^{137} \mathrm{Cs}$ (a) and ${ }^{154} \mathrm{Eu}(\mathrm{b})$, measured in solid form and as measured in solution for $\mathrm{Cs}$ and $\mathrm{Eu}$ (c and d, respectively). Qualitatively, the four plots illustrate a radial burnup gradient and are consistent with the PGS tomographic scan data.

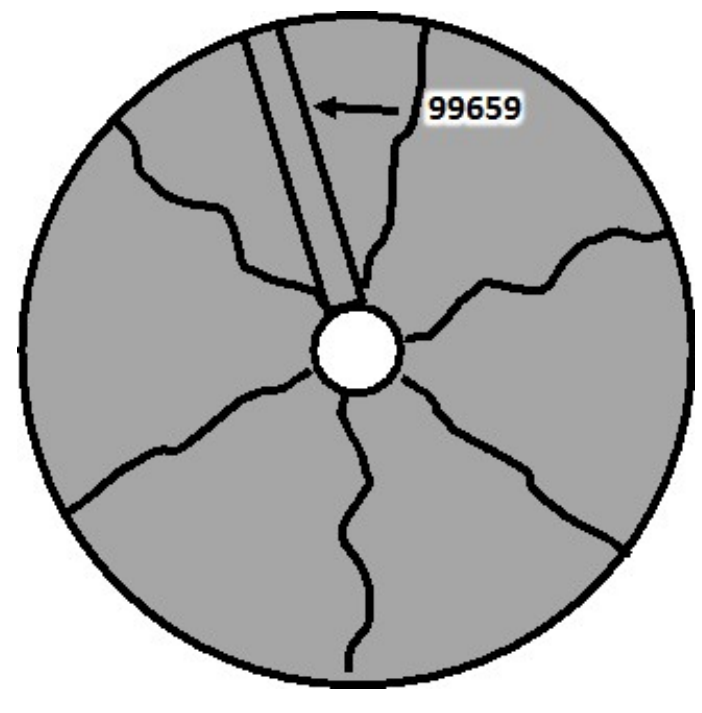

(a)

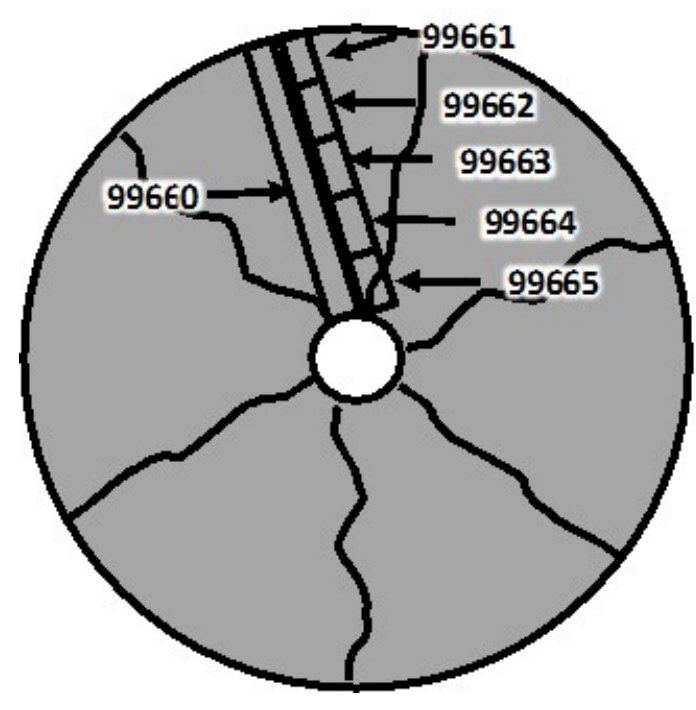

(b)

Figure 13. Chemistry sample-sectioning diagrams from Specimen BOT215 from Fuel Rod 10172, fuel pieces -2 (a) and -1 (b). 


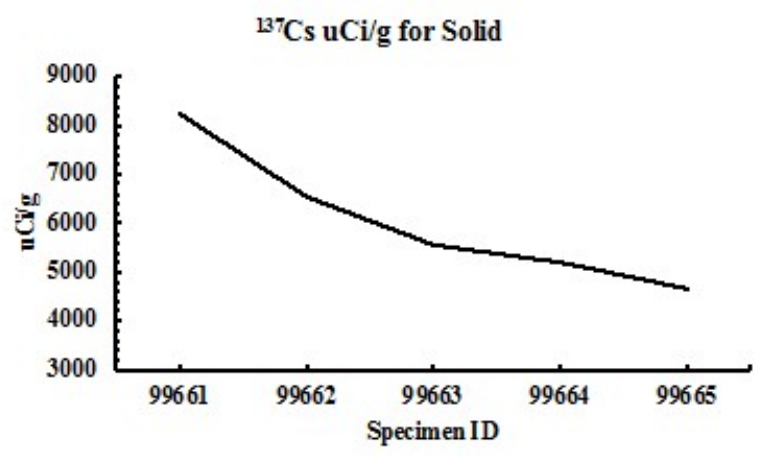

(a)

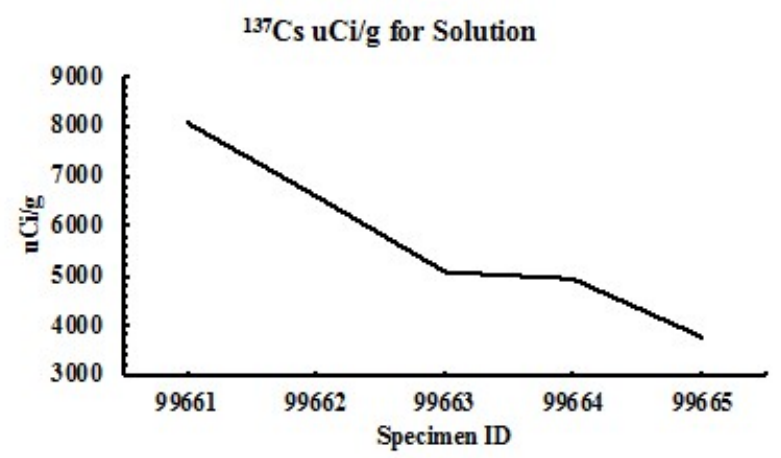

(c)

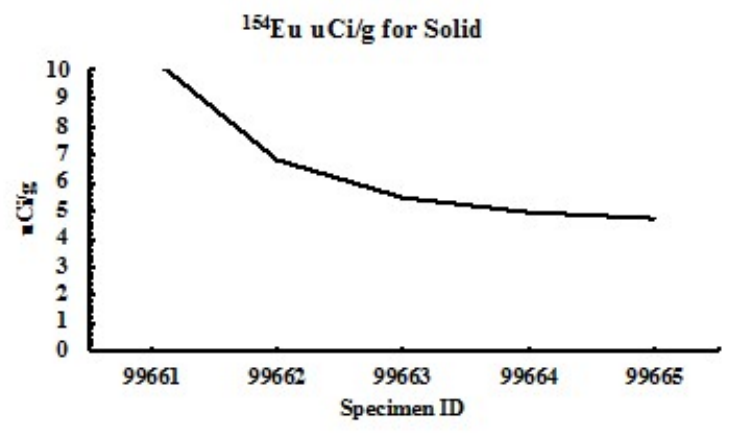

(b)

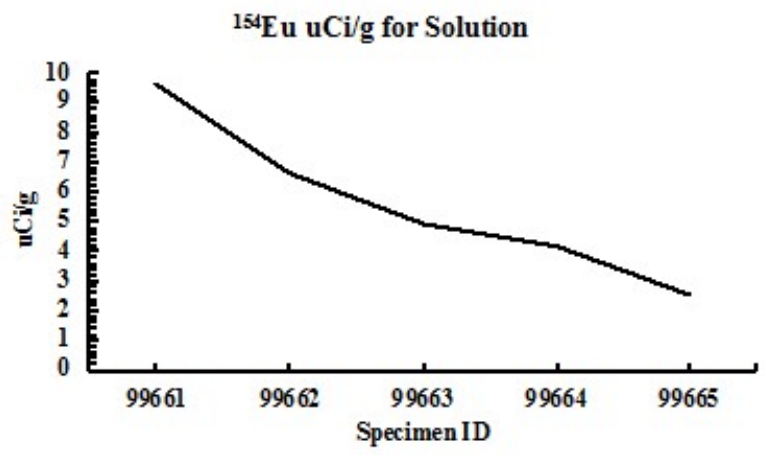

(d)

Figure 14. BOT215 134Cs (a), and 154Eu (b) gamma spectroscopy results as measured as a solid and $134 \mathrm{Cs}(\mathrm{c})$, and 154Eu (d) as measured in solution.

\subsection{Analytical Chemistry}

Chemical analysis was performed to establish the burnup level and fission-product inventories for selected test specimens. These data were coupled with the gamma-scan data to determine the fissionproduct density, burnup, and fission-product inventories for each heat-treated test specimen. Chemical analysis was performed according to PLN-5058 "Chemical Analysis of Burnup and Fission-Product Inventories for TRIGA Fuel Eutectic Studies," and MCP-3948, "US HPRR Fuel Development Data Qualification." Specimens were cut from each of the fuel-meat sections to determine the fuel-rod axial burnup levels relative to gamma-scan data. Specimens had the SS cladding removed prior to chemical analysis.

The burnup results for the $20 \%$ enriched fuel meat are found in Table 3 for the radial specimens that received chemical analysis. A specimen-sectioning diagram is shown in Figure 13 for fuel-rod Slugs 10172-2, specimen ID 99659 (a.) and Fuel Rod 10172-1, specimen IDs 99660-99665 (b.). Data obtained from chemical analysis and ICP-MS are shown in Table 3 and plotted in Figure 15 for the radial minisections for piece 1 . These results indicate a radial gradient burnup profile in the ${ }^{235} \mathrm{U}$, which is consistent with the tomographic gamma-scan data. The burnup value for specimen 99659 of $18 \%$ is in reasonable agreement with the physics burnup calculation of $20 \%$. 
Table 3. Burnup percent calculated from select fission-product inventories.

\begin{tabular}{|c|c|c|c|c|}
\hline \multicolumn{5}{|c|}{ Depletion of ${ }^{235} \mathrm{U}$ Calculated from Generation of Fission Product } \\
\hline Specimen ID & 130La & $141 \mathrm{Pr}$ & 99Tc & Comments \\
\hline 99659 & $18.3 \%$ & $18.3 \%$ & $17.9 \%$ & $\begin{array}{l}\text { From highest-burnup section of Fuel Rod } 10172 \\
\text { (Figure 13a) }\end{array}$ \\
\hline 99660 & $8.7 \%$ & $8.7 \%$ & $8.7 \%$ & Largest piece from lower burnup section (Figure 13b) \\
\hline 99661 & $12.0 \%$ & $12.1 \%$ & $12.2 \%$ & \multirow{5}{*}{ Subsectioned radial strip piece (Figure 13b). } \\
\hline 99662 & $9.1 \%$ & $9.4 \%$ & $9.5 \%$ & \\
\hline 99663 & $7.7 \%$ & $8.0 \%$ & $8.0 \%$ & \\
\hline 99664 & $7.1 \%$ & $7.6 \%$ & $7.8 \%$ & \\
\hline 99665 & $7.8 \%$ & $7.9 \%$ & $7.5 \%$ & \\
\hline
\end{tabular}

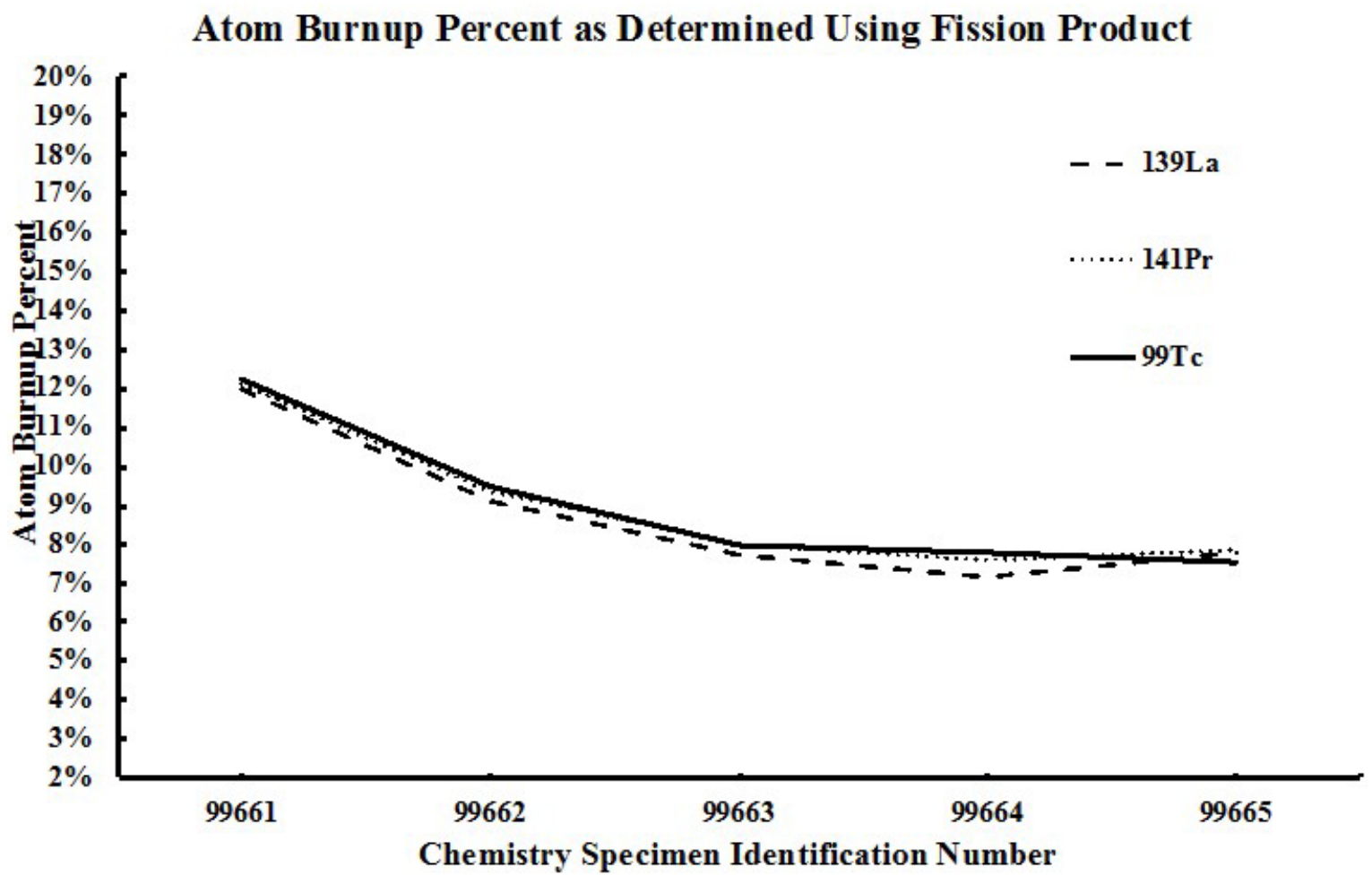

Figure 15. Plotted burnup values calculated via fission product measured using chemistry and ICP-MS.

\subsection{Heat-treating Specimen Selection}

Specimens for heat treating-treating were selected based on the highest fission density regions as indicated by the gamma-scan profiles that did not also appear to be damaged per the NRAD results. NRAD data also revealed the regions that were less desirable for sampling (e.g., possibly due to dehydration). The annealing experiment specimens and target annealing temperatures are summarized in Table 4. 
Table 4. List of anneal, chemistry, and non-annealed specimens with analysis performed.

\begin{tabular}{|l|l|}
\hline \multicolumn{1}{|c|}{ Specimen ID } & \multicolumn{1}{|c|}{ Analysis/Test Temp ${ }^{\circ}$ C/Hold Time (hr) } \\
\hline BOT 228/MNT55Y & Anneal/730/6 \\
\hline BOT 223/MNT94Y & Anneal/800/6 \\
\hline BOT 222/MNT91Y & Anneal/900/6 \\
\hline BOT 221/MNT92Y & Anneal/950/6 \\
\hline BOT 220/MNT93Y & Anneal/1000/6 \\
\hline BOT 234/MNT57Y & No heat treat-Metallography/NA/NA \\
\hline BOT 229/MNT56Y & No heat treat-Metallography/NA/NA \\
\hline BOT 224/MNT99Y & Immersion density before/after anneal/950/6 \\
\hline BOT 217, 218, 219 & Gamma scan/NA/NA \\
\hline BOT 225/MNT01Z & Anneal/950/12 \\
\hline $\begin{array}{l}\text { BOT 215/KGT1700/KGT2260 (AL99660), 2265 } \\
\text { (AL99661), 2264 (AL99662), 2263 (AL99663), 2262 }\end{array}$ & Chemistry and Gamma Scan/NA/NA \\
\hline BOT216/KGT1699/KGT2259 (AL99659) & \\
\hline
\end{tabular}

\subsection{Heat Treatments}

Seven specimens were annealed in alumina crucibles in the bake-out furnace, which was located in the argon hot cell located in the HFEF at the Materials and Fuels Complex at INL. Images of the bake-out furnace are presented in Figure 16. Each specimen was wrapped in three layers of high-purity tantalum to prevent the specimen's reacting with any residual oxygen or other impurities remaining in the ultra-highpurity argon used as both the purge and sweep gas. The closest layer of tantalum to the specimen remained completely unreacted to any trace oxygen or other impurities left in the ultra-high-purity argon at the conclusion of the heat-treating period for all specimens. An example of this is shown in Figure 17 of Specimen BOT223 held at $800^{\circ} \mathrm{C}$ for $6 \mathrm{hr}$ with the first layer of Ta reacted, as shown in (a), and the final layer of $\mathrm{Ta}$ is in pristine condition, as shown in (b). 

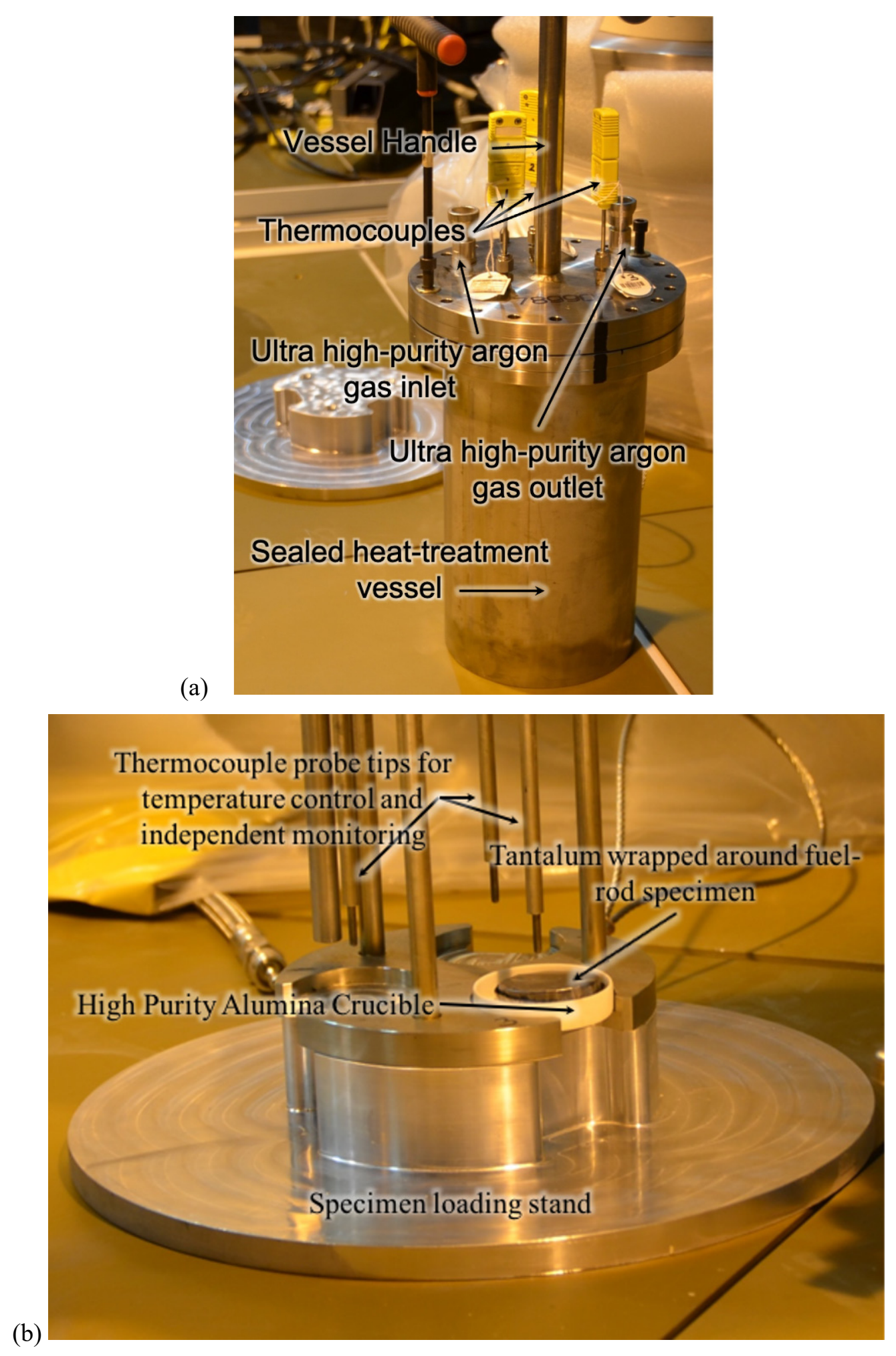

Figure 16. Experiment furnace configuration for the TRIGA fuel heat-treating experiments. (a) Photo of sealed furnace insert assembly, and (b) the inside of the insert assembly where the samples reside in alumina crucibles. 


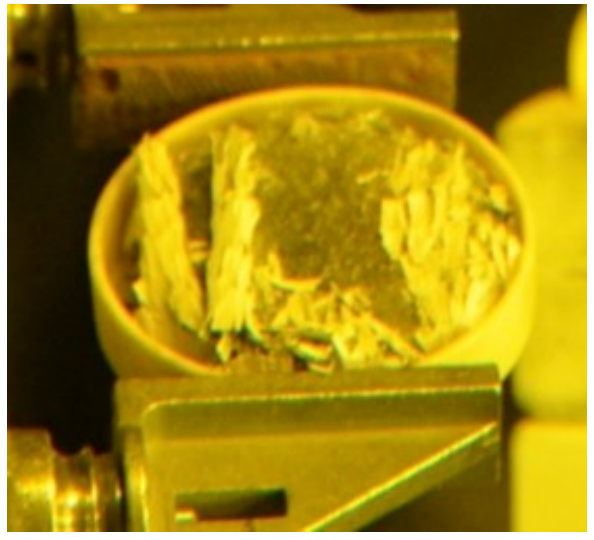

(a)

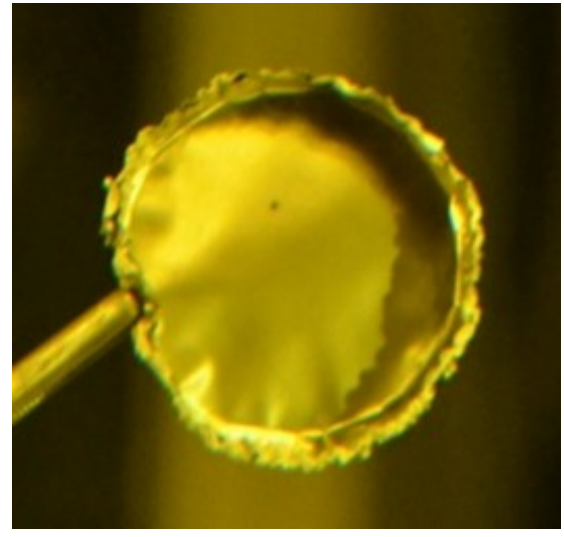

(b)

Figure 17. Tantalum wrap for Specimen BOT223 heat treated at $800^{\circ} \mathrm{C}$ for $6 \mathrm{hr}$ with first layer of Ta reacted, as shown in (a), and the final layer of Ta in pristine condition, as shown in (b).

The heat-treating temperatures were $730,800,900,950$, and $1000^{\circ} \mathrm{C}$. For all but one specimen, the heat-treating period at the target temperature was $6 \mathrm{hr}$. Three specimens received an anneal at $950^{\circ} \mathrm{C}$. One sample received a $12-\mathrm{hr}$ anneal at $950^{\circ} \mathrm{C}$. Figure 18 shows an image of Specimen BOT 221 that was annealed at $950^{\circ} \mathrm{C}$ for $6 \mathrm{hr}$ where bulging was observed near the fuel and cladding interface. A 6-hr anneal at $950^{\circ} \mathrm{C}$ was repeated using another specimen, BOT224, so that the dimensional changes observed at this anneal temperature could be quantified using immersion density.

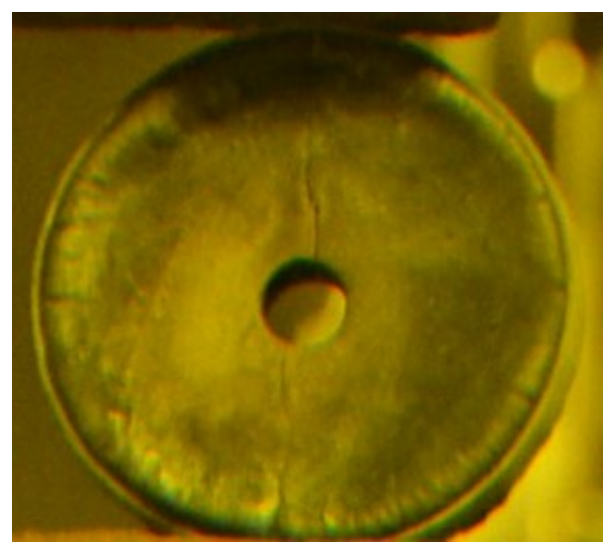

Figure 18. Specimen BOT221 showing fuel bulging near the cladding following a heat treatment at $950^{\circ} \mathrm{C}$ for $6 \mathrm{hr}$.

\subsection{Immersion Density}

Dimensional changes in the specimen height were noted during the visual exam following the highertemperature tests of 950 and $1000^{\circ} \mathrm{C}$. An example of this is shown in Figure 19 for Specimen BOT224. Note the bulged area adjacent to the perimeter of the specimen. Immersion density was performed on an additional $950^{\circ} \mathrm{C}$ specimen both before and after heat treating to quantify dimensional changes. Results for immersion density for BOT224 indicated a dimensional increase of $23 \%$. A mass loss of $\sim 5 \%$ was also noted and assumed to be a loss of hydrogen from the $\mathrm{UZrH}_{1.6}$ fuel. The fuel appears to expand in the axial direction due to constraint from the cladding. Immersion density measurements have not been performed on additional specimens at the other heat-treatment temperatures. 


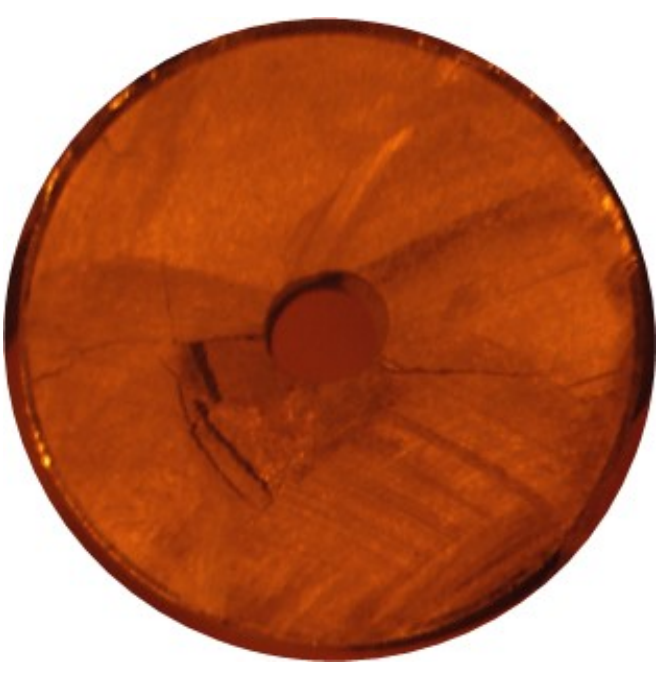

a

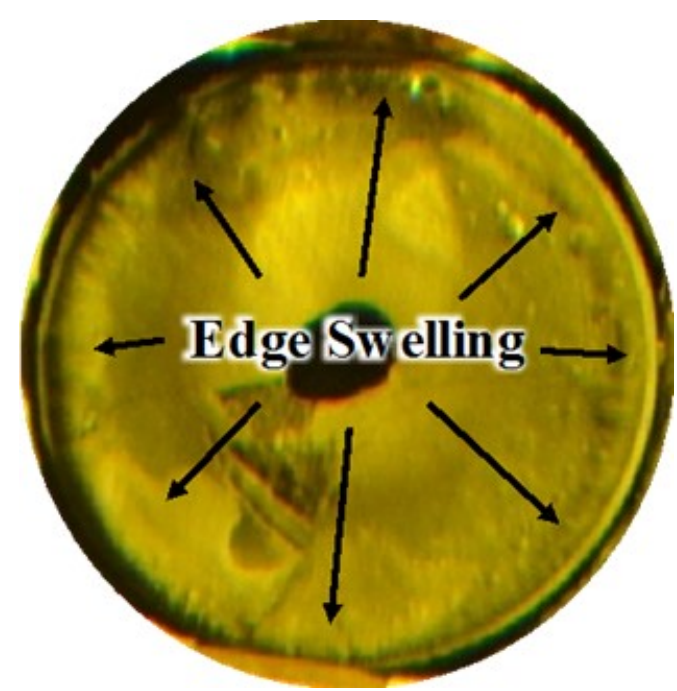

$\mathrm{b}$

Figure 19. Pre-anneal image of BOT224 (a) and the post-anneal swelling shown for Specimen BOT224 (b).

\subsection{Microstructural Characterization}

\subsubsection{Optical Metallography}

$\mathrm{OM}$ is routinely used to characterize microstructural features in nulear fuels and materials. OM can resolve micron-sized features. OM data and images were used to evaluate changes at the fuel and cladding interface between heat-treated specimens, non-heat-treated specimens, and non-irradiated, nonheat-treated specimens.

All specimens were ground and polished for microstructural examination. The specimens tested at higher temperatures appeared to be increasingly brittle, which affected the quality of the polish. Brittleness created an issue with fuel pullout, which can cause scratching of the specimen during the polishing stages. Focus was given to all areas along the fuel and cladding interface to determine the quality of the fuel and cladding contact and to identify any indications of fuel and cladding interaction.

\subsubsection{As-Received Irradiated Specimen}

A montage of $31.5 \times$ magnification optical images of the as-irradiated TRIGA fuel is shown in Figure 20, and a 200× magnification image of the fuel and cladding interface in the specimen is presented in Figure 21. It is not clear from the image in Figure 21 whether or not the as-received fuel had regions where the fuel and cladding were in contact with each other. 


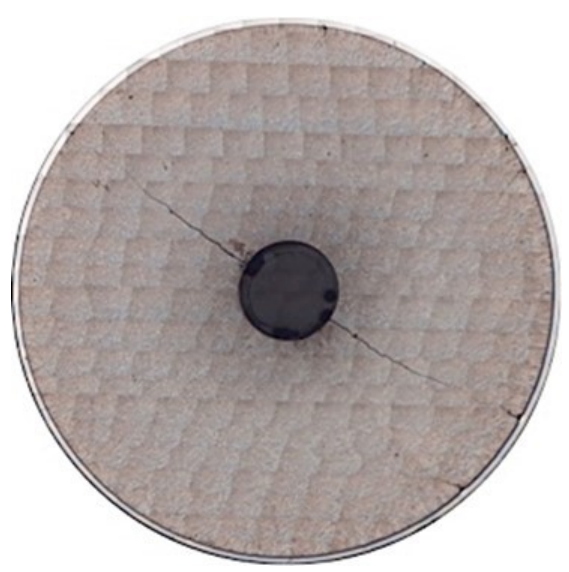

Figure 20. BOT229/MNT56Y non-heat-treated as-received specimen full montage at 31.5× magnification.

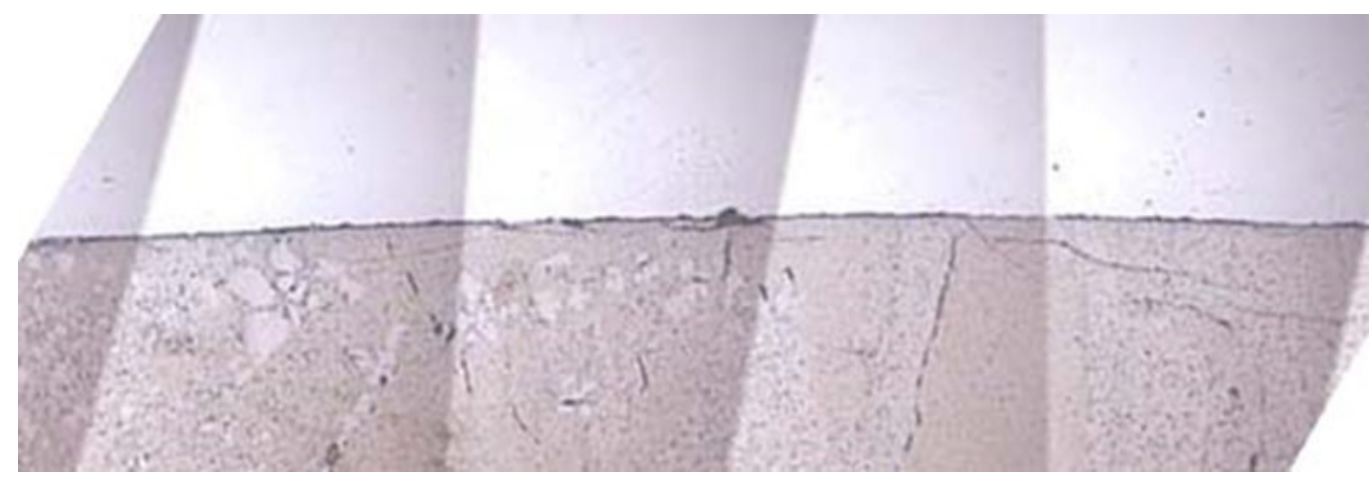

Figure 21. BOT229/MNT56Y non-heat-treated as-received specimen at 200× magnification, showing a fuel to cladding region with the best signs of potential fuel and cladding contact.

\subsubsection{Irradiated Specimen Annealed at $730^{\circ} \mathrm{C}$}

A montage of $31.5 \times$ magnification optical images of the as-irradiated TRIGA fuel after a heat treatment at $730^{\circ} \mathrm{C}$ for $6 \mathrm{hr}$ is shown in Figure 22, and a $200 \times$ magnification image of the fuel and cladding interface in the specimen is presented in Figure 23. The image in Figure 22 suggests that intimate contact at the fuel and cladding interface was not commonly present after heat treatment.

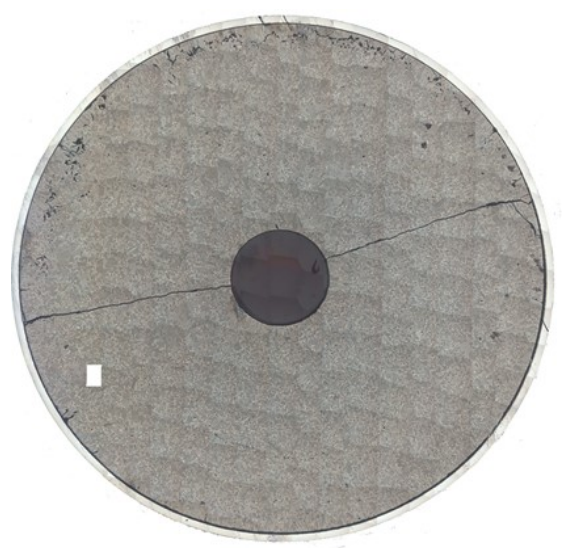

Figure 22. BOT228/MNT55Y $730^{\circ} \mathrm{C}$-heat-treated specimen full montage at $31.5 \times$ magnification. The white rectangle is a missing image in the montage. 


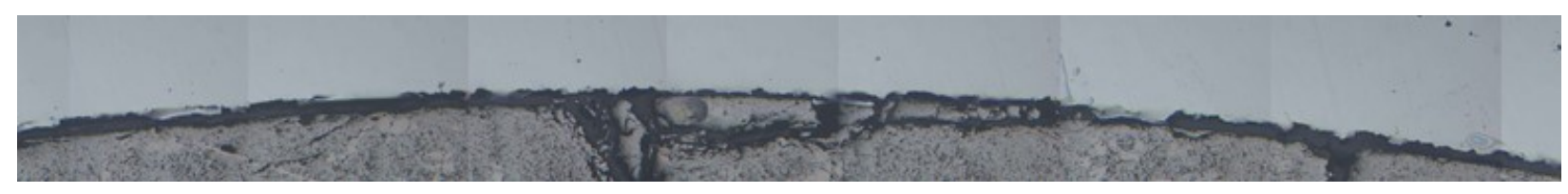

Figure 23. BOT228/MNT55Y $730^{\circ} \mathrm{C}$-heat-treated specimen partial montage at $100 \times$ magnification, showing a fuel to cladding region with the best signs of good contact.

\subsubsection{Irradiated Specimen Annealed at $800^{\circ} \mathrm{C}$}

A montage of $31.5 \times$ magnification optical images of the as-irradiated TRIGA fuel after a heat treatment at $800^{\circ} \mathrm{C}$ for $6 \mathrm{hr}$ is shown in Figure 24, and a $200 \times$ magnification image of the fuel and cladding interface in the specimen is presented in Figure 25. The image in Figure 24 suggests that intimate contact at the fuel and cladding interface was not commonly present after heat treatment.

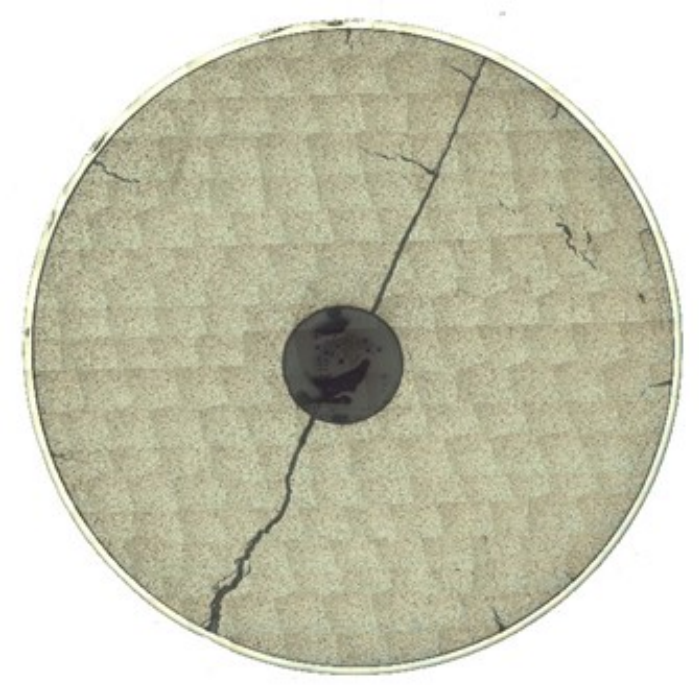

Figure 24. BOT223/MNT94Y $800^{\circ} \mathrm{C}$ heat-treated specimen full montage at $31.5 \times$ magnification. A crack is running down the center of the specimen.

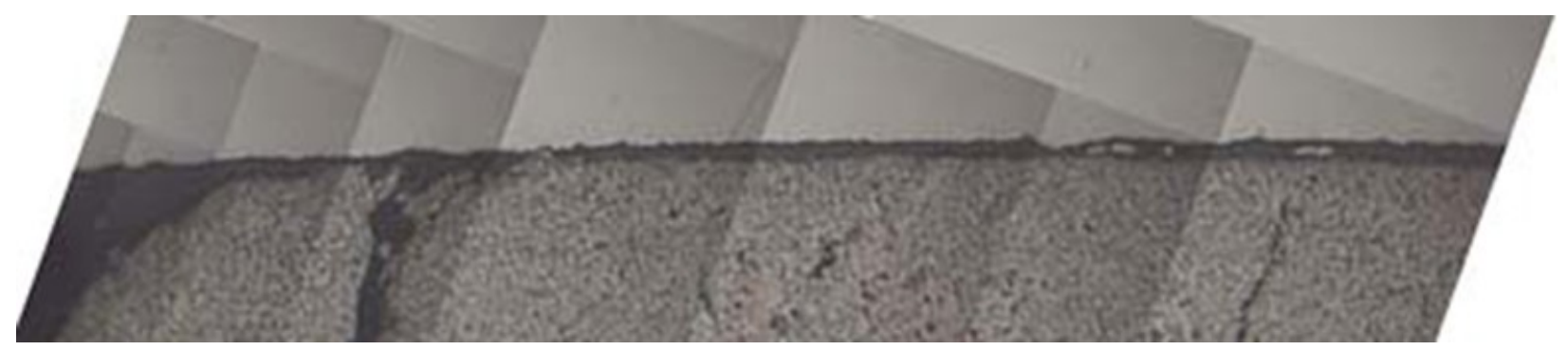

Figure 25. BOT223/MNT94Y $800^{\circ} \mathrm{C}$ heat-treated specimen partial montage at $200 \times$ magnification showing a fuel to cladding region with the best signs of good contact. 


\subsubsection{Irradiated Specimen Annealed at $900^{\circ} \mathrm{C}$}

A montage of $31.5 \times$ magnification optical images of the as-irradiated TRIGA fuel after a heat treatment at $900^{\circ} \mathrm{C}$ for $6 \mathrm{hr}$ is shown in Figure 26, and a 200× magnification image of the fuel and cladding interface in the specimen is presented in Figure 27. The image in Figure 27 shows the quality of contact at the fuel and cladding interface after heat treatment. The Ta foil was observed to be stuck to this specimen after heat treating. The cause is not definitively known but does suggest some reaction occurred between the fuel segment and Ta during heat treating.

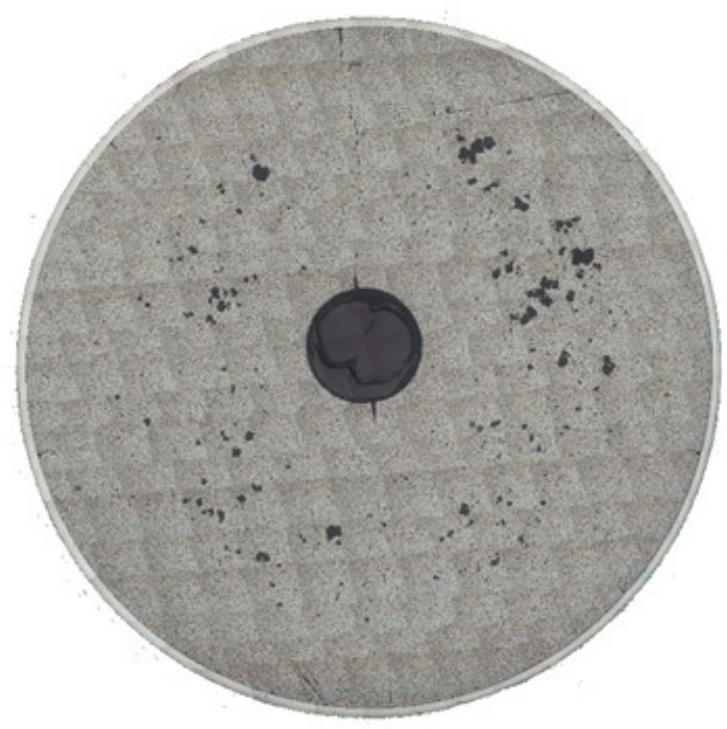

Figure 26. BOT222/MNT91Y $900^{\circ} \mathrm{C}$ heat-treated specimen full montage at $31.5 \times$ magnification. Dark regions toward center of specimen are $\mathrm{Zr}-\mathrm{H}$ phase.

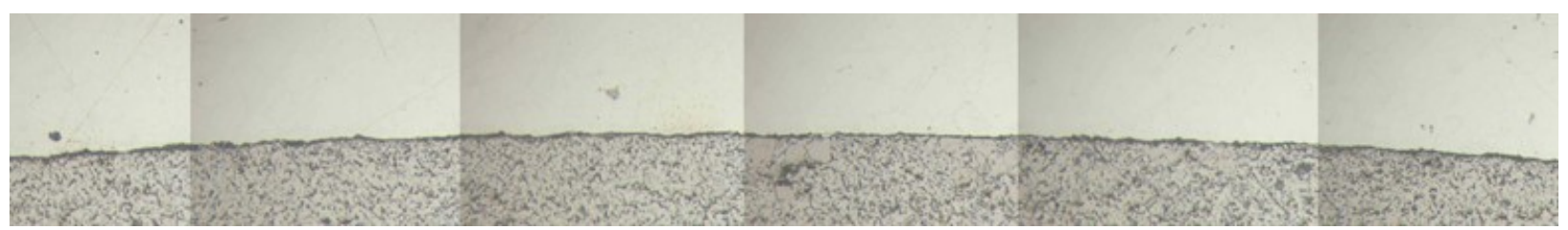

Figure 27. BOT222/MNT91Y $900^{\circ} \mathrm{C}$ heat-treated specimen partial montage at $200 \times$ magnification showing a fuel to cladding contact region.

\subsubsection{Irradiated Specimens Annealed at $950^{\circ} \mathrm{C}$}

A montage of $31.5 \times$ magnification optical images of the as-irradiated TRIGA fuel segment BOT221/MNT92Y, after a heat treatment at $950^{\circ} \mathrm{C}$ for $6 \mathrm{hr}$, is shown in Figure 28, and a 200× magnification image of the fuel and cladding interface in the specimen is presented in Figure 29. The image in Figure 29 suggests that intimate contact at the fuel and cladding interface was present, at least in some locations after heat treatment resulting in the development of an interaction layer. A montage of $31.5 \times$ magnification optical images of the as-irradiated TRIGA fuel segment BOT224/MNT99Y, after a heat treatment at $950^{\circ} \mathrm{C}$ of $6 \mathrm{hr}$, is shown in Figure 30. A 200× magnification image of the fuel and cladding interface in the specimen is presented in Figure 31 that shows FCCI had likely occurred and an interaction layer had developed. 


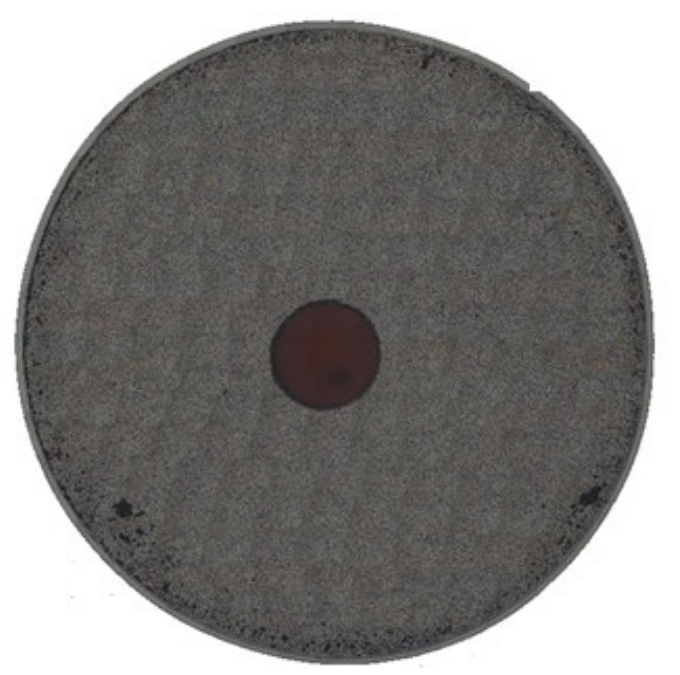

Figure 28. BOT221/MNT92Y $950^{\circ} \mathrm{C}$ heat-treated specimen full montage at $31.5 \times$ magnification.

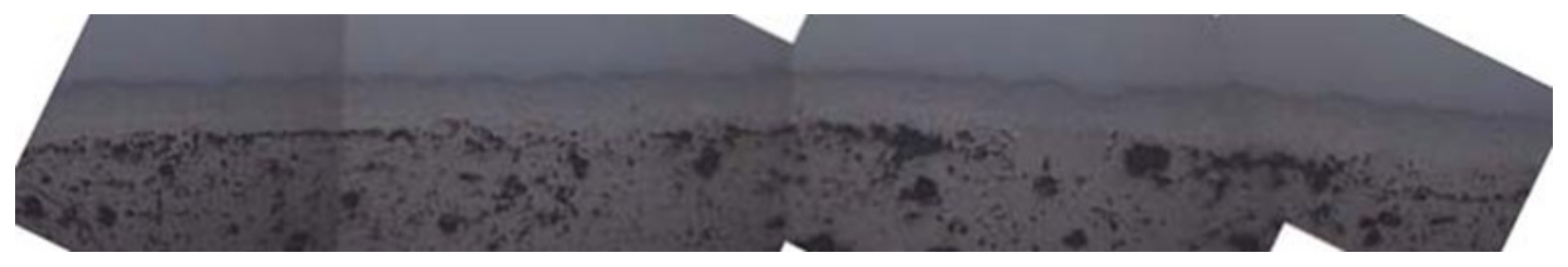

Figure 29. BOT221/MNT92Y $950^{\circ} \mathrm{C}$ heat-treated specimen partial montage at $200 \times$ magnification showing observed FCCI that resulted in the formation of a layer at the fuel and cladding interface.

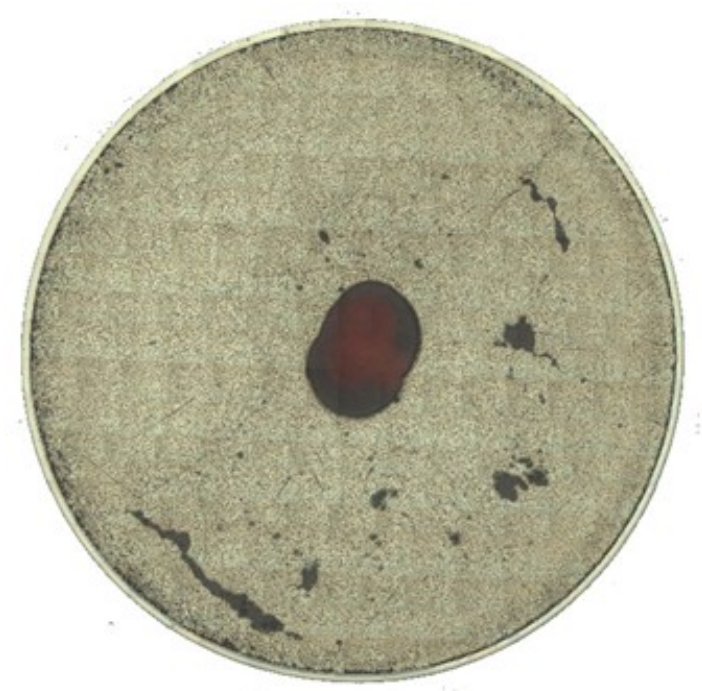

Figure 30. BOT224/MNT99Y $950^{\circ} \mathrm{C}$ heat-treated specimen full montage at $31.5 \times$ magnification. Dark regions toward center of specimen are $\mathrm{Zr}-\mathrm{H}$ phase. 


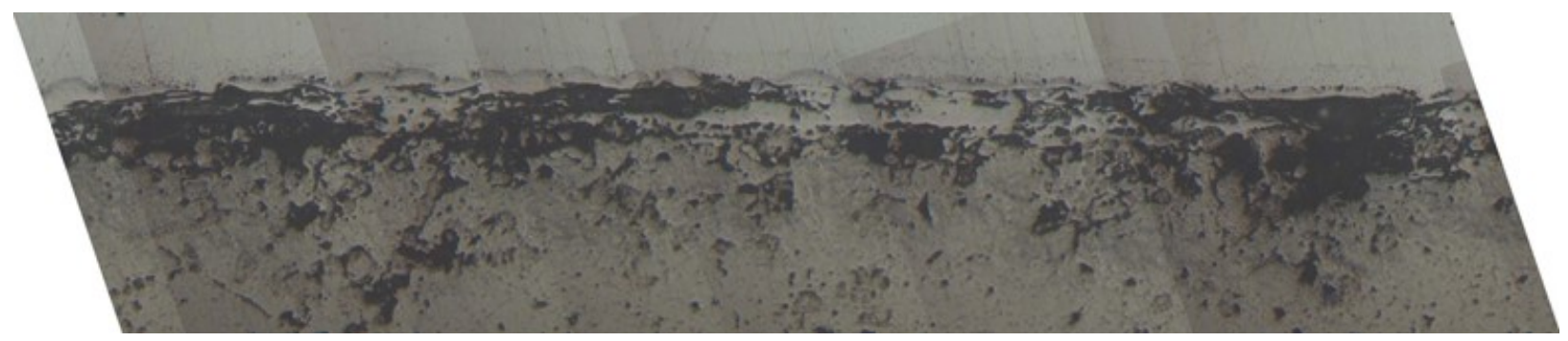

Figure 31. BOT224/MNT99Y $950^{\circ} \mathrm{C}$ heat-treated specimen partial montage at $200 \times$ magnification showing observed FCCI at the fuel and cladding interface.

BOT221/MNT92Y was the only specimen heat treated for $12 \mathrm{hr}\left(\right.$ at $\left.950^{\circ} \mathrm{C}\right)$. A montage of $31.5 \times$ magnification optical images of this as-irradiated TRIGA fuel segment, after heat treatment, is shown in Figure 32, and a 200× magnification image of the fuel and cladding interface in the specimen is presented in Figure 33. The image in Figure 33 suggests that intimate contact at the fuel and cladding interface was present in some locations after heat treatment resulting in the development of an interaction layer. Dark regions toward the fuel center could be fuel defects or $\mathrm{Zr}-\mathrm{H}$ regions.

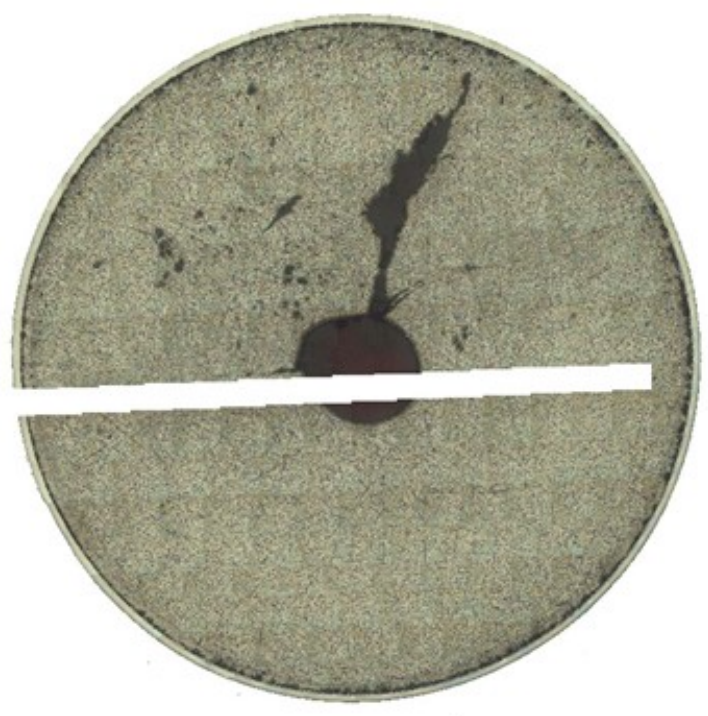

Figure 32. A full montage at $31.5 \times$ magnification of the BOT225/MNT01Z specimen heat treated at $950^{\circ} \mathrm{C}$ for $12 \mathrm{hr}$. The white strip is missing montage data discovered after micrographs were collected. Dark regions toward center of specimen are $\mathrm{Zr}-\mathrm{H}$ phase or specimen damage that occurred during sample preparation. 


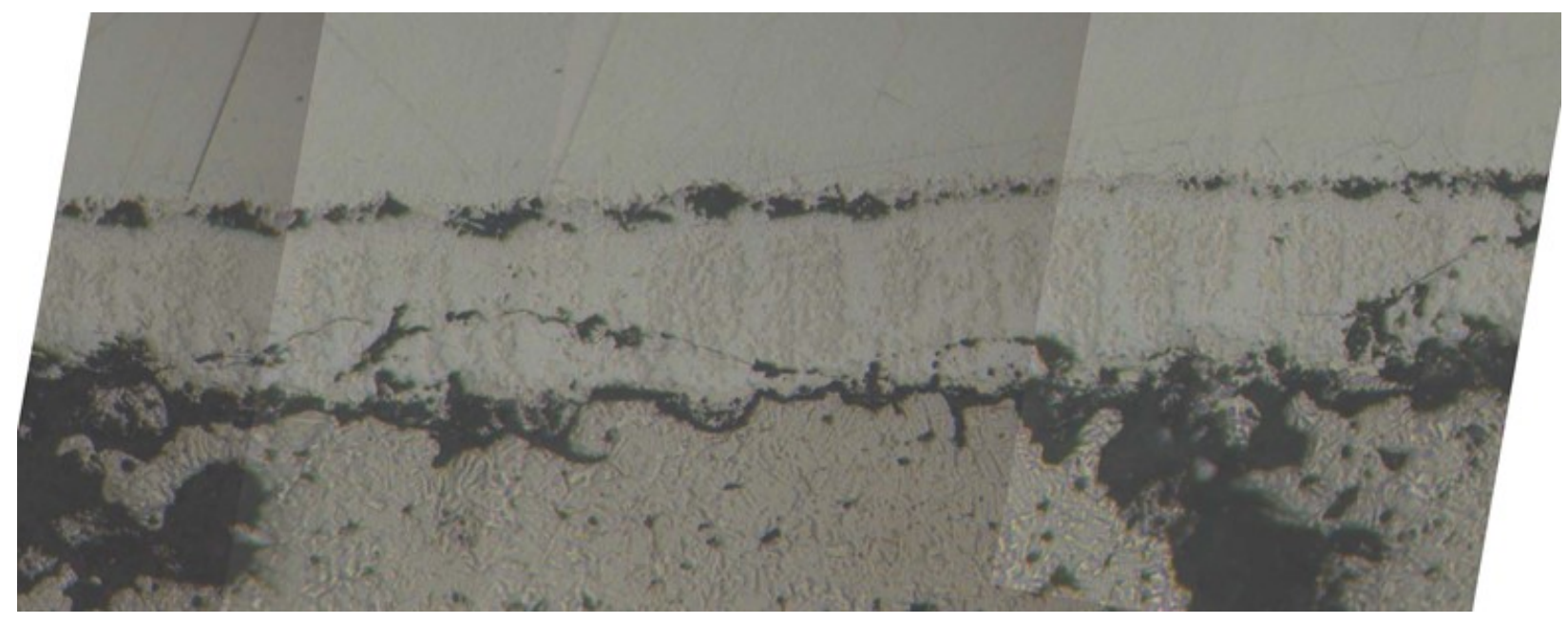

Figure 33 . BOT225MNT01Z $950^{\circ} \mathrm{C} 12$-hr heat-treated specimen partial montage at $200 \times$ magnification showing observed FCCI at the fuel and cladding interface and the resulting development of an interaction layer.

\subsubsection{Irradiated Specimen Annealed at $1000^{\circ} \mathrm{C}$}

A montage of $31.5 \times$ magnification optical images of the as-irradiated TRIGA fuel segment BOT220/MNT93Y, after a heat treatment at $1,000^{\circ} \mathrm{C}$ for $6 \mathrm{hr}$, is shown in Figure 34, and a 200× magnification image of the fuel and cladding interface in the specimen is presented in Figure 35 . The image in Figure 35 suggests that intimate contact at the fuel and cladding interface was present in some locations after heat treatment resulting in the development of an interaction layer. Dark regions toward the fuel center could be fuel defects or $\mathrm{Zr}-\mathrm{H}$ regions.

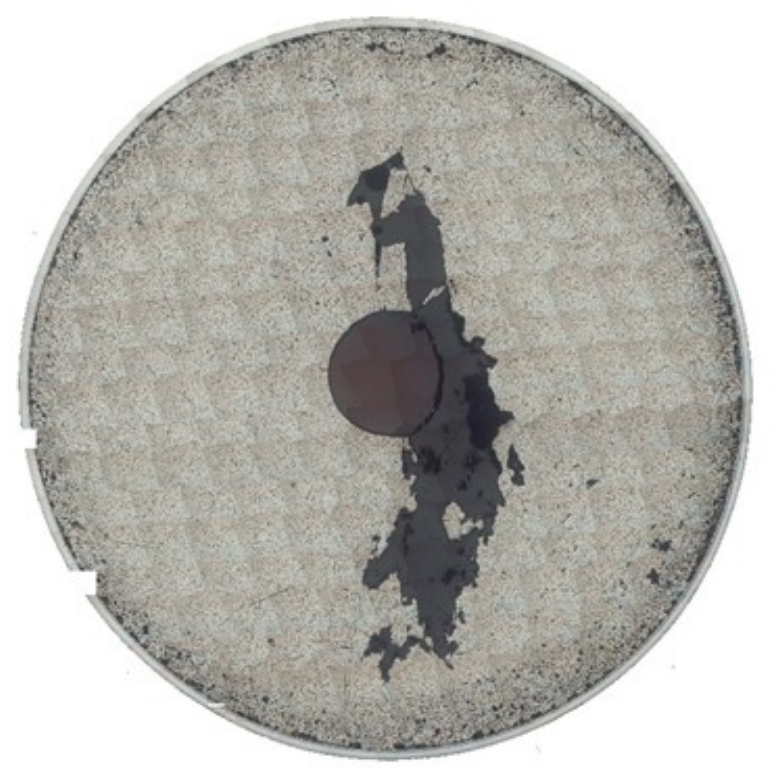

Figure 34 . BOT220/MNT93Y $1000^{\circ} \mathrm{C}$ heat-treated specimen full montage at $31.5 \times$ magnification. Dark regions toward center of specimen are $\mathrm{Zr}-\mathrm{H}$ phase or sample damage during polishing. 


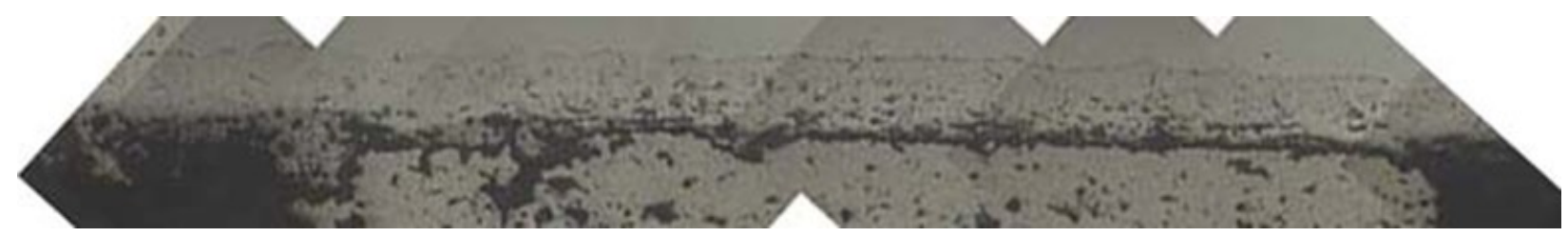

Figure 35 . BOT220/MNT93Y $1000^{\circ} \mathrm{C}$ heat-treated specimen partial montage at $200 \times$ magnification showing the fuel to cladding contact region.

The thickness of the cladding not impacted by FCCI at different locations for the different specimens was evaluated using the OM images. The results are shown in Figure 36, along with the nominal starting cladding thickness. For specimens annealed at $950^{\circ} \mathrm{C}$ and $1,000^{\circ} \mathrm{C}$, a reduction in this thickness was observed, due to the development of a FCCI layer on the inner surface of the cladding. A larger than expected cladding thickness was observed for the specimen tested at $730^{\circ} \mathrm{C}$. This could be due to the specimen being cut at a slight angle which would increase the thickness that is measured. Even at $1,000^{\circ} \mathrm{C}$, over $75 \%$ of the cladding thickness is devoid of fuel and cladding interaction.

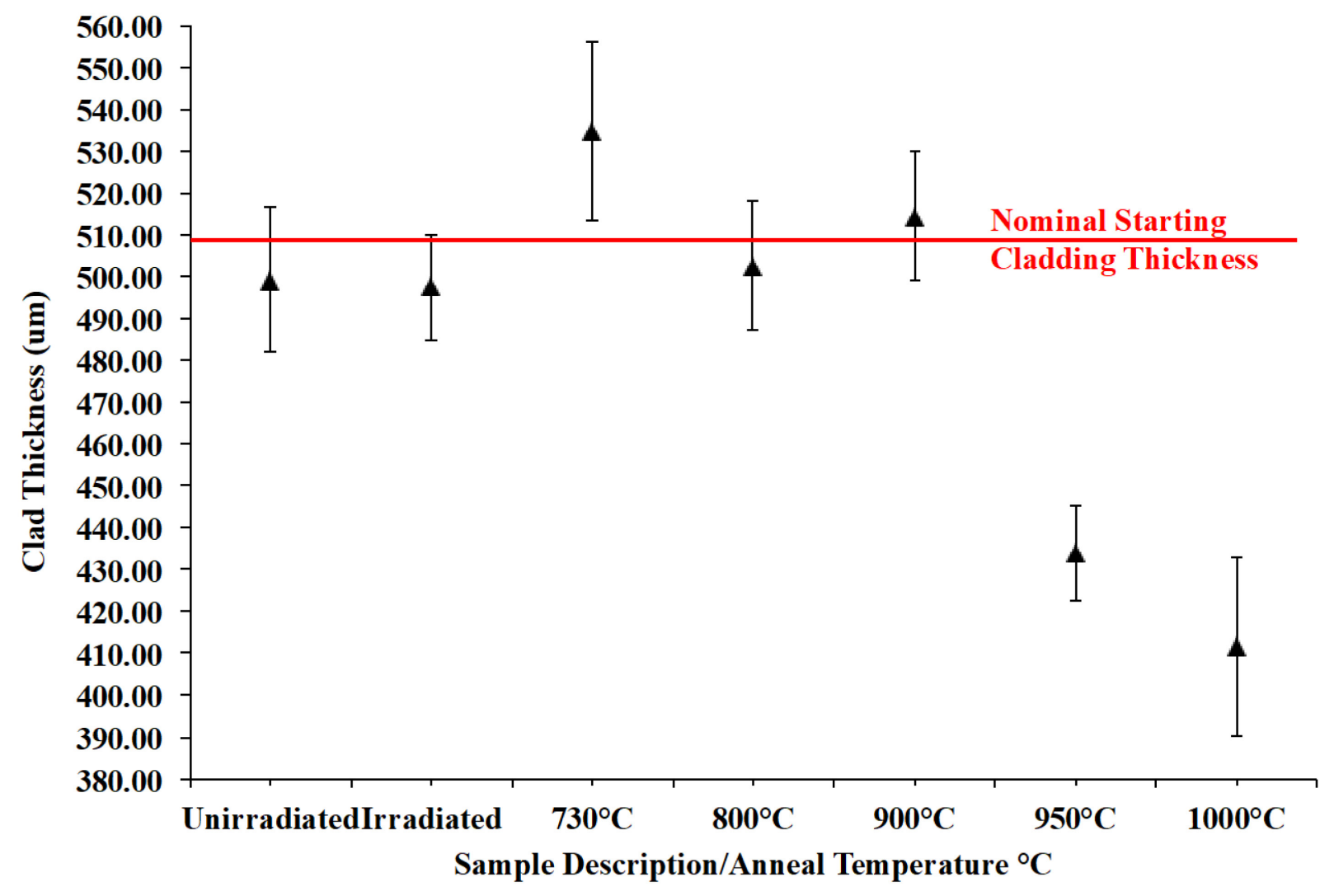

Figure 36. A plot of the thickness of the cladding not impacted by FCCI at different locations for the different annealed specimens. Data is based on evaluation of $\mathrm{OM}$ images. Even at $1,000^{\circ} \mathrm{C}$, over $75 \%$ of the cladding thickness is devoid of fuel and cladding interaction. 


\subsubsection{Scanning Electron Microscopy}

Samples for SEM analysis were taken from an as-irradiated specimen and specimens tested at $730^{\circ} \mathrm{C}$ and $950^{\circ} \mathrm{C}$ for $6 \mathrm{hr}$. Irradiated samples were examined using SEM, EDS, and WDS. Microstructural features of interest were imaged using secondary electrons (SE) and backscattered electrons (BSE). Phase compositions and compositional line scans were determined using EDS. X-ray maps were generated using EDS and WDS. Hydrogen could not be measured using EDS or WDS. X-ray or electron diffraction is needed to identify phases that contain hydrogen. Diffraction analysis was not performed on irradiated samples.

\subsubsection{As-Irradiated Specimen}

BSE images of the as-irradiated specimen microstructure are presented in Figure 37. As depicted in Figure 37(a), the as-irradiated TRIGA fuel specimen is a multiphase material that is comprised of a U-rich precipitate phase and a $\mathrm{Zr}-\mathrm{H}$ matrix phase as the major phases. Figure 37(b) and Figure 37(c) show that the specimen exhibited a gap at the fuel and cladding interface, and after careful inspection of the inner surface of the cladding, no evidence of any FCCI zones could be observed that may have suggested there was fuel and cladding contact at some time during irradiation so that interaction between the fuel and cladding could have transpired. WDS x-ray maps were produced (see Figure 38) to confirm the partitioning behavior for the $\mathrm{U}$ and $\mathrm{Zr}$ in the TRIGA fuel. Hydrogen cannot be detected using WDS and so is not shown.
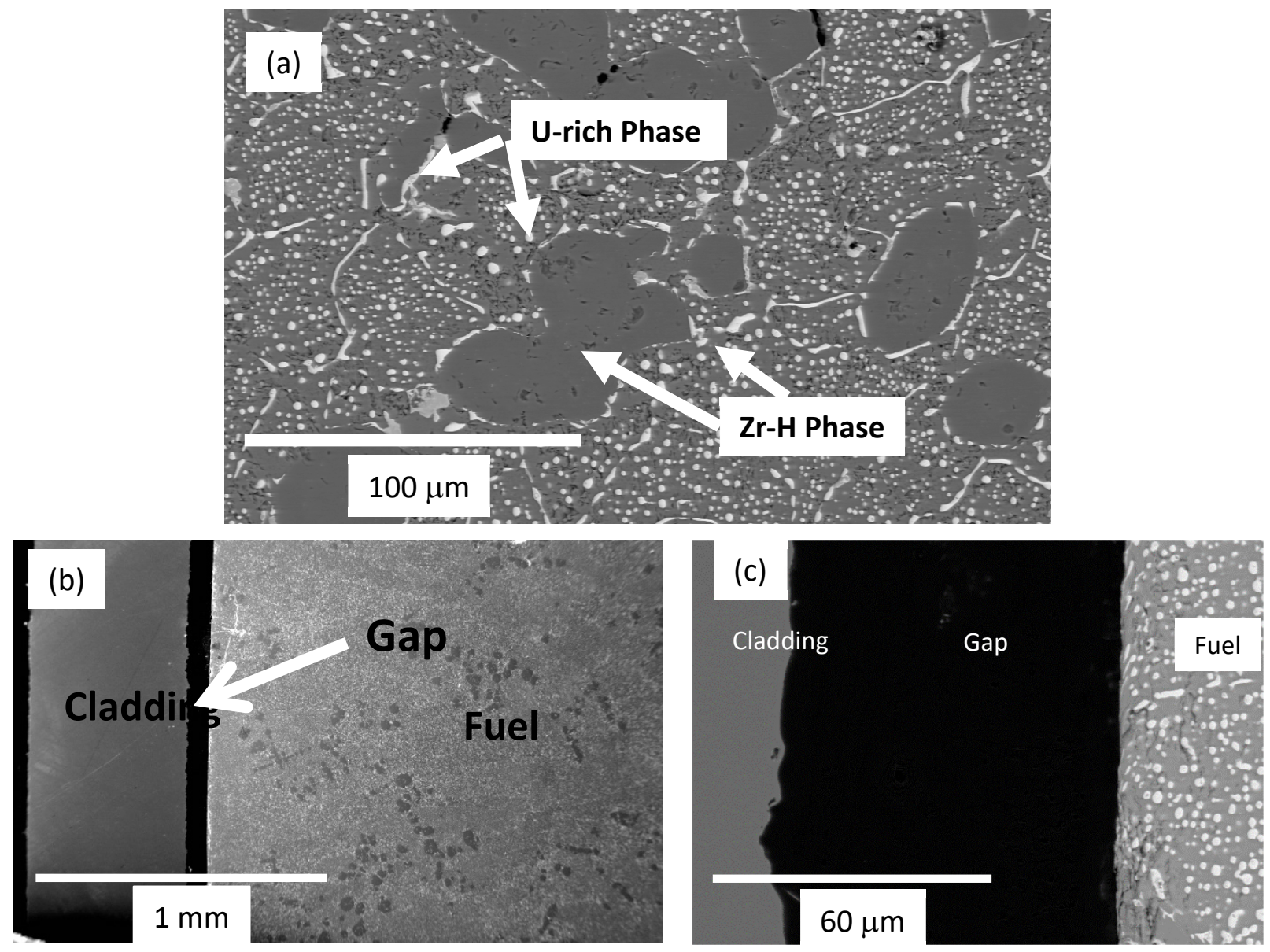

Figure 37. Backscattered electron images $(\mathrm{a}-\mathrm{c})$ showing the as-irradiated TRIGA fuel microstructure (a) and a gap $(b, c)$ that was observed at the fuel and cladding interface. 

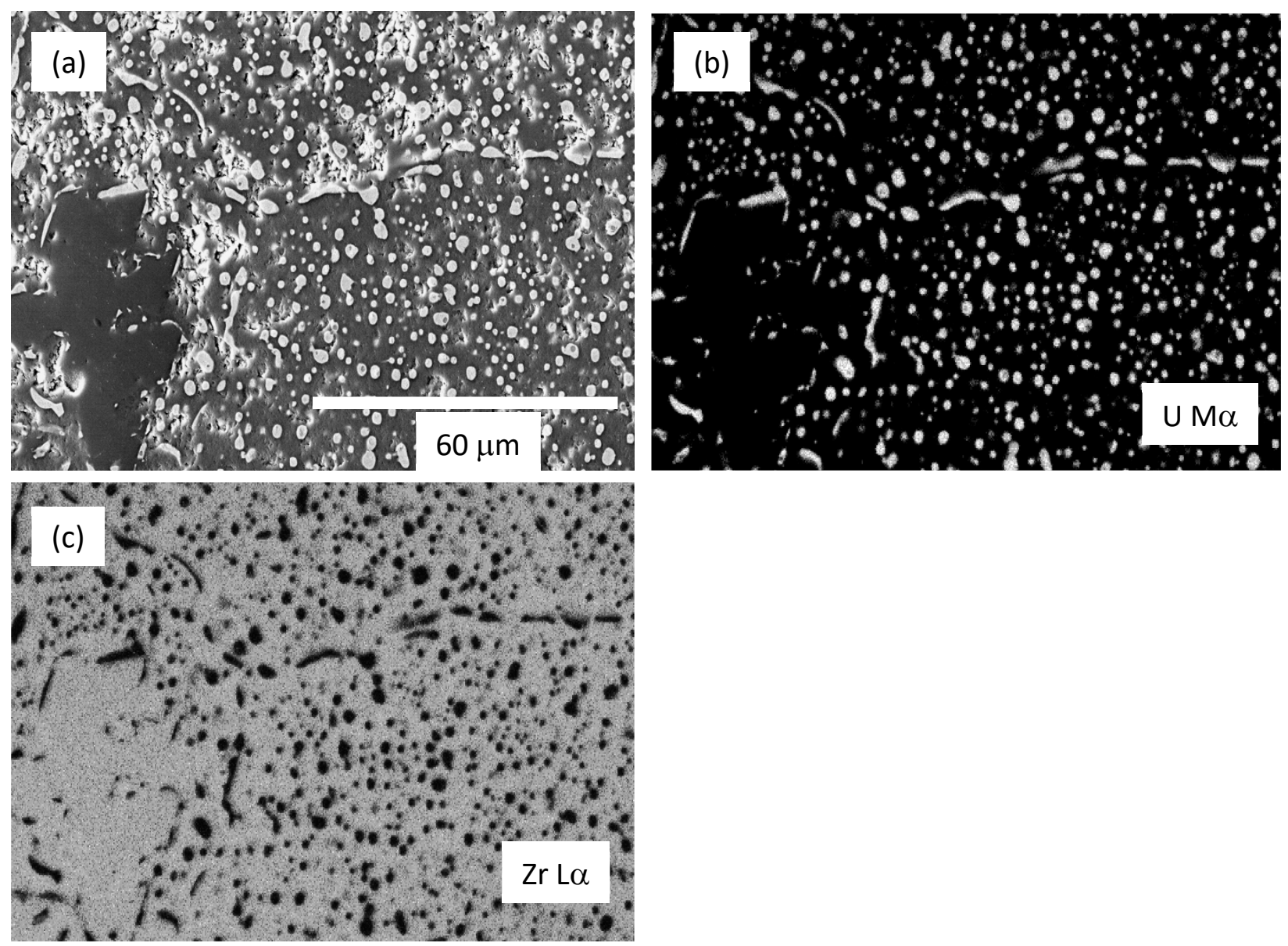

Figure 38. A BSE image of the irradiated fuel specimen microstructure (a) and WDS x-ray maps for (b) U and (c) Zr. Hydrogen cannot be detected using WDS.

A montage of optical images of as-fabricated TRIGA fuel are presented in Figure 39 to show that noticeable changes in the TRIGA fuel microstructure are not observed after irradiation, and Figure 40 shows BSE images of as-fabricated TRIGA fuel that confirms the fact that little microstructural change has occurred during irradiation (compare with Figure 37a). 


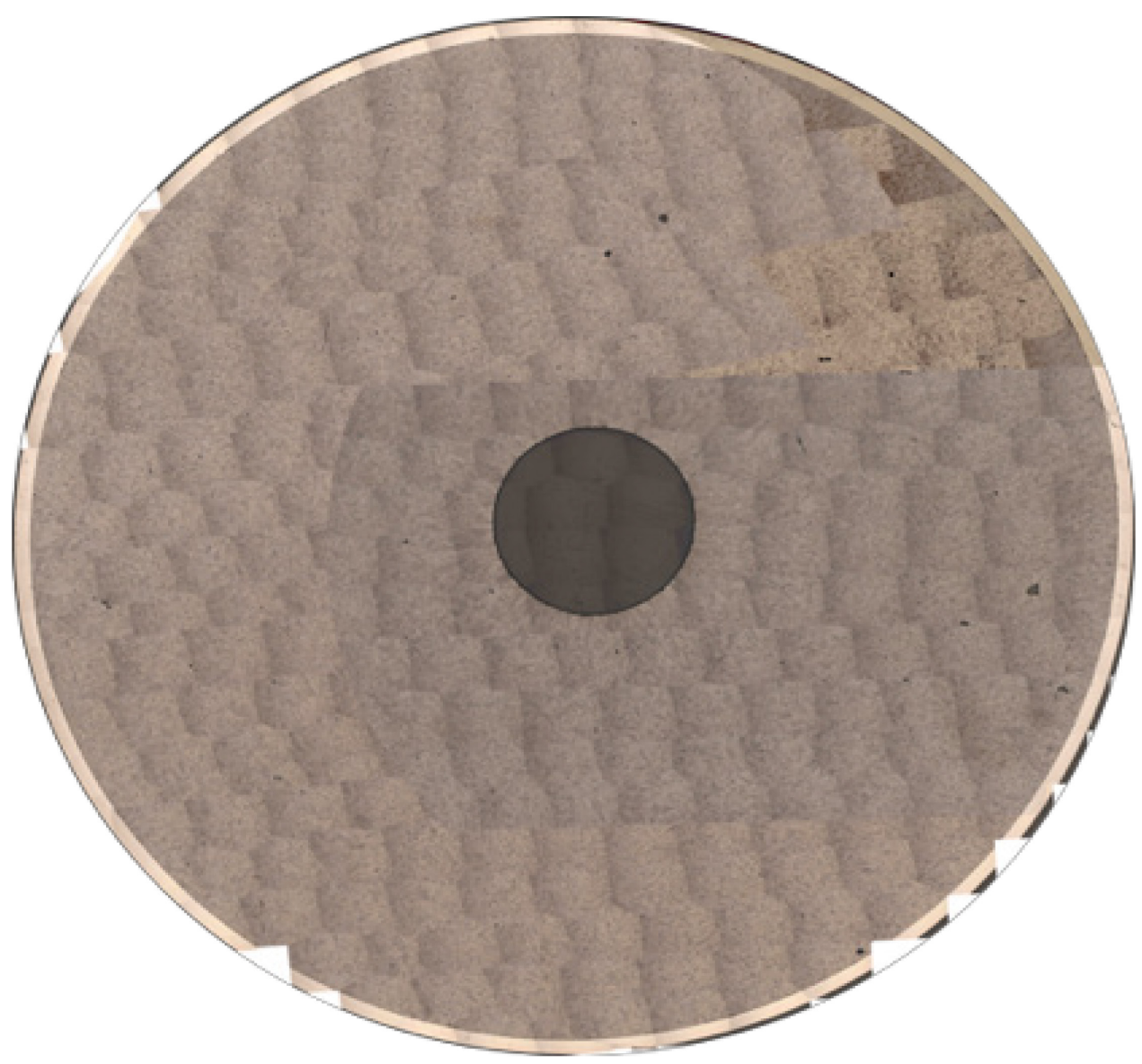

Figure 39. Montage of optical images showing as-fabricated TRIGA fuel.
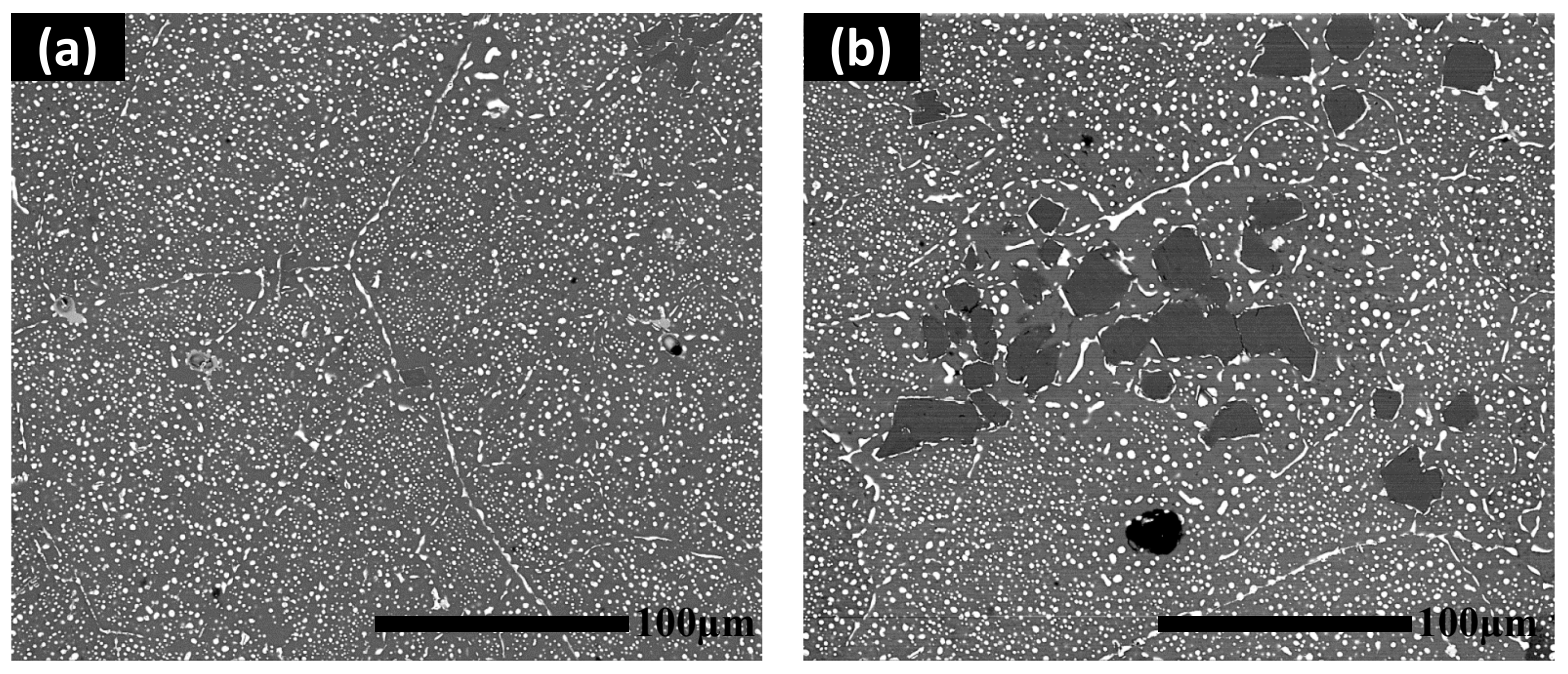

Figure 40. BSE images $(a, b)$ of the microstructure for as-fabricated TRIGA fuel [2]. 
Characterization by $\mathrm{x}$-ray diffraction (XRD) was performed to obtain data on the phase compositions of the as-received TRIGA fuel. An XRD pattern collected from an area in one of the samples is shown in Figure 41. XRD showed that the dominant phase in the fuel was the cubic- $\mathrm{H}_{1.6} \mathrm{Zr}(\mathrm{cF} 12, \mathrm{Fm}-3 \mathrm{~m})$ phase. Lower intensity peaks identified the orthorhombic- $\alpha-U$ phase. Low-intensity peaks showed that the tetragonal- $\mathrm{H}_{2} \mathrm{Zr}$ phase (tI6, I4/mmm) phase was also present in the material. The peaks for the $\mathrm{H}_{2} \mathrm{Zr}$ phase were predominantly convoluted with other peaks in the patterns. Nonetheless, they are discernable in the pattern.

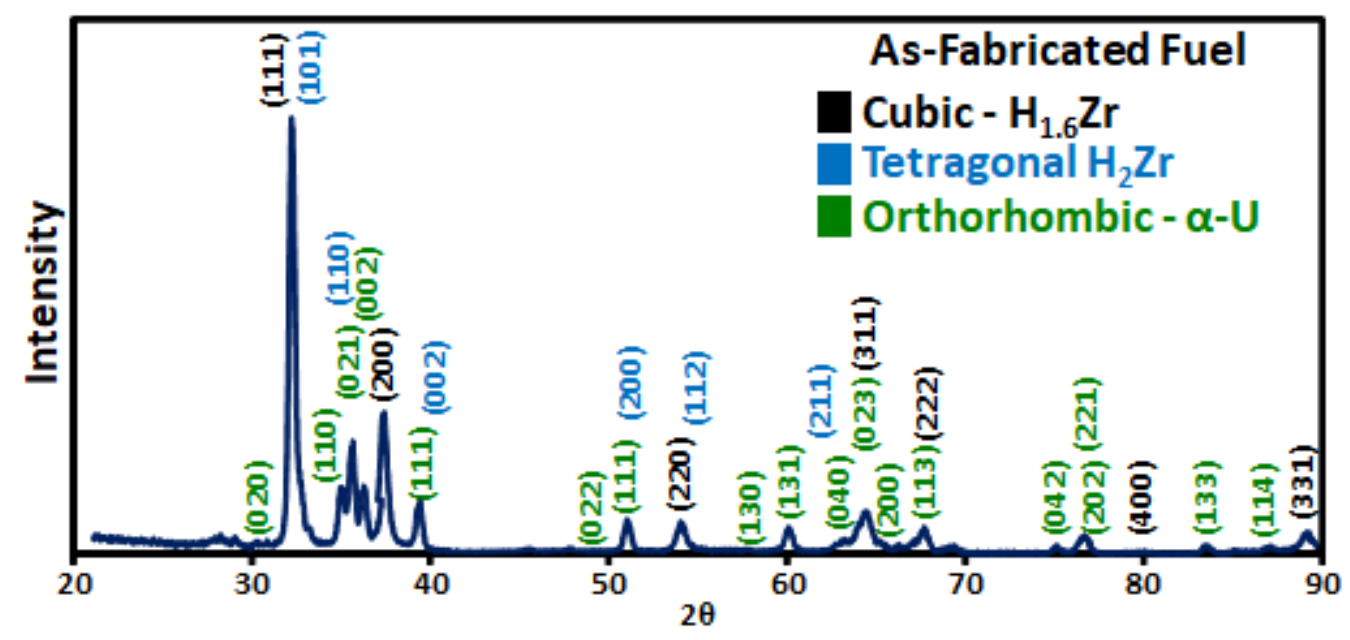

Figure 41. XRD pattern obtained from as-fabricated TRIGA fuel.

\subsubsection{Irradiated Specimen Annealed at $730^{\circ} \mathrm{C}$}

The specimen tested at $730^{\circ} \mathrm{C}$ for $6 \mathrm{hr}$ was selected for SEM characterization, since this temperature is just above the eutectic U-Fe composition that can exhibit melting at $725^{\circ} \mathrm{C}$ [3], and it has been hypothesized that due to fuel and cladding interaction this phase might be present in irradiated TRIGA fuel [1]. An optical image that shows where the SEM specimen was produced for characterization of the fuel and cladding interface is presented in Figure 42. Some dark-contrast, precipitate-like features were present at this location that might indicate some interaction had occurred between the fuel and cladding during the $730^{\circ} \mathrm{C}$ heat treatment for $6 \mathrm{hr}$. The specimen was sliced into two pieces using a slow-speed saw to fit into available mounts. Figure 43 shows photographs of the mounted pieces. 


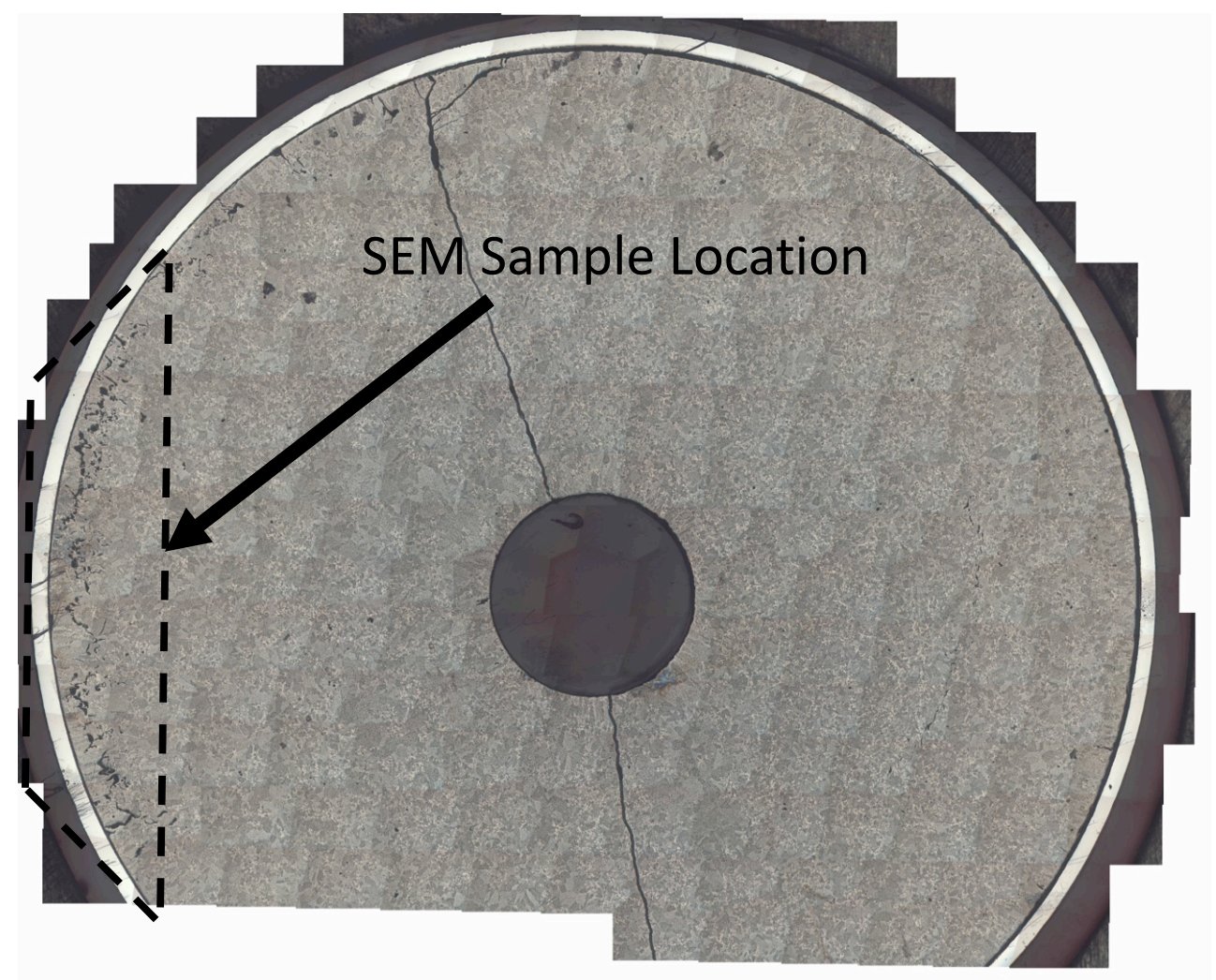

Figure 42. Montage of OM images showing location where SEM sample was taken (area in dashed line box).

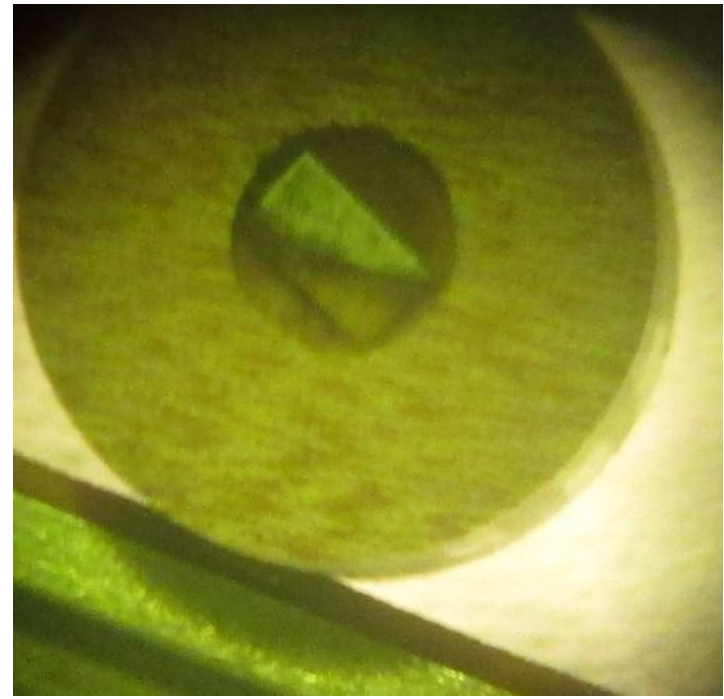

Sample 03A $\left(730^{\circ} \mathrm{C}, 6 \mathrm{Hrs}\right)$

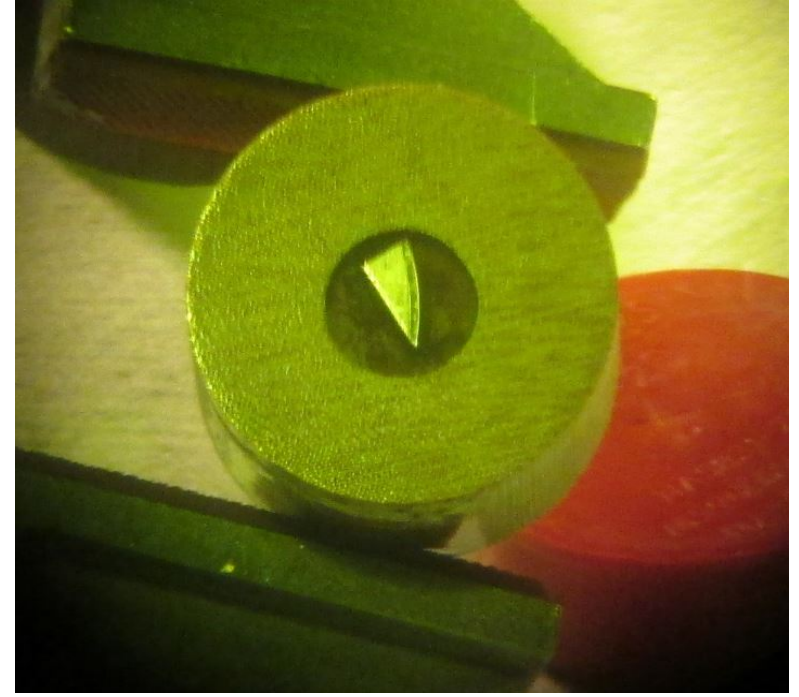

Sample 05A $\left(730^{\circ} \mathrm{C}, 6 \mathrm{Hrs}\right)$

Figure 43. Photographs of the as-mounted samples from the TRIGA fuel that was heat treated at $730^{\circ} \mathrm{C}$ for $6 \mathrm{hr}$ that were generated for SEM analysis. 
A BSE image of the fuel and cladding interface for Sample 03A is shown in Figure 44. A clear gap was observed at the interface. WDS x-ray maps taken in the fuel meat (see Figure 45) show that the microstructure of the fuel after a $730^{\circ} \mathrm{C}$ heat treatment looks very similar to the as-irradiated fuel microstructure. Careful examination along the inner surface of the cladding revealed no evidence of fuel and cladding interaction phases.

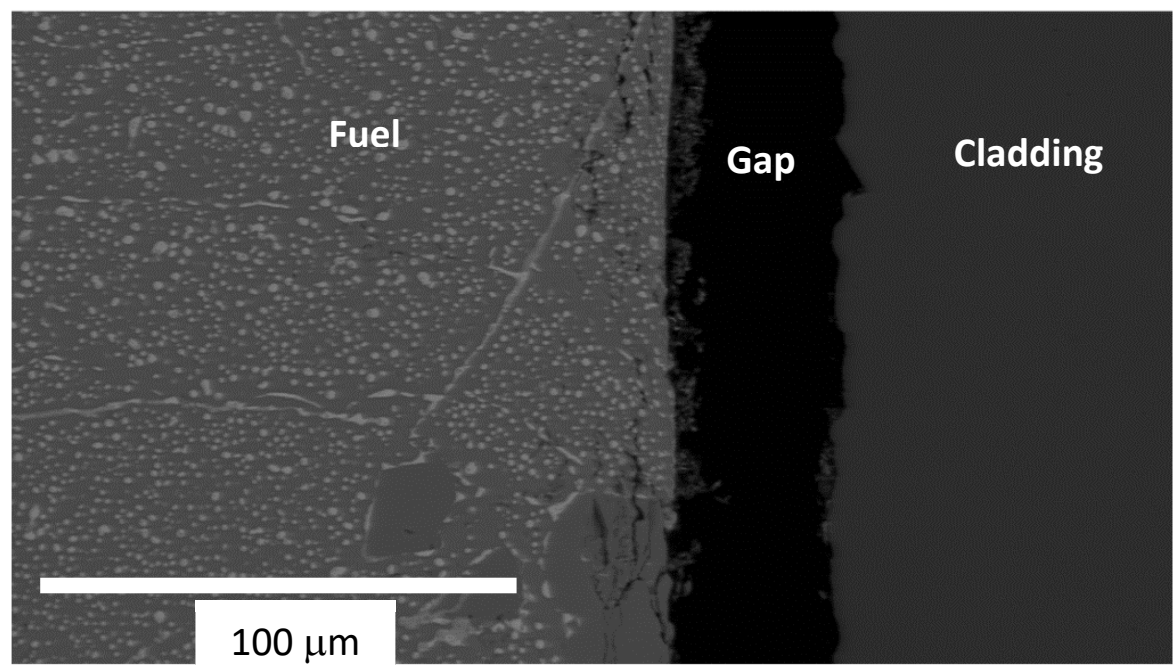

Figure 44. BSE image of the fuel and cladding interface for Sample 03A. A gap was observed.
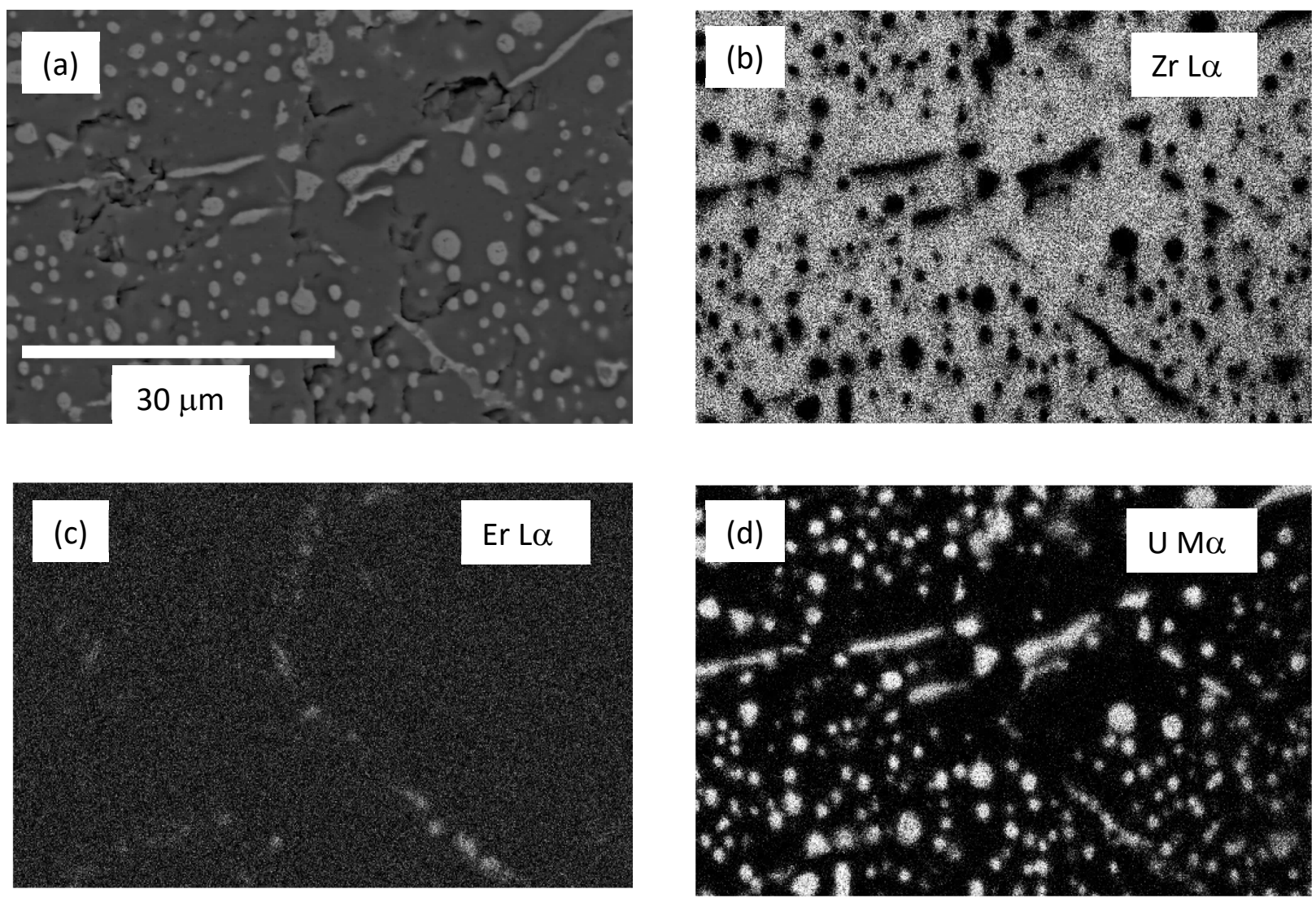

Figure 45. BSE image (a) and WDS x-ray maps for (b) Zr, (c) Er, and (d) U in the TRIGA fuel for Specimen $03 \mathrm{~A}$ after the heat treatment at $730^{\circ} \mathrm{C}$ for $6 \mathrm{hr}$. 
An EDS line scan (see Figure 46) was taken across the fuel and cladding interface to look for any evidence that fuel and cladding interaction had taken place. No fuel and cladding interaction phases could be observed.

(a)

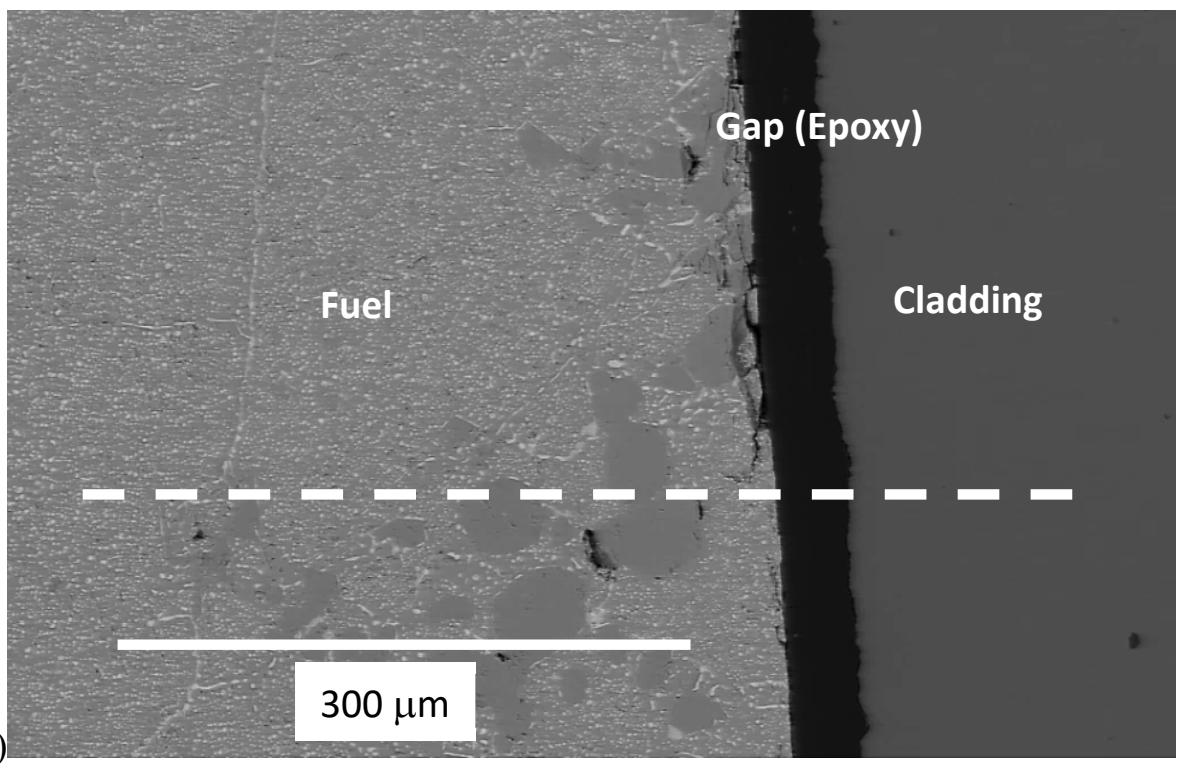

(b)

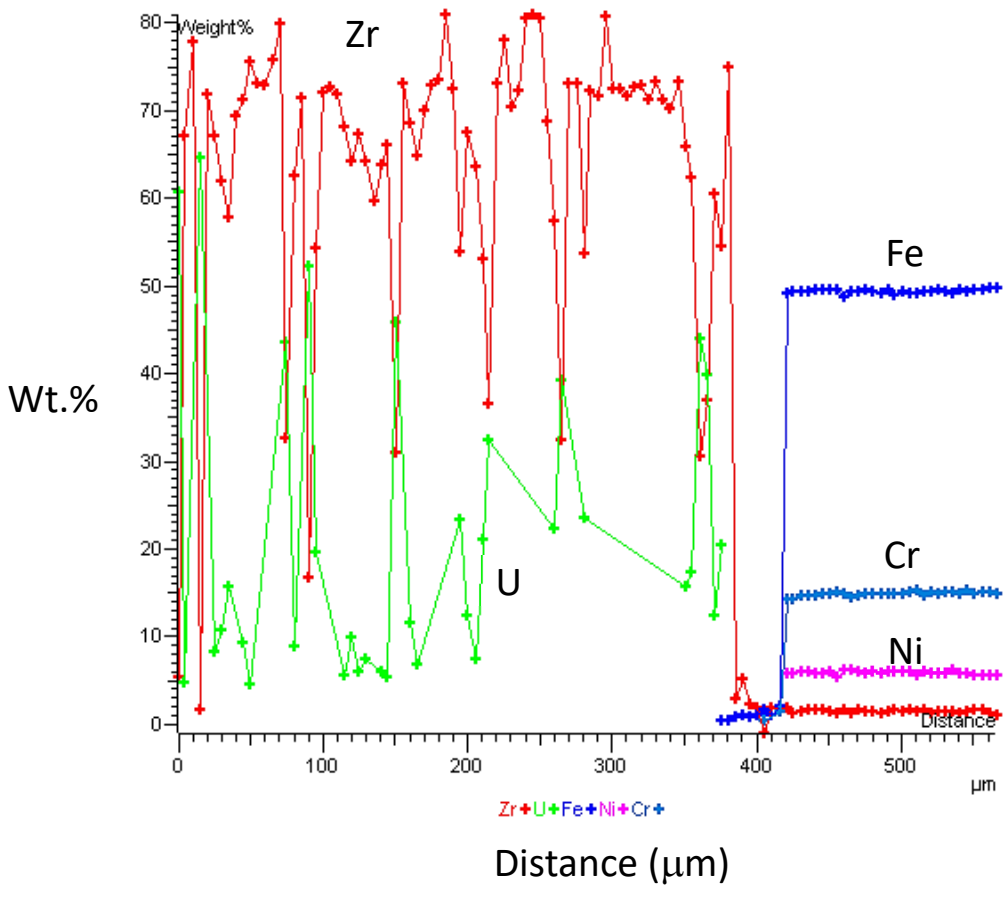

Figure 46. BSE image (a) showing location of EDS line scan (dashed line), and (b) variations of $\mathrm{Fe}, \mathrm{Cr}$, $\mathrm{Ni}, \mathrm{Zr}$, and $\mathrm{U}$ concentrations along line scan for Sample 03A.

Figure 47 shows BSE images that were produced for Sample 05A. This sample also exhibited a gap at the fuel and cladding interface. 


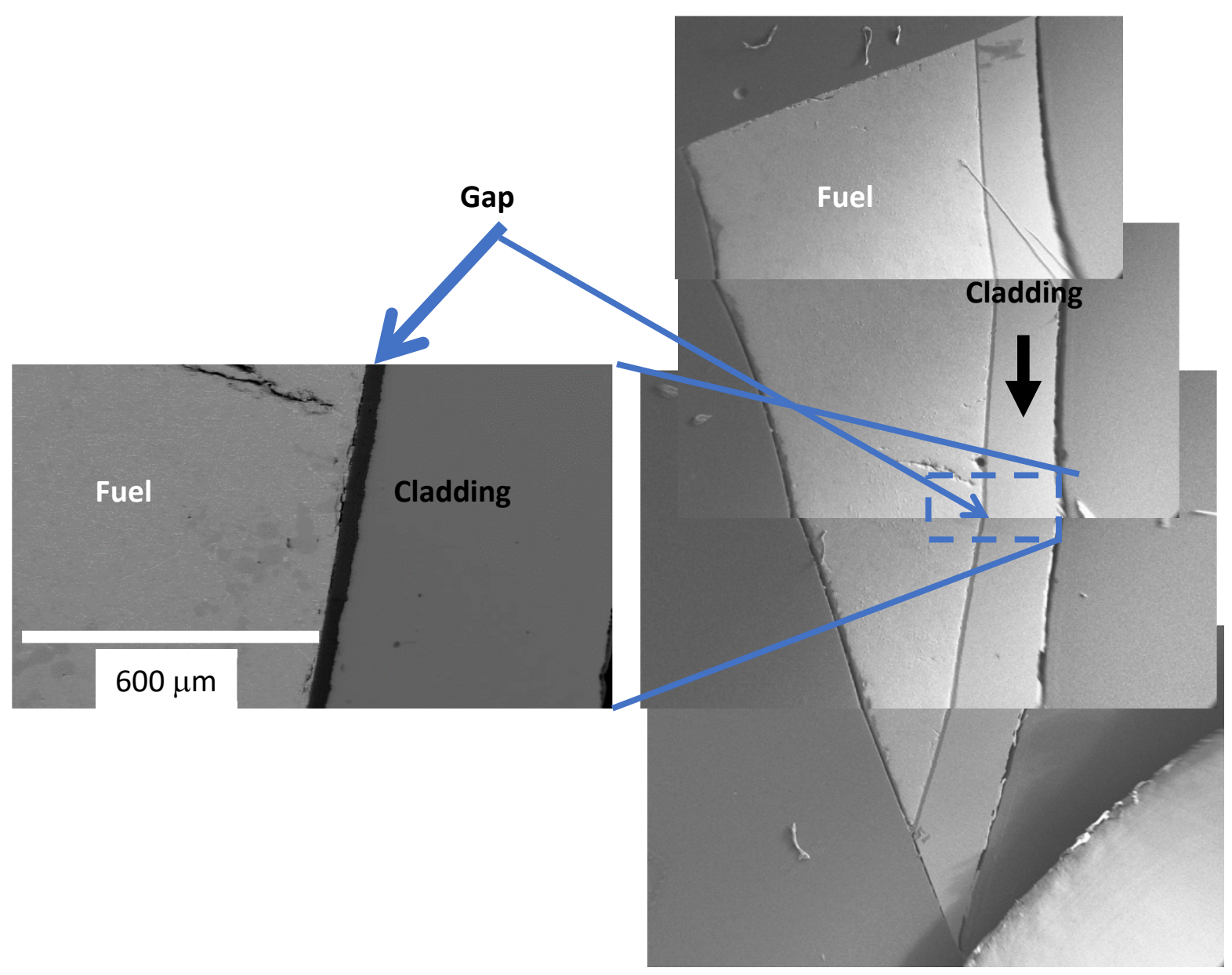

Figure 47. BSE micrographs of Sample 05A. A gap was observed at the fuel and cladding interface.

\subsubsection{Irradiated Specimen Annealed at $950^{\circ} \mathrm{C}$}

Since $950^{\circ} \mathrm{C}$ is the safety limit for TRIGA fuel, the specimen annealed at this temperature was selected for microstructural characterization using SEM [4]. A montage of optical images of the irradiated specimen annealed at $950^{\circ} \mathrm{C}$ for $6 \mathrm{hr}$ that shows where an SEM sample was produced is presented in Figure 48. Some dark-contrast, precipitate-like features were present at the fuel and cladding interface for this sample that might indicate some interaction had occurred between the fuel and cladding during the $950^{\circ} \mathrm{C}$ heat treatment for $6 \mathrm{hr}$. The region with dashed lines is where an SEM sample was produced, and a photograph of the mounted samples is shown in Figure 49. 


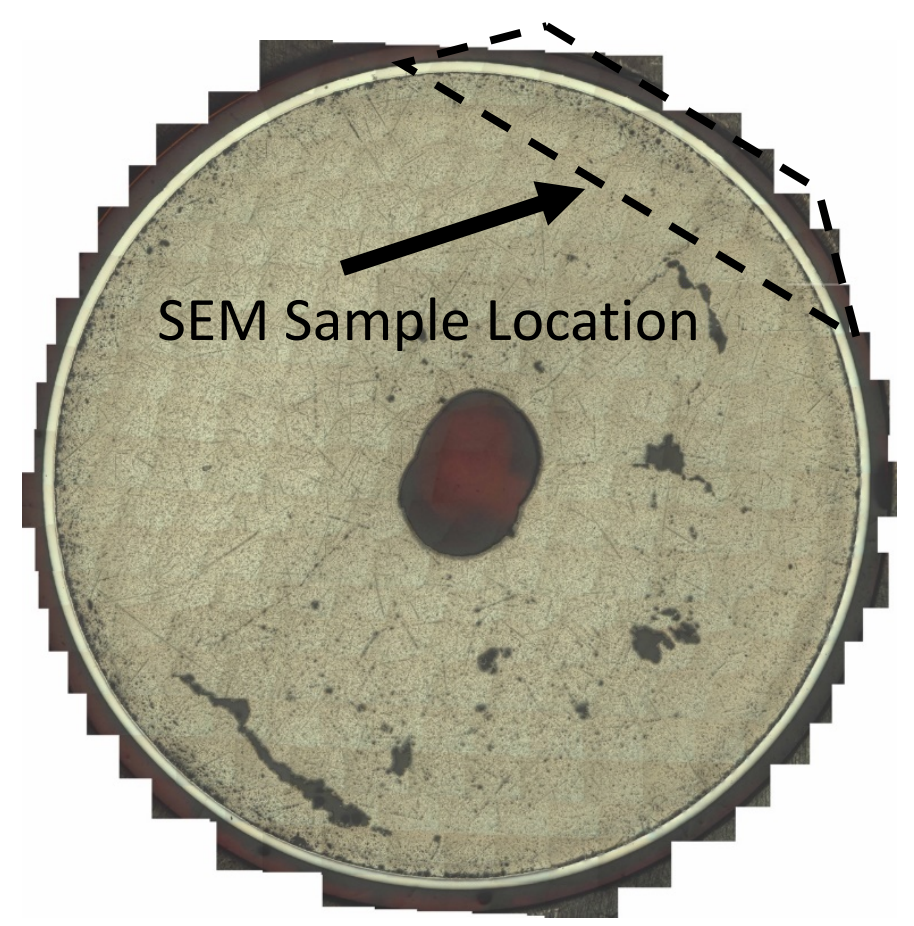

Figure 48. Montage of OM images showing location where SEM sample was taken (area in dashed line box). Isolated dark areas are $\mathrm{Zr}-\mathrm{H}$ phase.

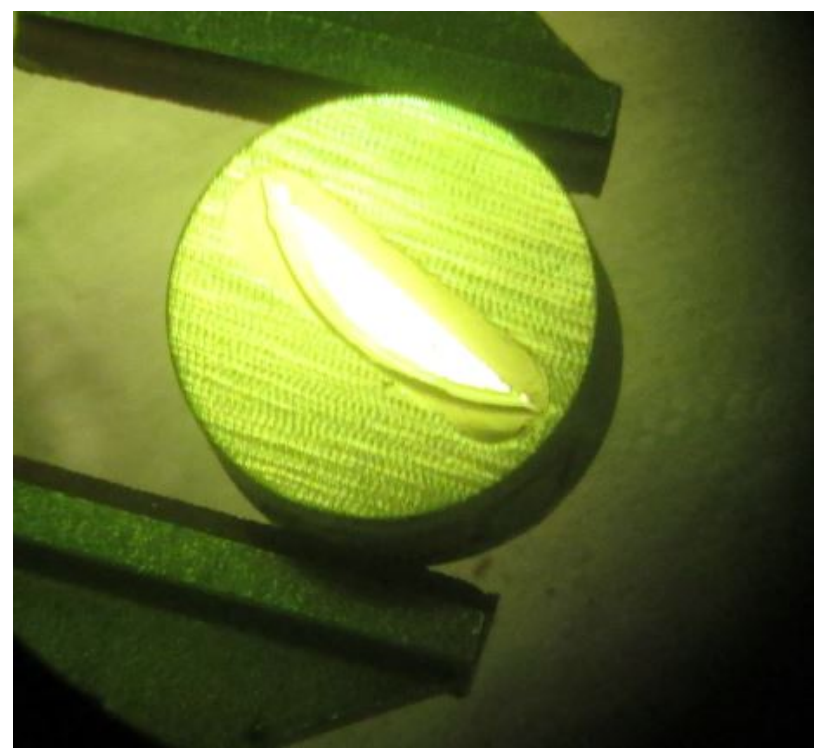

Sample 02A $\left(950^{\circ} \mathrm{C}, 6 \mathrm{Hrs}\right)$

Figure 49. Photograph of the as-mounted sample that was generated for SEM analysis.

BSE images of a fuel and cladding interaction zone that was observed in the sample are presented in Figure 50. Also, images on the fuel side of the interaction zone are presented where a Zr-rich matrix phase was observed with over 80 at.\% Zr. A crack was observed parallel to the fuel and cladding interface. It is not clear if the crack developed during the heat treatment or during the cutting and polishing that followed to get a sample for SEM. 
(a)

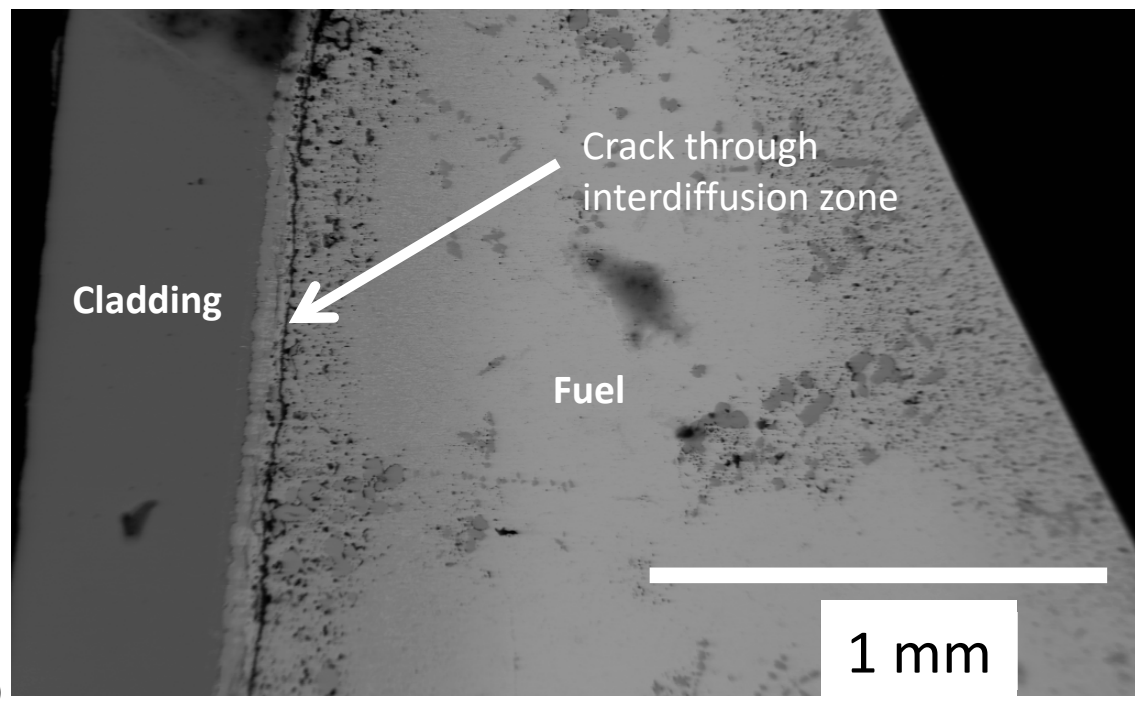

(b)
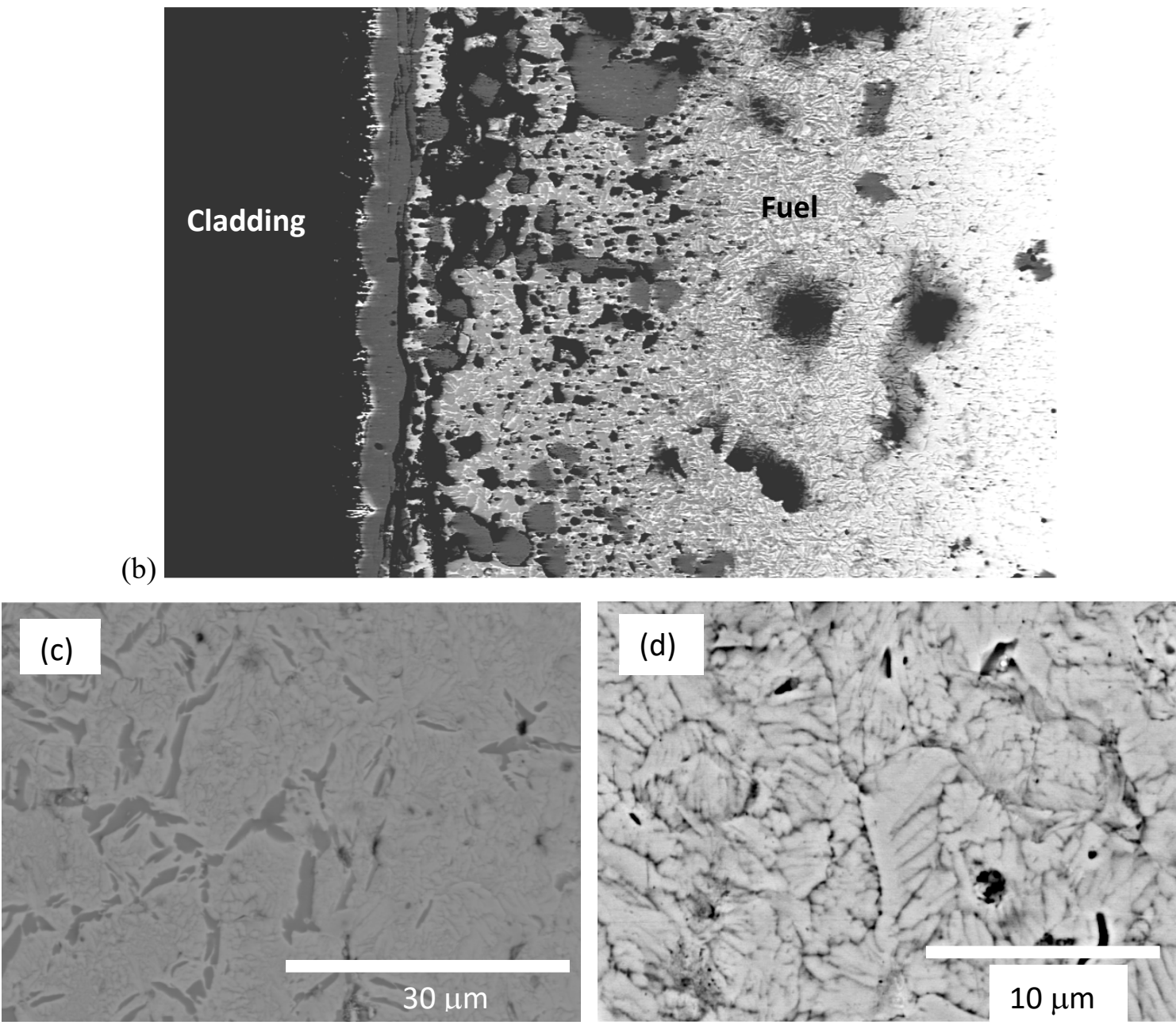

Figure 50. BSE images (a-b) The microstructure at the fuel and cladding interface for Sample 02A (annealed at $950^{\circ} \mathrm{C}$ for $6 \mathrm{hr}$ ). A crack parallel to the fuel and cladding interface was observed towards the fuel (c-d). The fuel microstructure is well away from the interdiffusion zone. Over 80 at.\% $\mathrm{Zr}$ was measured in the bright-contrast phase depicted in (c-d). 
SE and BSE images of porosity observed in the interdiffusion zone are presented in Figure 51. In (f) locations are shown where EDS composition measurements were made. Points 1 and 2 (darkest contrast phase) contained over $99 \% \mathrm{Zr}$. Point 3 (brightest contrast phase) had $89 \% \mathrm{Zr}$ and $11 \% \mathrm{U}$, and Point 4 (medium contrast phase) had over $99 \% \mathrm{Zr}$.
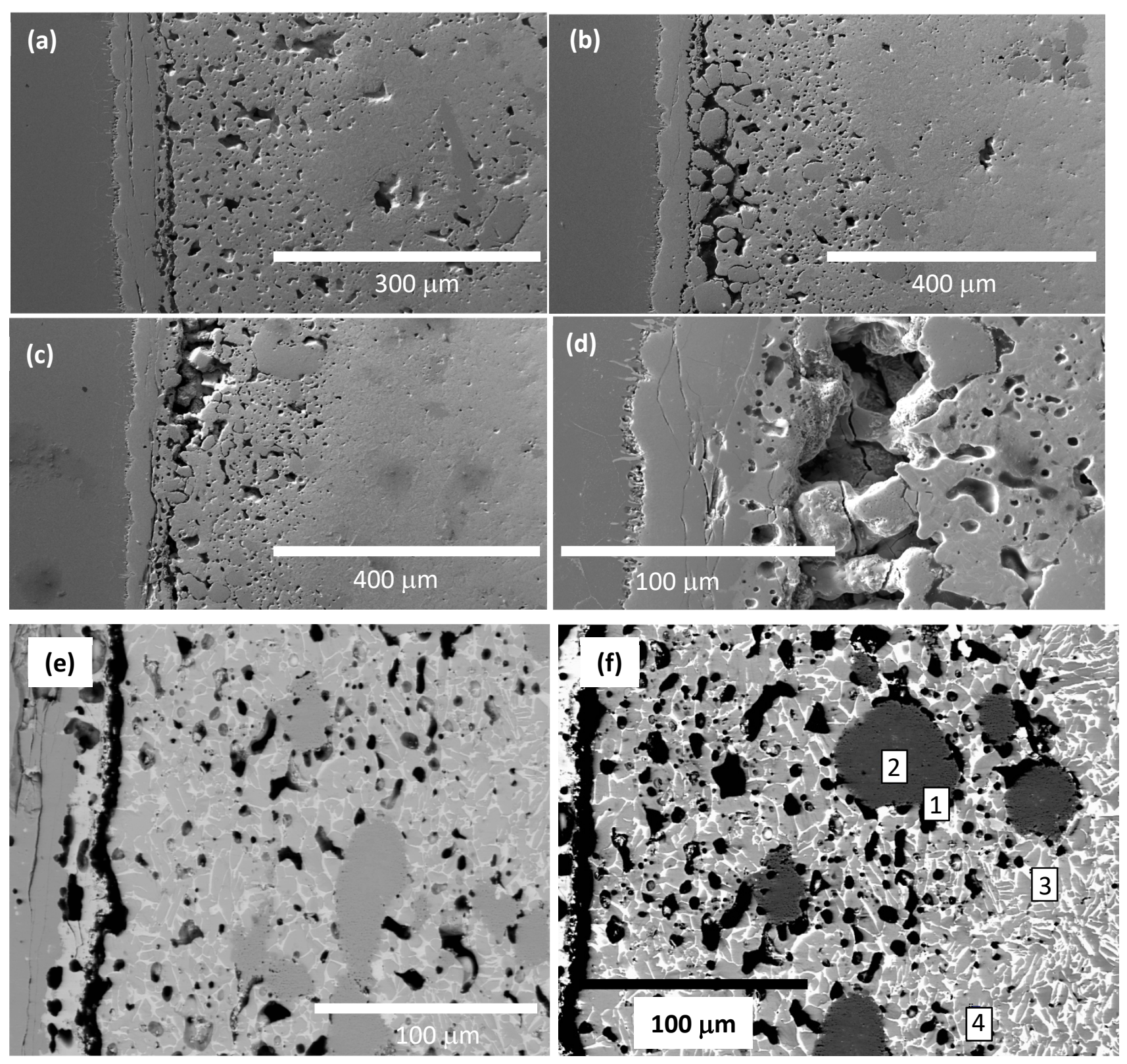

Figure 51. SE images (a-d) and BSE image (e-f) showing porosity that can be observed in the interaction zone. Points 1-4 in (e) are locations where compositions were measured using EDS. Points 1 and 2 are in the darkest contrast phase, Point 3 is in the brightest contrast phase, and Point 4 is in the medium-gray contrast phase.

In Figure 52 are presented WDS x-ray maps for $\mathrm{Cr}, \mathrm{Fe}, \mathrm{Ni}, \mathrm{Mn}, \mathrm{U}, \mathrm{Zr}, \mathrm{Nd}$, and $\mathrm{Pu}$ in the fuel and cladding interaction region. Figure 53 shows WDS x-ray maps ( $\mathrm{Fe}, \mathrm{Cr}, \mathrm{U}, \mathrm{Zr}, \mathrm{Ce}, \mathrm{Nd}$, and $\mathrm{Er}$ ) at another region along the fuel and cladding interaction. 


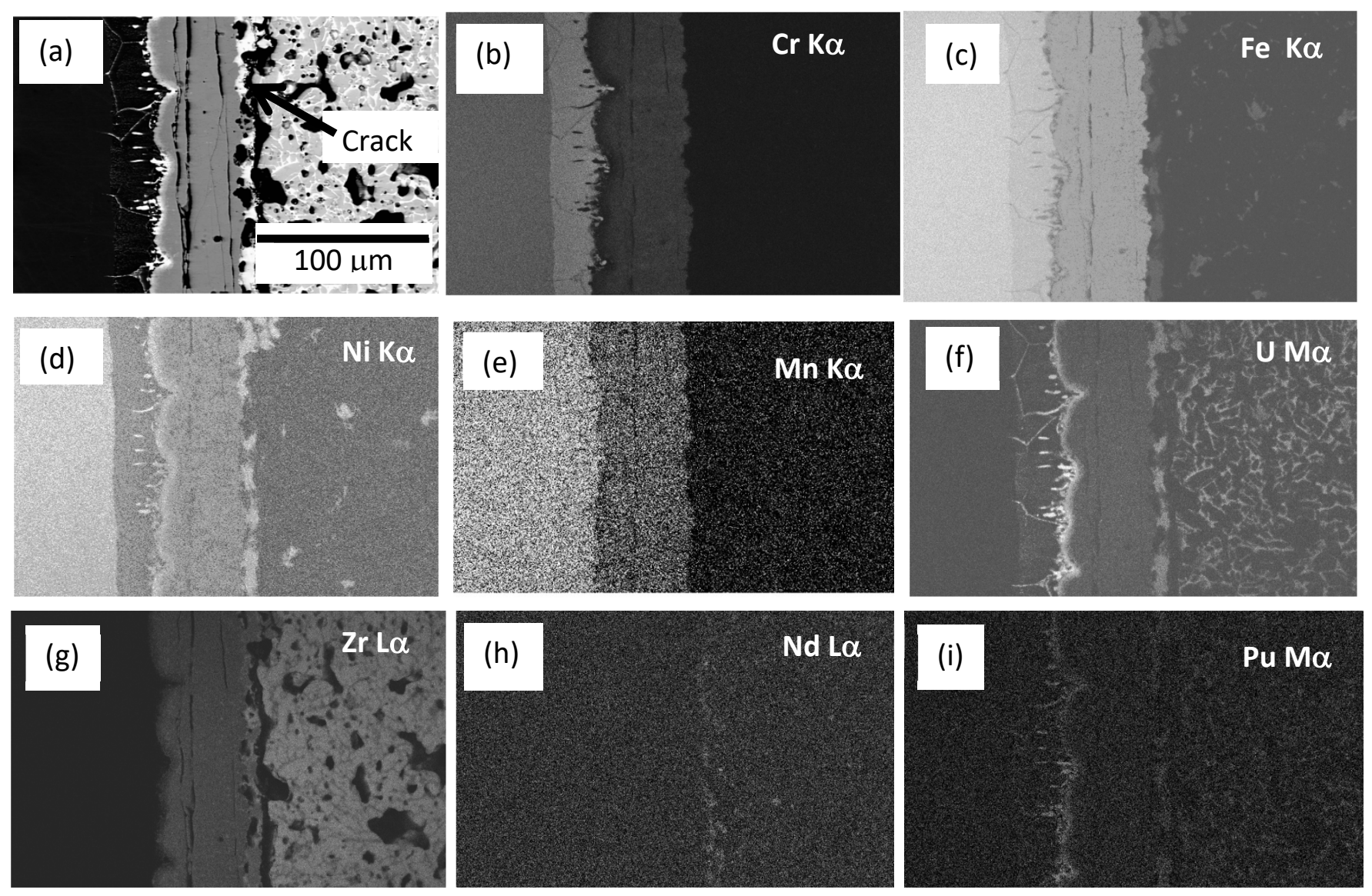

Figure 52. BSE image of interdiffusion zone (a) and WDS x-ray maps (b-i) for Cr, Fe, Ni, Mn, U, Zr, Nd, and $\mathrm{Pu}$, respectively. 

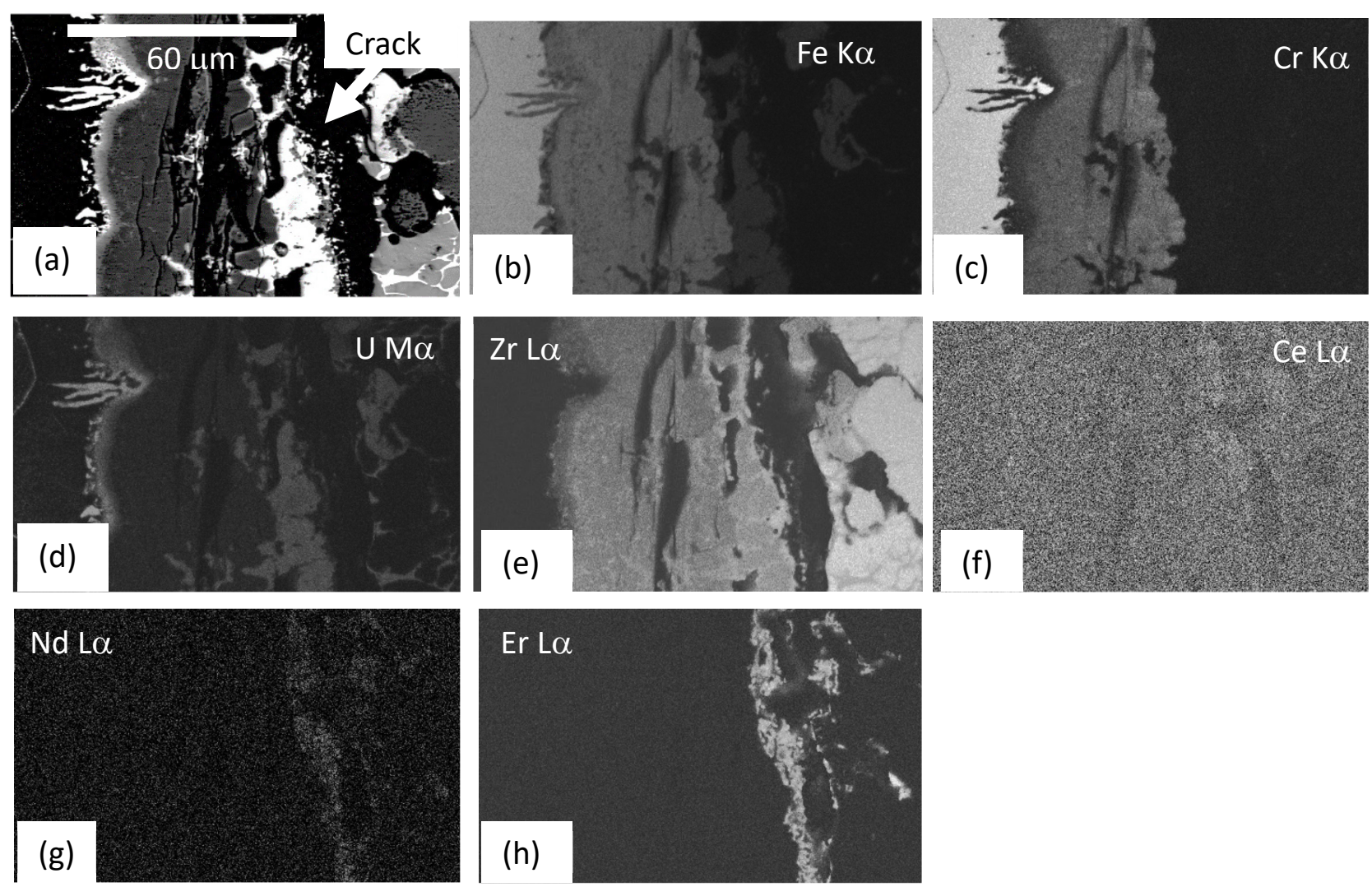

Figure 53. BSE image of interdiffusion zone (a) and WDS x-ray maps (b-h) for Fe, Cr, U, Zr, Ce, Nd, and Er, respectively.

To investigate the behavior of Er, a WDS x-ray map was generated (see Figure 54) in the interdiffusion zone, and the composition of an Er-rich phase was measured using EDS. Fe-bearing precipitates were observed moving towards the fuel. 

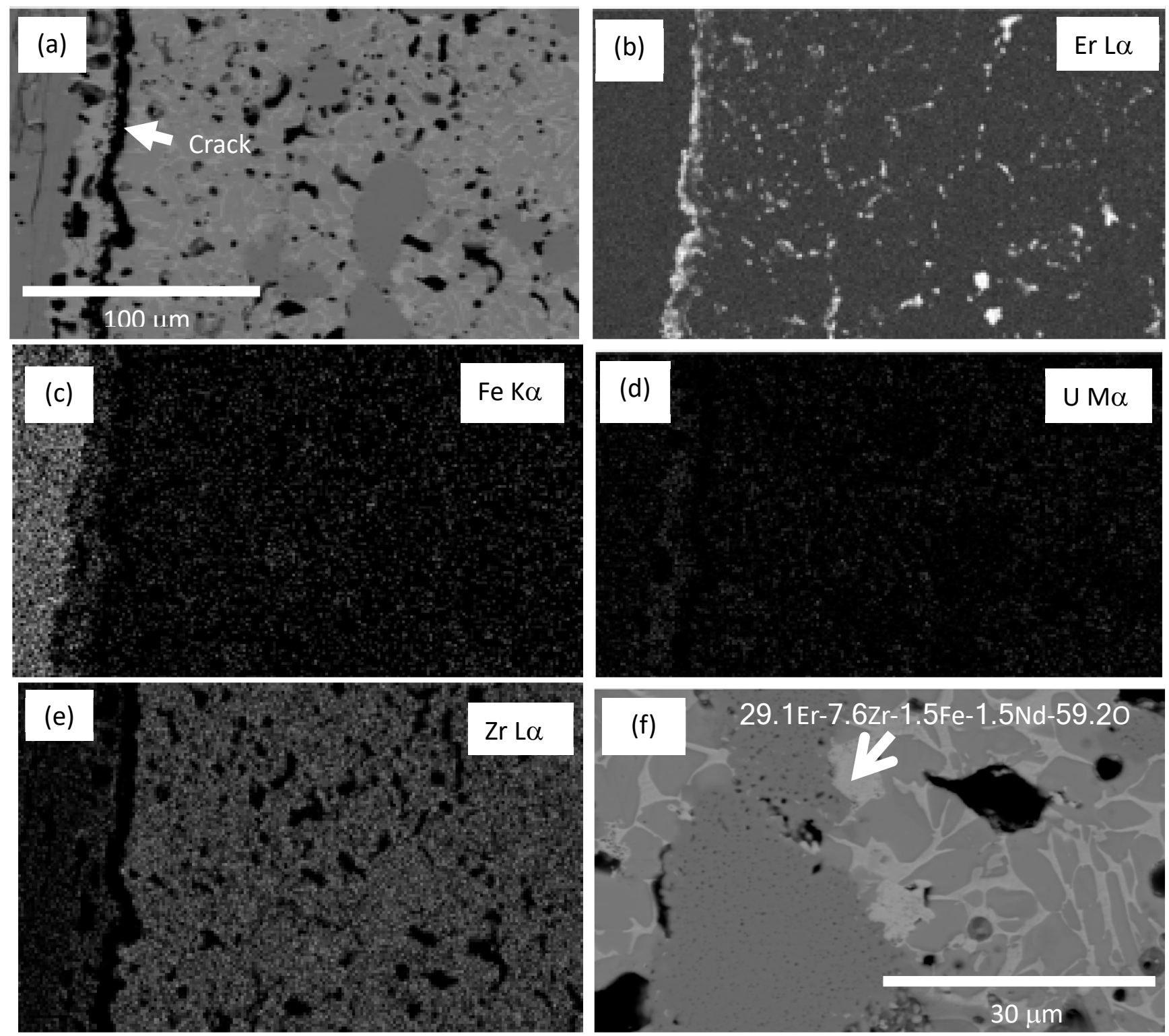

Figure 54. BSE image of interdiffusion zone (a) and WDS x-ray maps for (b) Er, (c) Fe, (d) U, and (e) Zr. The BSE micrograph in (f) shows the location where the composition of an erbium-containing phase was determined using EDS analysis, with the caveat that oxygen is difficult to measure with EDS at a high accuracy. Hydrogen cannot be measured using SEM and EDS and is not included as a possible constituent.

Figure 55 shows the results for line scans for $\mathrm{Cr}, \mathrm{Fe}, \mathrm{Ni}$, and $\mathrm{U}$ that were taken across the fuel and cladding interface. These results suggest that $\mathrm{Fe}$ and $\mathrm{Ni}$ precipitates are present towards the fuel side of the interaction zone. An Fe x-ray map (see Figure 56) was generated to investigate these precipitates, and it suggested that relatively small precipitates were present. 

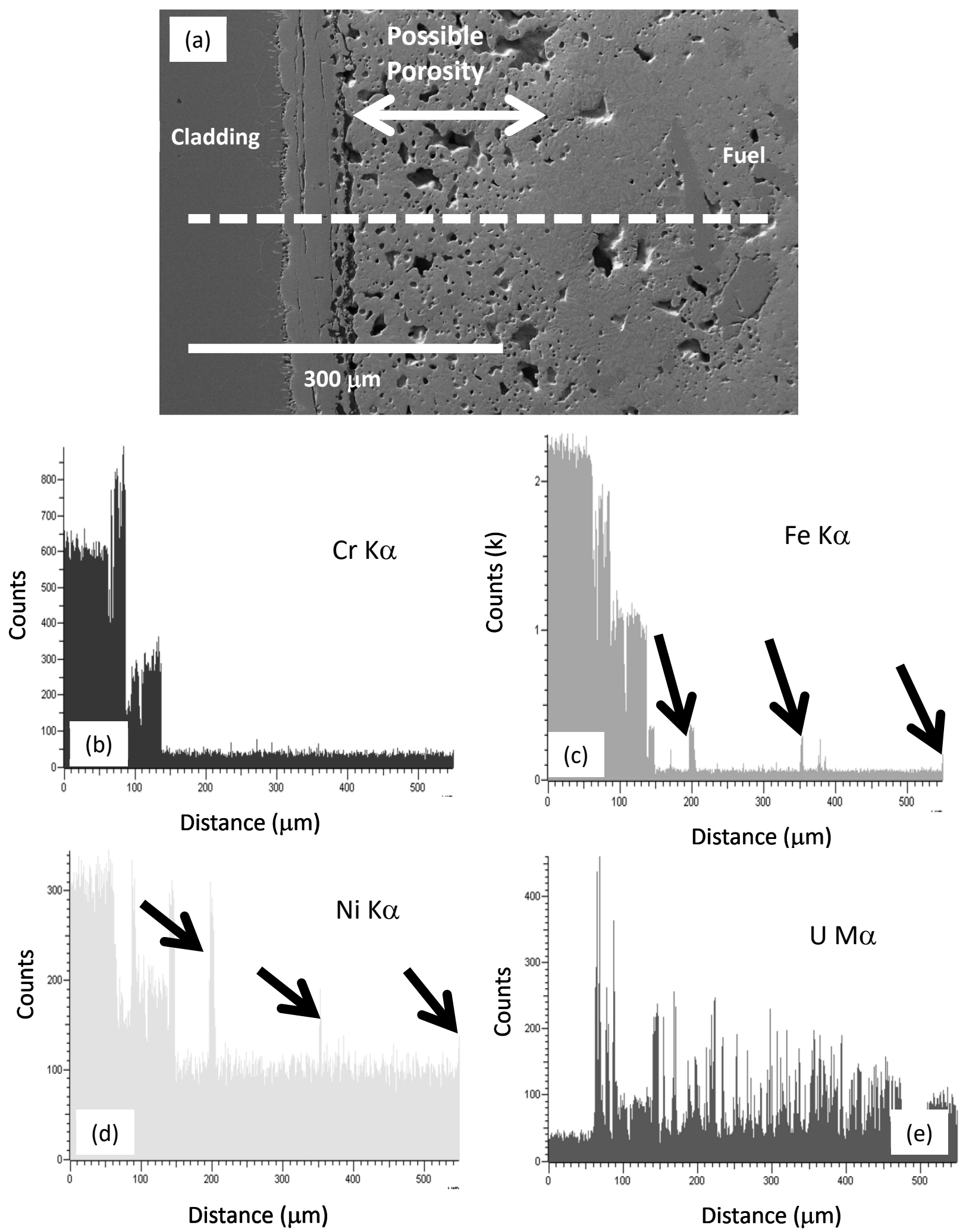

Figure 55. BSE image (a) showing where a WDS line scan was performed at the fuel and cladding interface for Sample 02A, and the results for $\mathrm{Cr}, \mathrm{Fe}, \mathrm{Ni}$, and $\mathrm{U}$ are shown in (b), (c), (d), and (e), respectively. The $\mathrm{y}$-axis is in counts. 

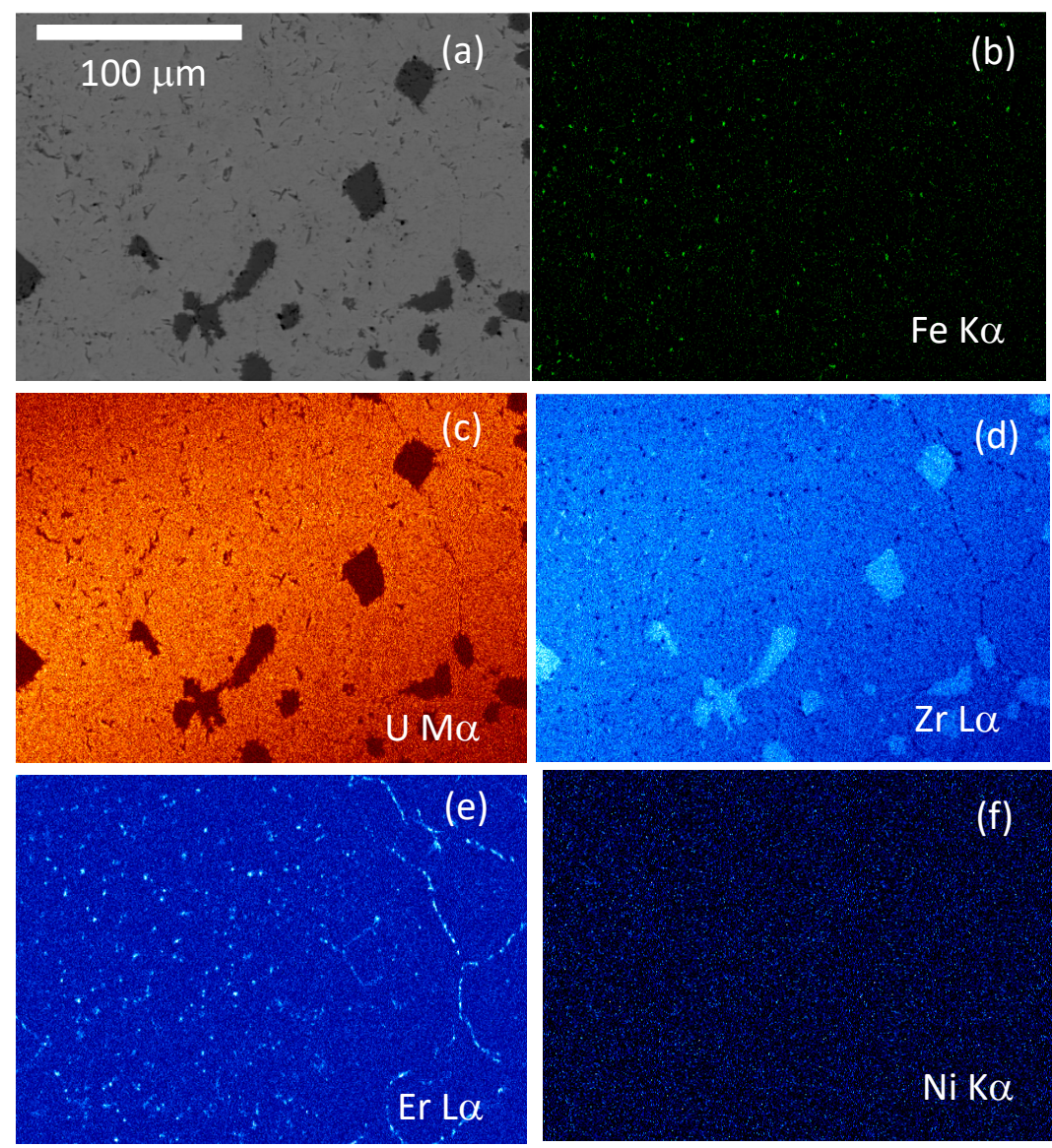

Figure 56. BSE image (a) and WDS x-ray maps for (b) Fe, (c) U, (d) Zr, (e) Er, and (f) Ni.

Point-to-point EDS measurements were performed along the line shown in Figure 57 to further investigate the precipitate phases that were observed in the interdiffusion zone. The results suggest that the Fe-containing precipitates also contained Ni. Figure 58 shows WDS x-ray maps of a region of the interdiffusion zone moving towards the fuel, and Fe-rich precipitates were observed in this region. 


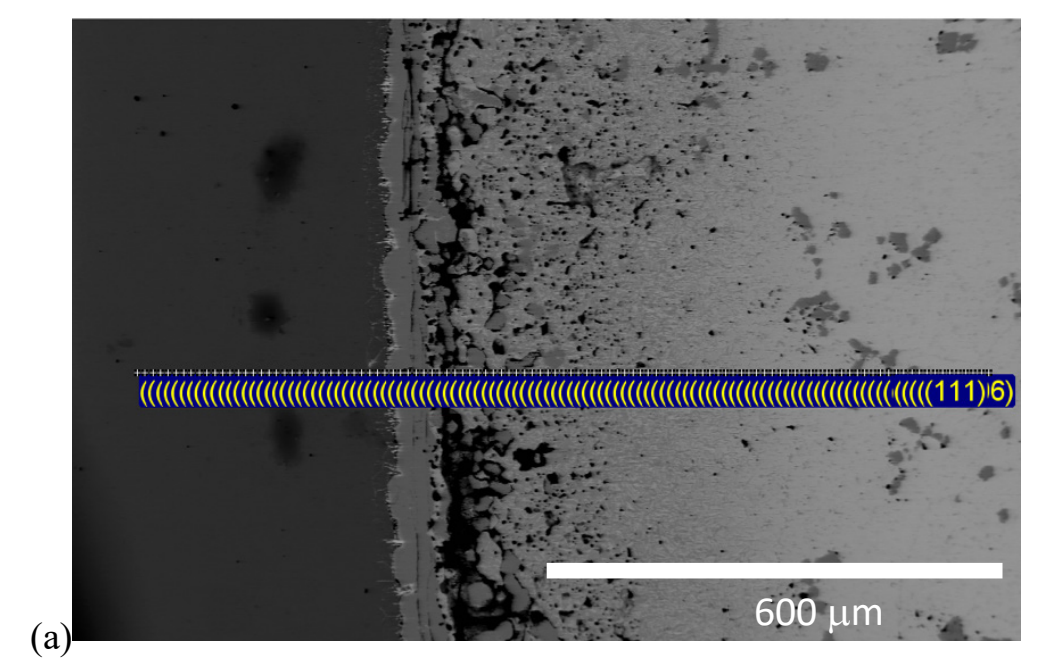

(b)

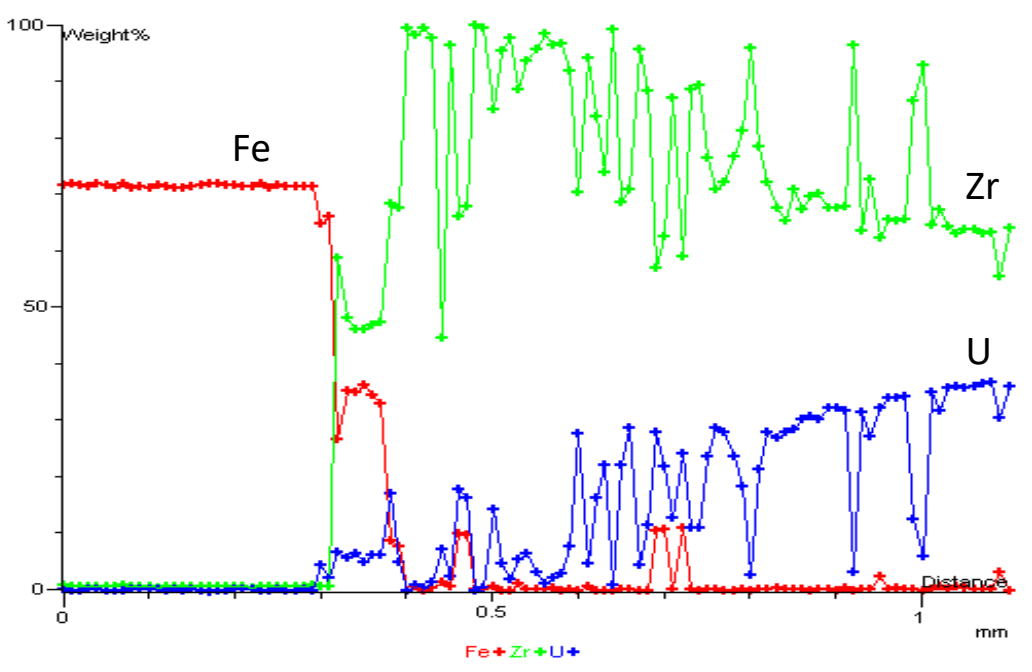

(c)

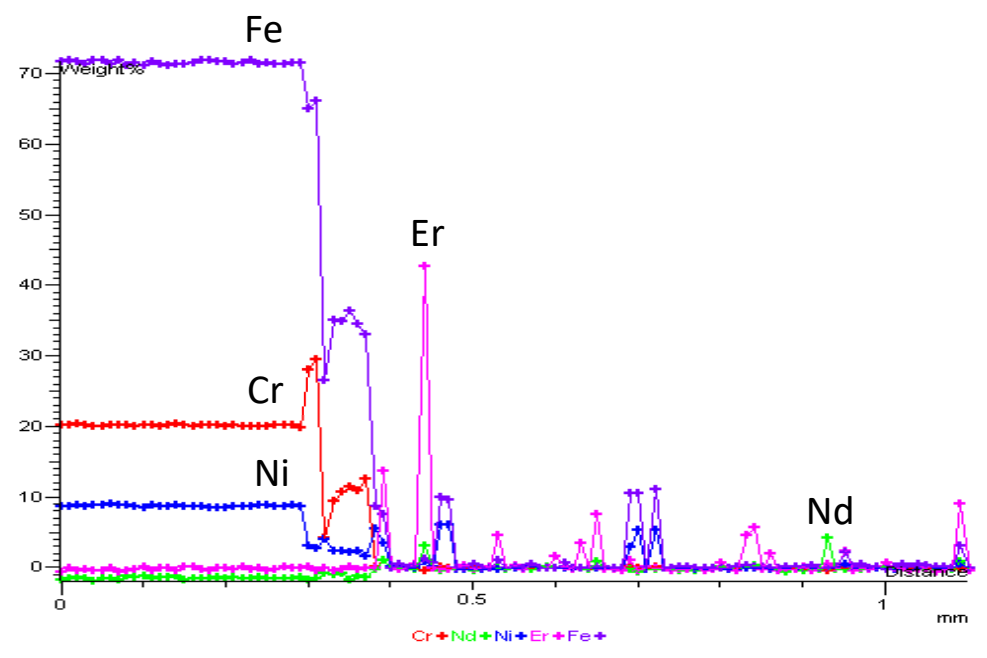

Figure 57. (a) BSE image showing a line of EDS composition measurements (in wt.\%) taken through the interdiffusion zone; (b) a plot of the results for $\mathrm{Fe}, \mathrm{Zr}$, and $\mathrm{U}$; and (c) a plot of the results for $\mathrm{Cr}, \mathrm{Nd}, \mathrm{Ni}$, $\mathrm{Er}$, and $\mathrm{Fe}$. 

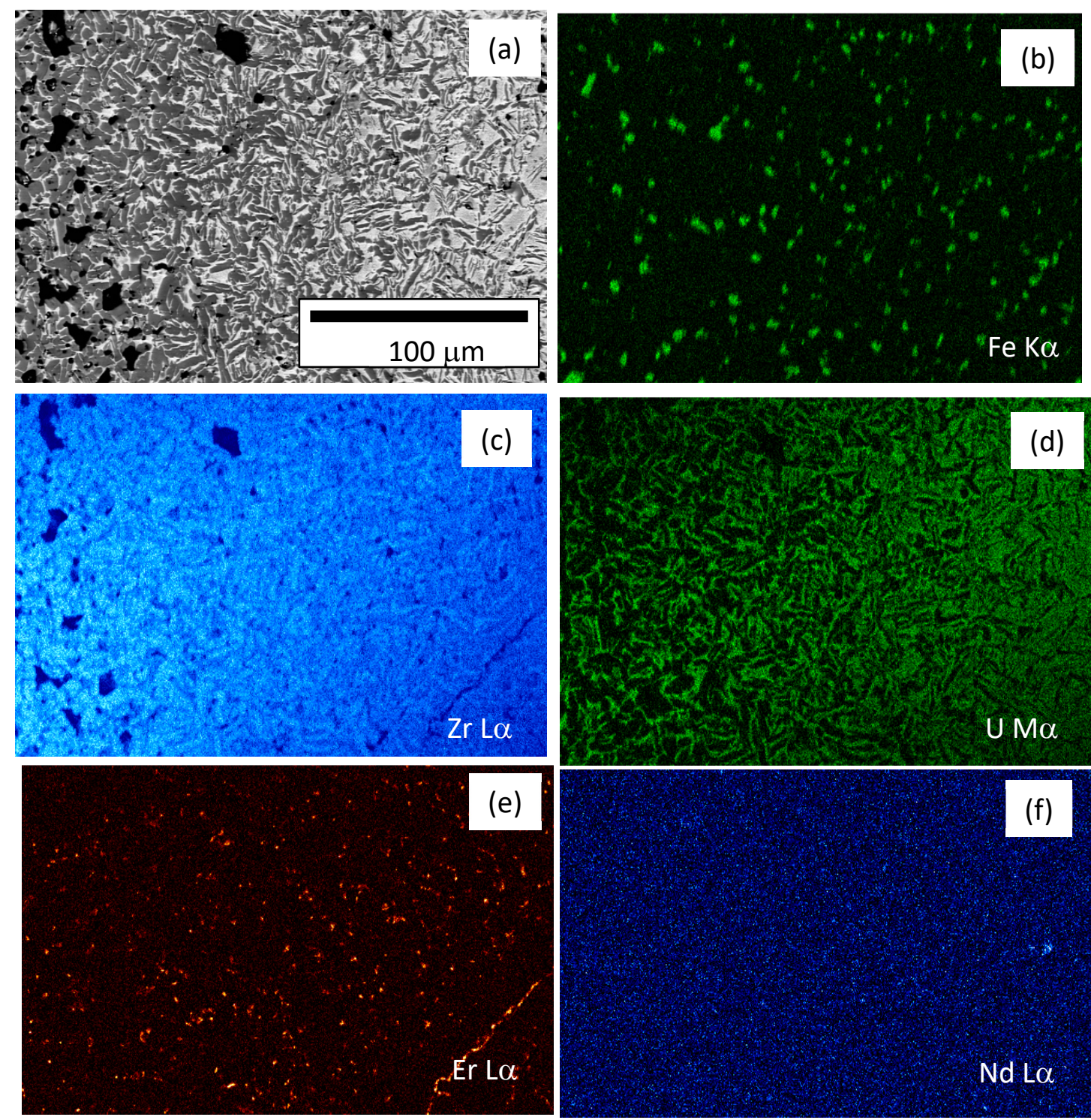

(e)
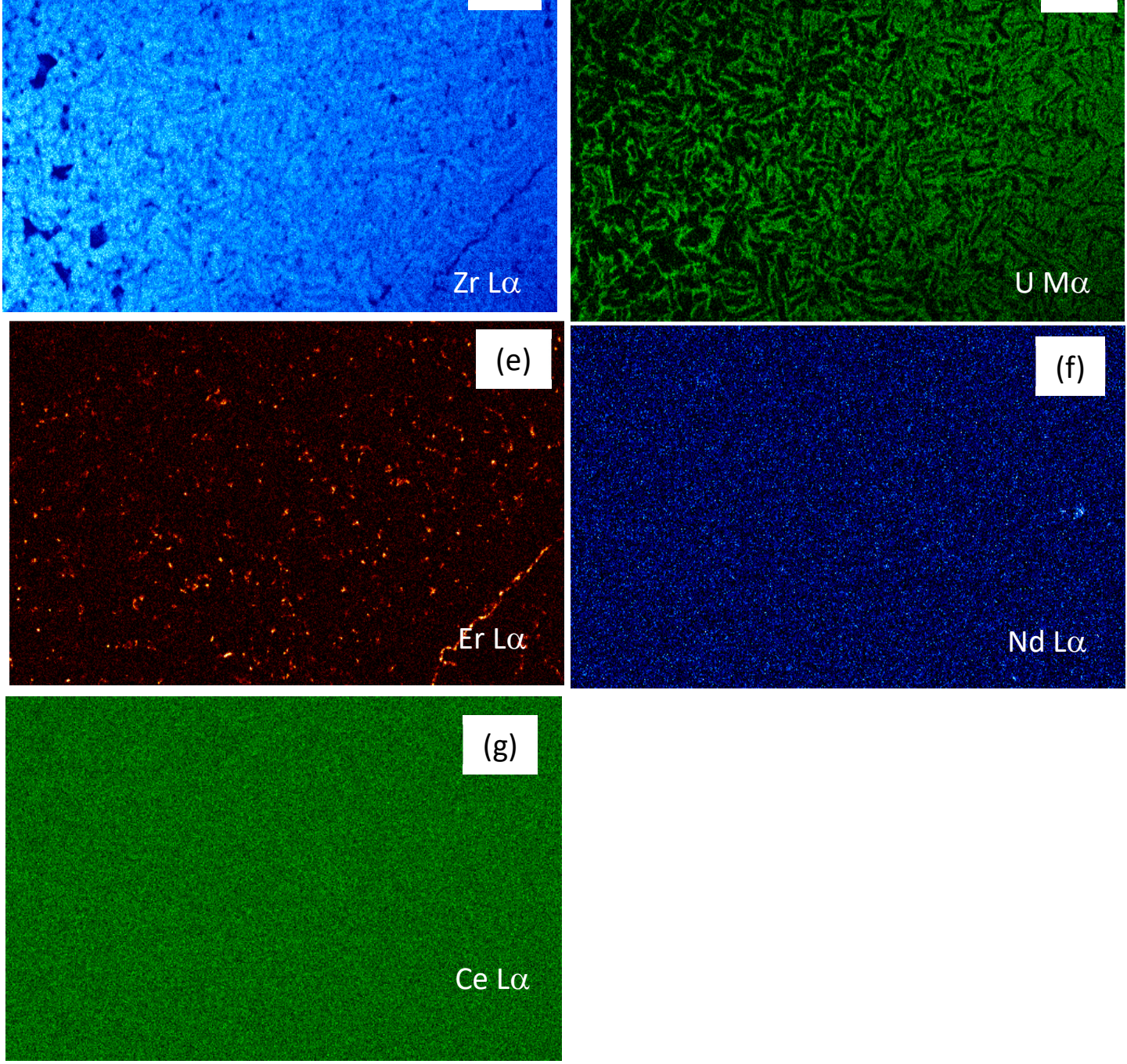

g)

Figure 58. BSE image (a) and WDS x-ray maps for (b) Fe, (c) Zr, (d) U, (e) Er, (f) Nd, and (g) Ce. 
Fine phases were observed on the cladding side of the fuel and cladding interaction zone (see Figure 59 and Figure 60). In Figure 60(b), specific locations where EDS composition measurements of specific phases were taken are shown. The results of these measurements are listed in Table 5. A mixture of phases can be seen near the cladding. Of the phases measured by EDS, most are rich in Zr. The one phase with relatively low $\mathrm{Zr}$ had around 29 at.\% U. Base on composition, $\mathrm{Fe}_{2} \mathrm{Zr}, \mathrm{FeZr}_{2}$, and $\mathrm{UFe}_{2}$-type phase may be present in these phase regions. Figure 61 shows a $100 \times$ magnification OM image the cladding for this sample, where grain boundary phases could be identified.

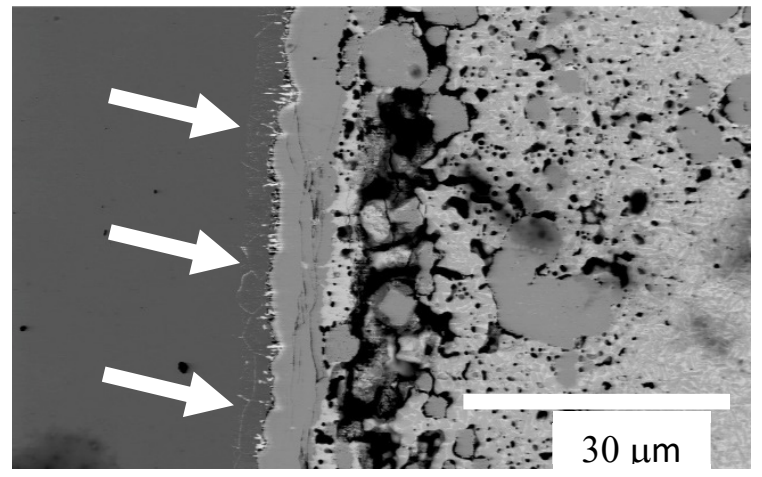

(a)

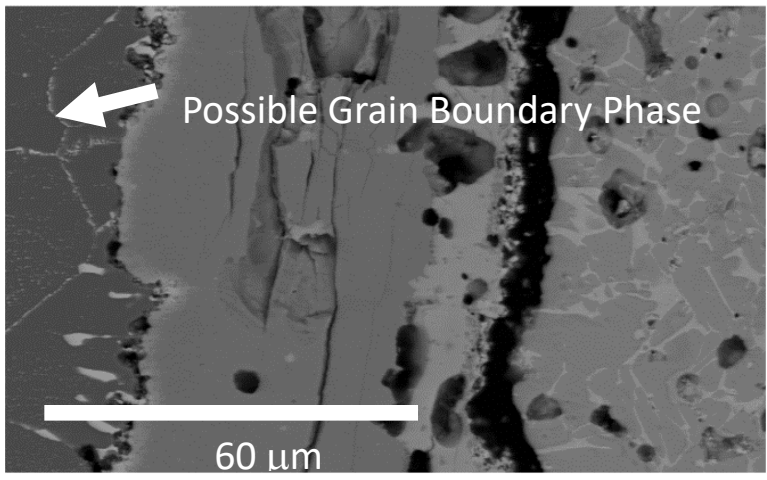

(b)

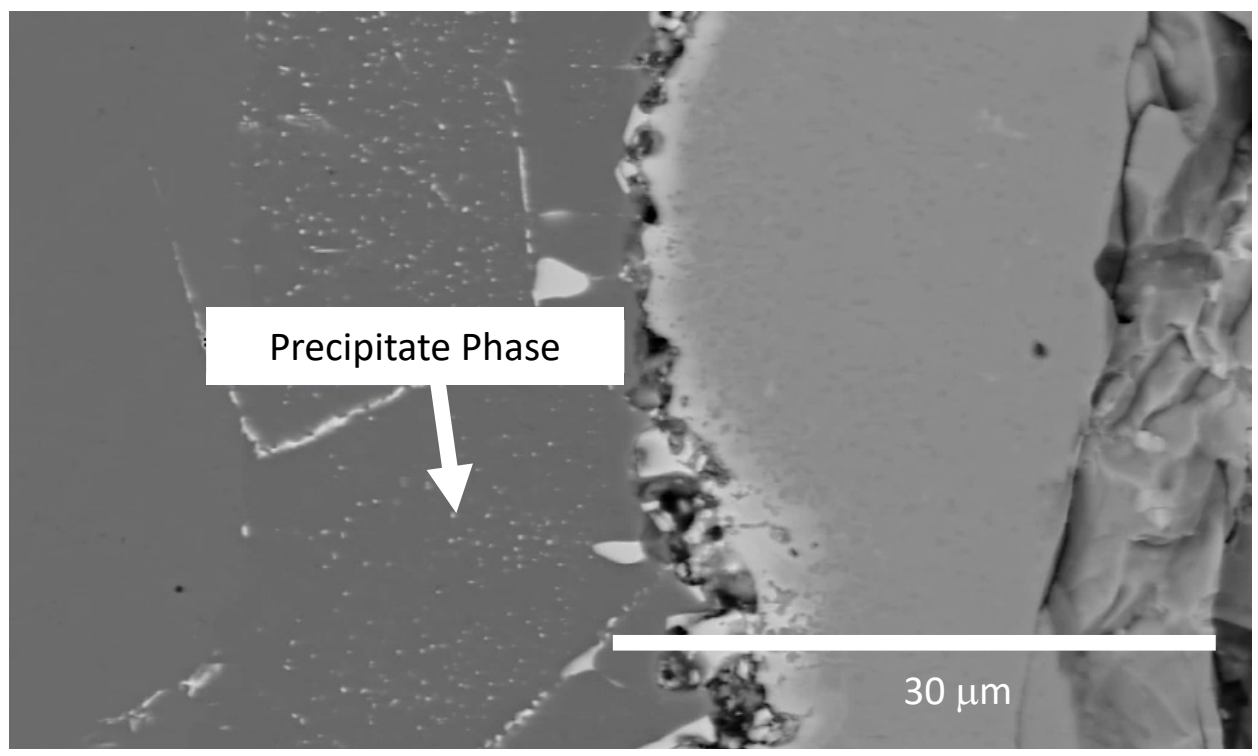

(c)

Figure 59. BSE images $(\mathrm{a}-\mathrm{c})$ showing fine phases present in the interdiffusion zone nearest the unreacted cladding. 

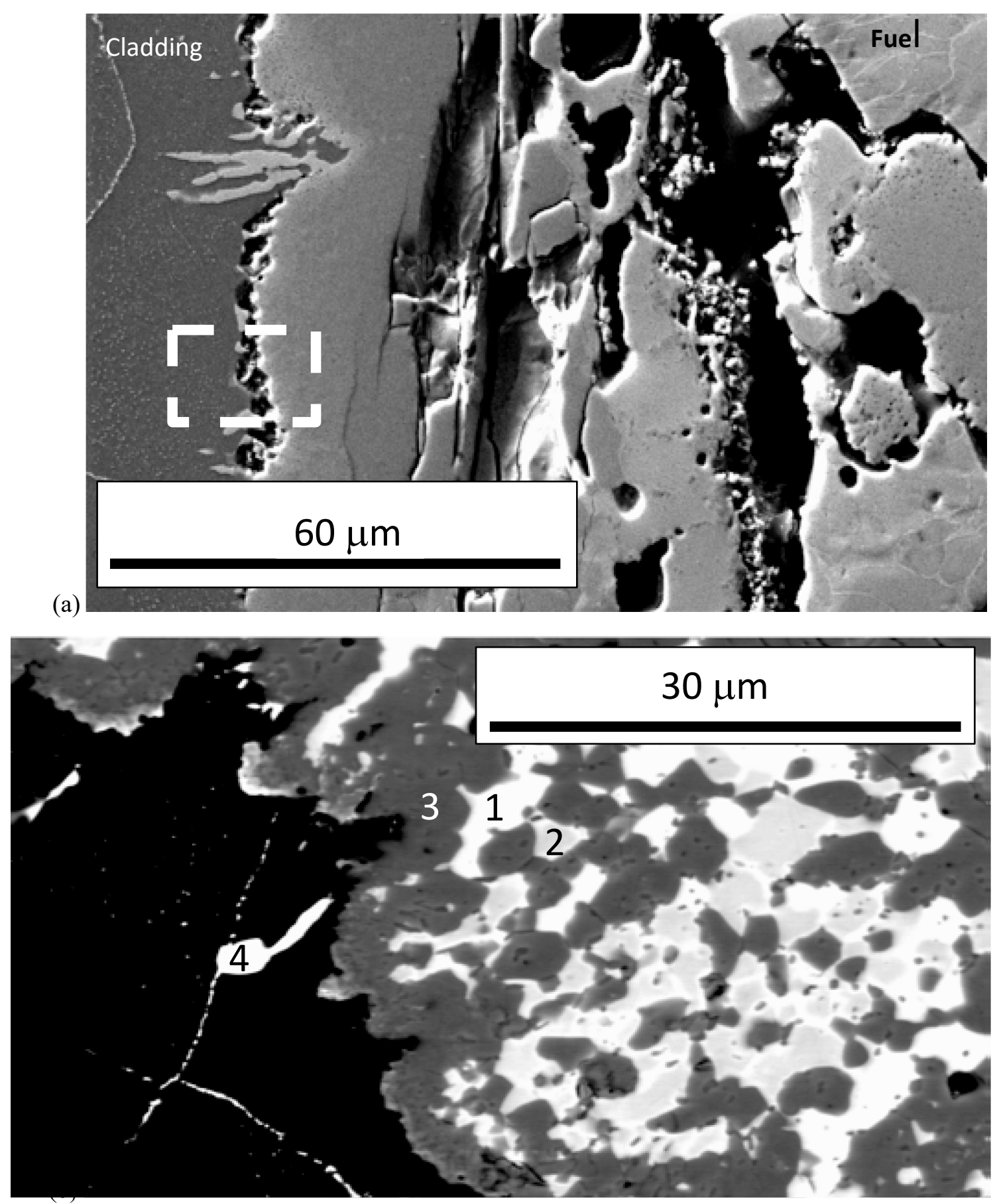

Figure 60. BSE image (a) at location of interdiffusion zone nearest the unreacted cladding. The BSE image in (b) shows the area in the box depicted in (a). The brightness and contrast of the image in (b) was adjusted to highlight the different phases present. Points 1-4 in (b) show where the composition of particular phases were measured, and the results are in Table 5. 
Table 5. Phase compositions, in at.\%, at Locations 1-4 depicted in Figure 60(b).

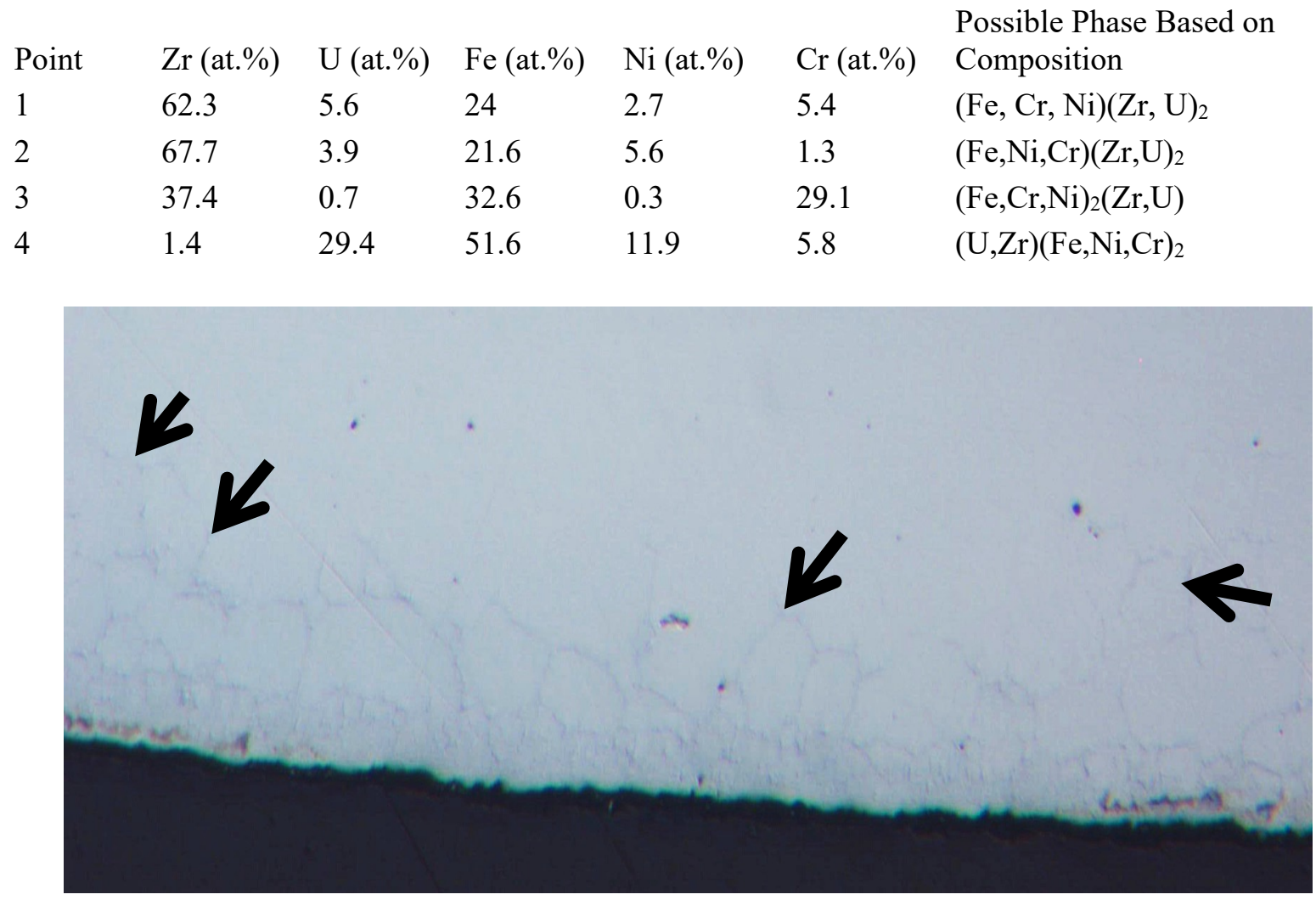

Figure 61. OM image (100x magnification) showing the location of possible grain boundary phase(s) present on the unreacted cladding side of the interdiffusion zone for the specimen annealed at $950^{\circ} \mathrm{C}$ for $6 \mathrm{hr}$.

To further investigate porosity in the fuel and cladding interaction zone, more imaging was performed using the SEM (see Figure 62). In addition, the compositions of selected phases were measured in the vicinity of observed pores. $\mathrm{Zr}$ and Er-rich phases were observed to be present, and the highest concentration of $\mathrm{Fe}$ observed in a phase was around 17 at.\%. Levels for oxygen concentration are given, and these values are of limited accuracy since EDS is not the best tool for measuring $\mathrm{C}, \mathrm{O}, \mathrm{N}$, or $\mathrm{H}$. 


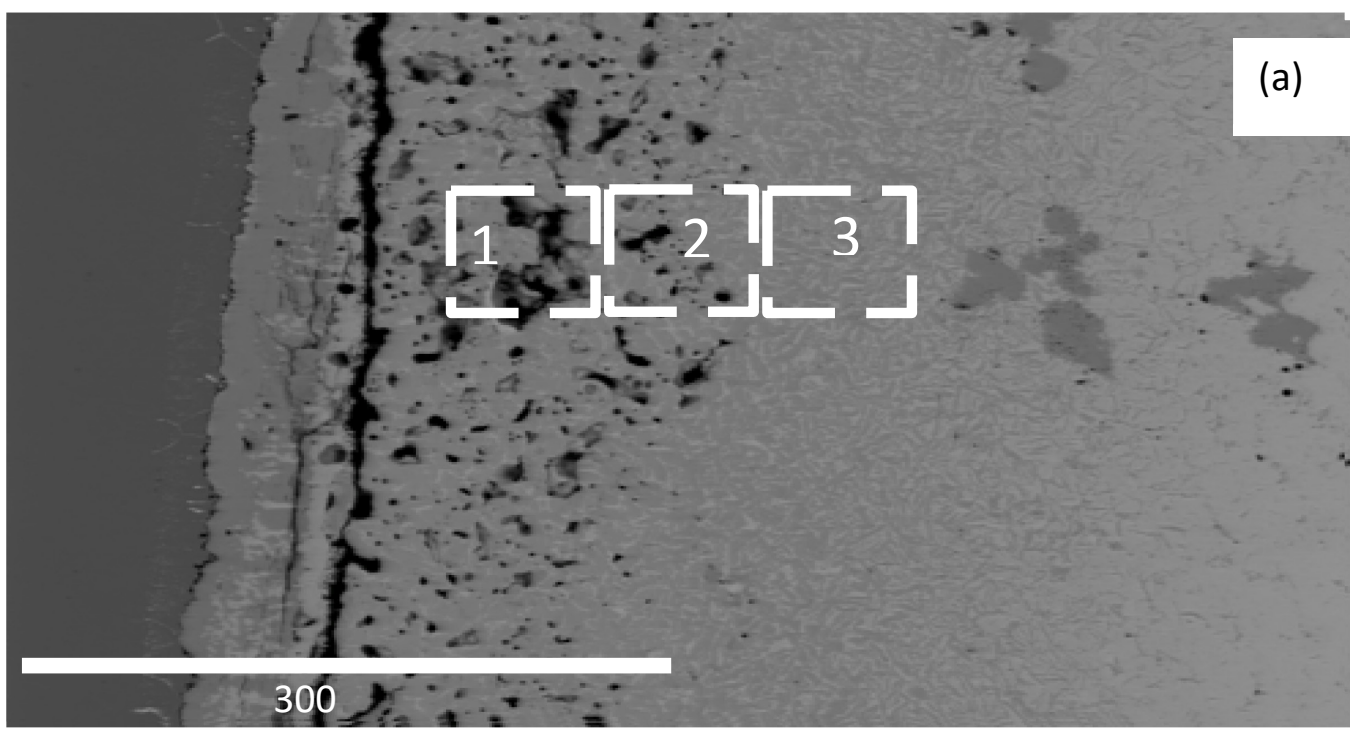

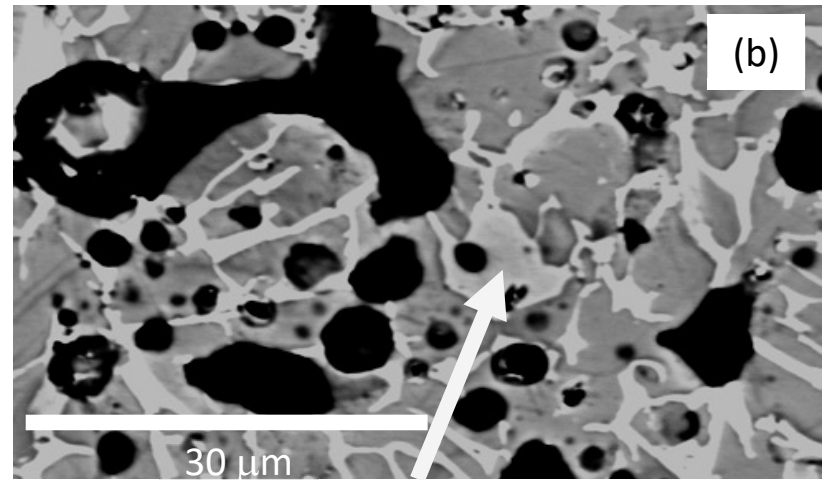

64.5Zr-4.6U-16.8Fe-12.5Ni-0.3Cr

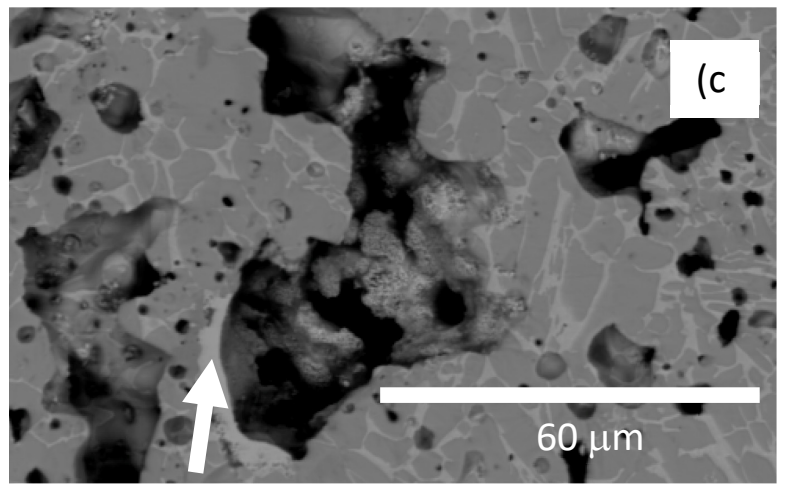

2.1U-7.2Zr-30Er-610
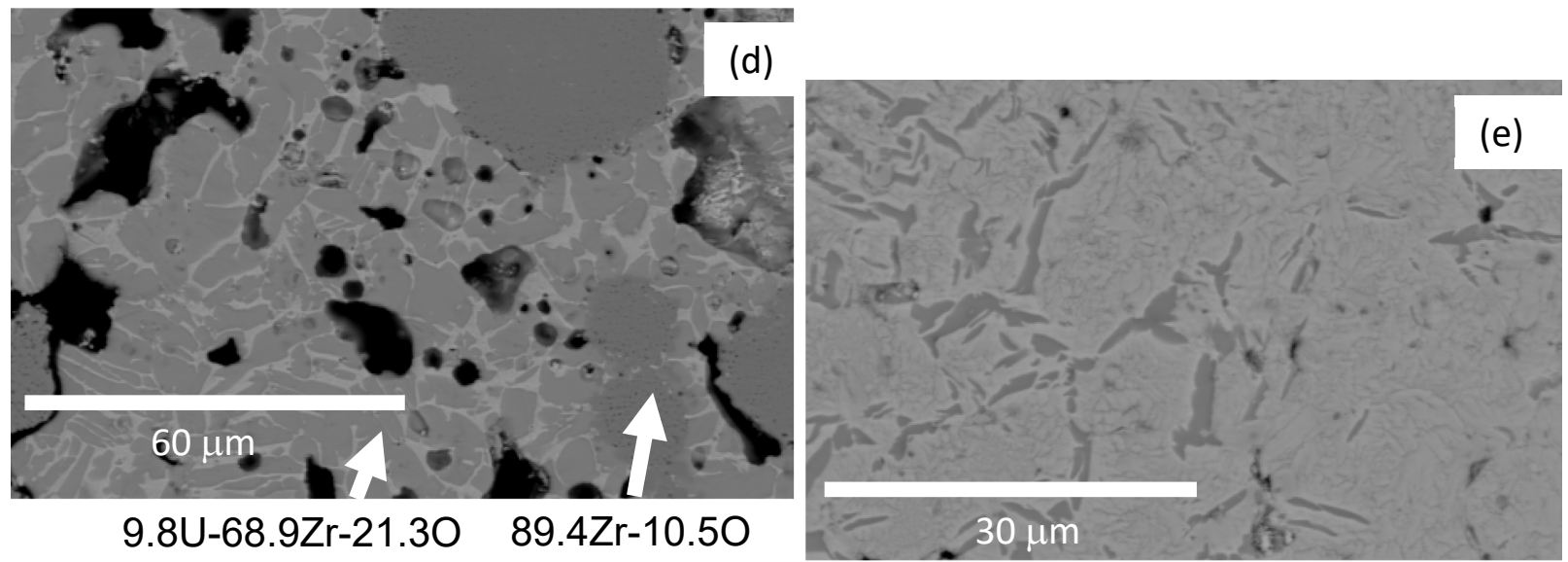

Figure 62. BSE image (a) showing microstructure of fuel and cladding interaction zone. BSE images in (b) and (c) show representative images of the microstructure observed in Box 1 of image (a), and (d) and (e) show representative images for Box 2 and Box 3, respectively. In (b-c) some phase compositions (in at.\%) are shown, with the caveat that oxygen is difficult to measure with EDS at a high accuracy. Hydrogen cannot be measured using SEM/EDS and is not included as a possible constituent. 
The main conclusions from the furnace testing performed at $730,800,900,950$ and $1000^{\circ} \mathrm{C}$ for $6 \mathrm{hr}$, with one additional test performed at $950^{\circ} \mathrm{C}$ for $12 \mathrm{hr}$, are as follows. As-irradiated TRIGA fuel exhibits a gap (around 50-75 $\mu \mathrm{m}$ wide) at the fuel and cladding interface. For irradiated TRIGA fuel annealed at $950^{\circ} \mathrm{C}$, the microstructure transforms to one that is comprised of a $\mathrm{Zr}$-rich, $\mathrm{Zr}-\mathrm{U}$ (over 80 at.\% $\mathrm{Zr}$ ) matrix phase(s) and Zr-rich phases with $\mathrm{C}$ or $\mathrm{H}$. For an irradiated TRIGA fuel specimen annealed at $730^{\circ} \mathrm{C}$, the original fuel and cladding gap is still present. A fuel and cladding interaction zone develops in an irradiated TRIGA fuel specimen annealed at $950^{\circ} \mathrm{C}$, and it is comprised of complex multicomponent phases comprised of different cladding, fuel, and fission-product constituents. OM images of the heattreated specimens can be used to show that the unreacted remaining thickness of the cladding for specimens heated at 950 and $1000^{\circ} \mathrm{C}$ for $6 \mathrm{hr}$ is no lower than $75 \%$ of the original thickness. For an irradiated TRIGA fuel specimen annealed at $950^{\circ} \mathrm{C}$, porosity has been observed near isolated phases at the fuel side of the interaction zone that contain $\mathrm{Zr}$ and $\mathrm{C}$ and $\mathrm{H}$ that could be the result of localized melting. Based on the evaluation of low-magnification OM images, no gross melting is observed for an irradiated TRIGA fuel specimen annealed up to a temperature of $1000^{\circ} \mathrm{C}$. No Fe-containing phases with high levels of lanthanide fission products, which could be low melting based on binary phase diagrams, are observed near the unreacted cladding. A U-rich, grain boundary phase is present nearest the unreacted cladding for an irradiated TRIGA specimen annealed at $950^{\circ} \mathrm{C}$ for $6 \mathrm{hr}$.

\section{DISCUSSION}

\subsection{Evidence of Liquefaction}

FCCI was not observed for the irradiated TRIGA fuel specimen annealed at $730^{\circ} \mathrm{C}$, and there was no evidence that any chemical interaction occurred between the fuel and cladding. However, FCCI was observed for the specimen annealed at $950^{\circ} \mathrm{C}$ for $6 \mathrm{hr}$, and porosity was observed on the fuel side of the interdiffusion zone for the specimen. Possible explanations for the development of this porosity include fission gas release from phases in the fuel during the interdiffusion that occurred at $950^{\circ} \mathrm{C}$ and the subsequent formation of pores, development of low-density phases at $950^{\circ} \mathrm{C}$ that contain pores, the localized melting of precipitate phase(s) with specific compositions, and pullout of brittle phases during specimen polishing. Since the focus of the current investigation is to investigate liquefaction in irradiated TRIGA fuel when it is exposed to relatively high temperatures, it is of interest to focus on the possible melting of specific precipitate phases for explaining the observed porosity for the specimen heat treated at $950^{\circ} \mathrm{C}$.

\subsubsection{Comparison to Out-of-Pile Diffusion Studies Using Unirradiated TRIGA Fuel and Type 304 SS}

To help investigate whether there is evidence that precipitate phases melted during heat treating, it is useful to compare the results of the irradiated TRIGA fuel heat-treating studies with those from hightemperature out-of-pile diffusion studies that employed as-fabricated TRIGA fuel sections and Type 304SS pieces. Results of out-of-pile diffusion couple experiments using TRIGA fuel and Type 304SS have been reported in [2, 5]. Schematic diagrams of diffusion couple jigs employed for these experiments are shown in Figure 63. 


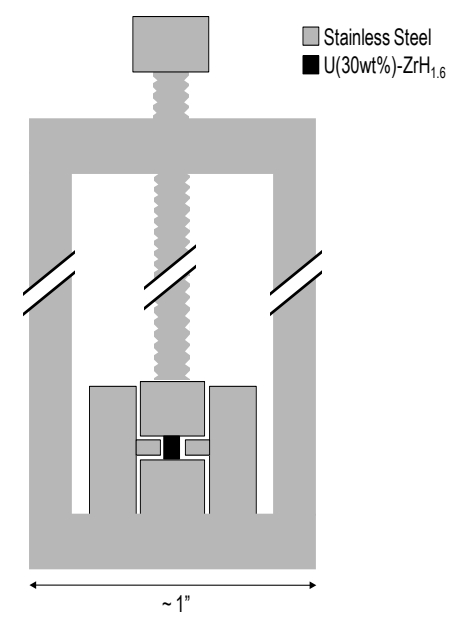

(a)

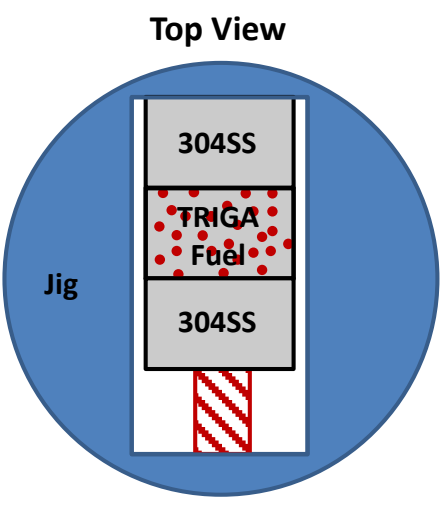

Side View

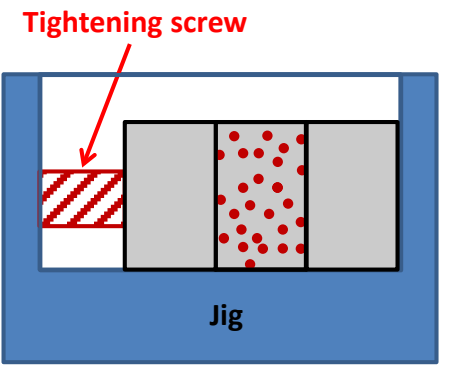

(b)

Figure 63. (a) is a schematic diagram of a diffusion couple jig employed for the diffusion couple experiments described in [5] and (b) shows a standard jig used for experiments performed by [2].

In [5], results for diffusion couples annealed under vacuum for $1 \mathrm{hr}$ at $730^{\circ} \mathrm{C}$ and $800^{\circ} \mathrm{C}$ are reported. Negligible interdiffusion between the fuel and cladding was observed (see Figure 64). However, the microstructure of the TRIGA fuel was observed to change going to a higher temperature. Instead of a microstructure comprised of U-rich precipitates distributed in a $\mathrm{Zr}-\mathrm{H}$ matrix, like what is observed for as-fabricated TRIGA fuel and for TRIGA fuel after heat treating at $730^{\circ} \mathrm{C}$, the TRIGA fuel after heat treating at $800^{\circ} \mathrm{C}$ is comprised of a $(\mathrm{Zr}, \mathrm{U})$ solid solution phase and islands of a $\mathrm{Zr}$-rich phase, assumed to be Zr-H but SEM/EDS cannot measure H. Overall, more of the U-containing phase (that also contained appreciable $\mathrm{Zr}$ ) was observed compared to what was seen in the $730^{\circ} \mathrm{C}$ couple. This could be because once TRIGA fuel is exposed to temperatures above $760^{\circ} \mathrm{C}$, there is a tendency for the material to experience some hydrogen dissociation [6]. This is impacted by the environment of the specimen being heated (vacuum versus having an inert cover gas). Also, the dehydriding is dramatically influenced by presence of surface oxide or nitride films, which are negligible for well-polished specimens. The hydrogen release rate depends on the specific diffusion rate of the oxide and the internal hydrogen pressure (the equilibrium dissociation pressure), both of which increase with specimen temperature as well as oxide thickness and morphology. The result of this dehydridation process could be release of hydrogen and reaction of $\mathrm{U}$ and $\mathrm{Zr}$ in the system to form the $\mathrm{Zr}-\mathrm{U}$ phase after some of the zirconium hydride had dissociated during heat treatment. However, even in the case in which more Zr-U phase was in contact with the cladding, no evidence of fuel interaction with the cladding could be observed. 

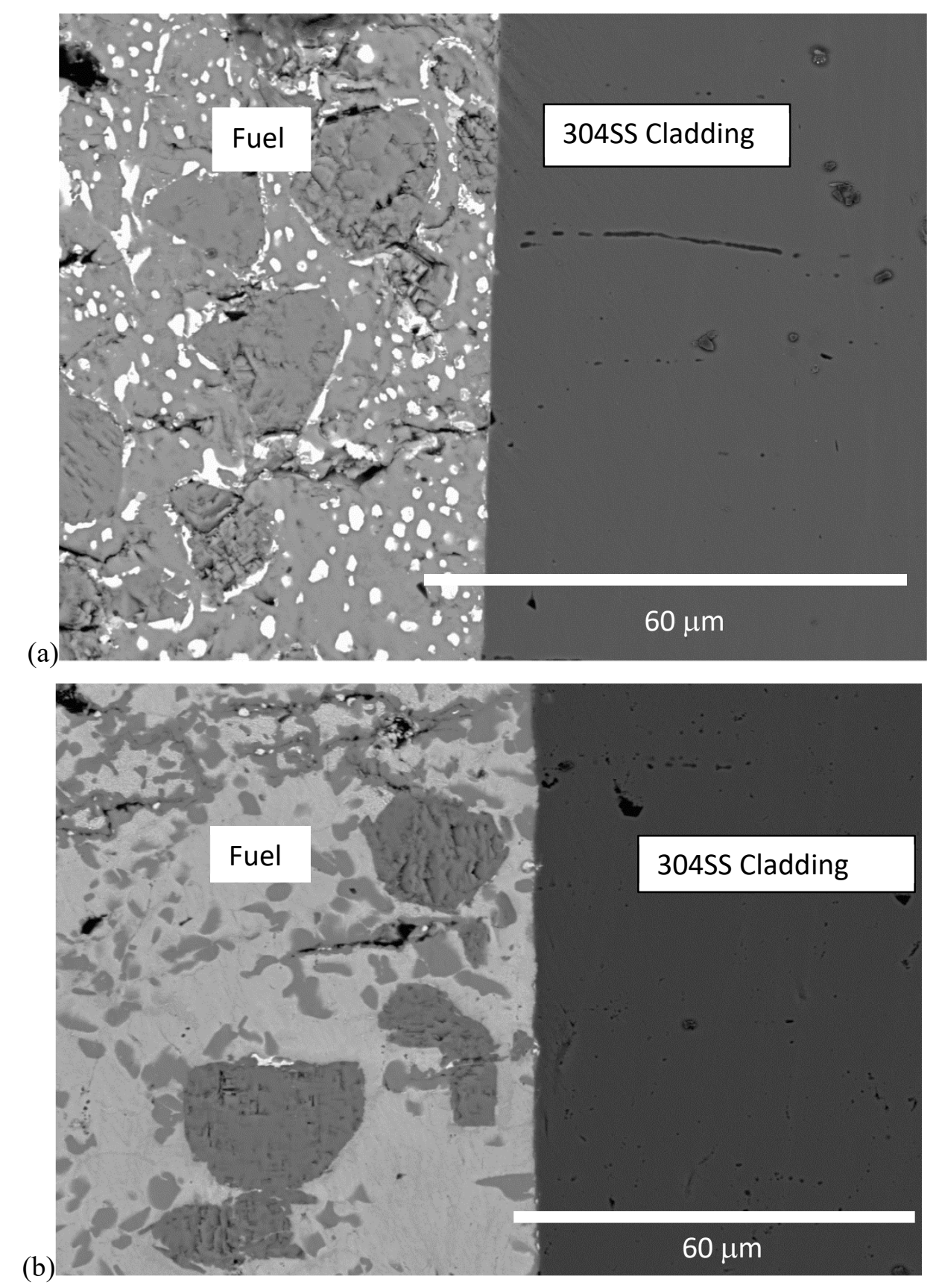

Figure 64. Fuel and cladding interface for a diffusion couple annealed at (a) $730^{\circ} \mathrm{C}$ for $1 \mathrm{hr}$ and (b) $800^{\circ} \mathrm{C}$ for $1 \mathrm{hr}[5]$.

In [2], results are reported for the characterization of TRIGA fuel annealed under a high-purity Ar cover gas at $950^{\circ} \mathrm{C}$ for 5,16 , and $24 \mathrm{hr}$. The temperature profiles for these heat treatments are shown in Figure 65. These results are of particular interest since the irradiated TRIGA fuel specimen annealed at $950^{\circ} \mathrm{C}$ for $6 \mathrm{hr}$ was the one characterized using SEM, and these results can be compared to those for the out-of-pile diffusion couple experiments run at $950^{\circ} \mathrm{C}$. These specimens came from diffusion couple experiments where debonding was observed between the fuel and cladding during the experiments. 

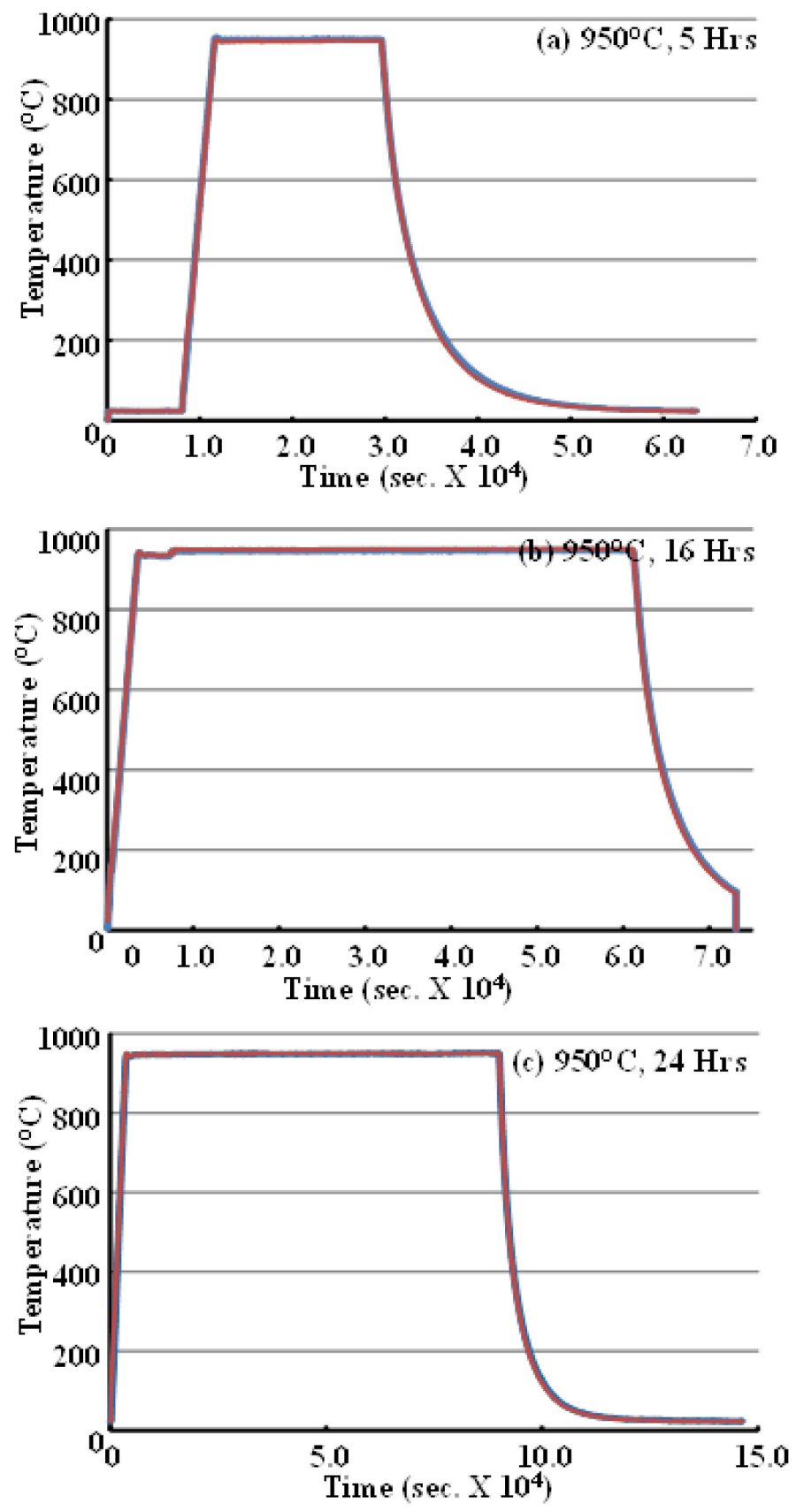

Figure 65 . Temperature profiles generated from the TRIGA fuel heat-treating process at $950^{\circ} \mathrm{C}$ for (a) 5 , (b) 16, and (c) $24 \mathrm{hr}$.

Figure 66 shows SEM images of the microstructure of TRIGA fuel after heat treating at $950^{\circ} \mathrm{C}$ for $5 \mathrm{hr}$, and Figure 67 shows X-ray maps for Zr, U, and Er for this sample. Table 6 shows the measured phase compositions in terms of U, Zr, and Er. Since EDS is ineffective in measuring light elements like $\mathrm{C}, \mathrm{O}, \mathrm{N}$, and $\mathrm{H}$, these constituents were not measured. The developed microstructures look similar to the one reported by [5] for a diffusion couple annealed at $800^{\circ} \mathrm{C}$. 

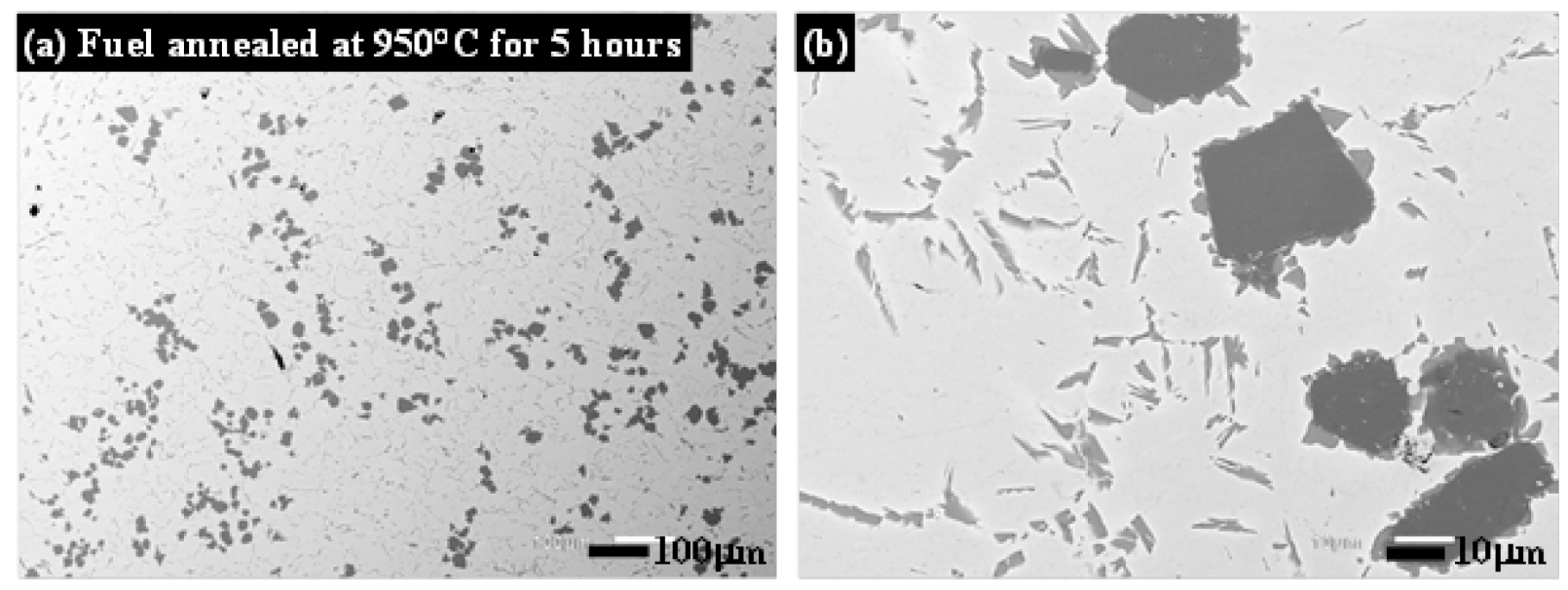

Figure 66. TRIGA fuel microstructure after heat treating at $950^{\circ} \mathrm{C}$ for $5 \mathrm{hr}$ : (a) low and (b) higher magnification BSE micrographs.
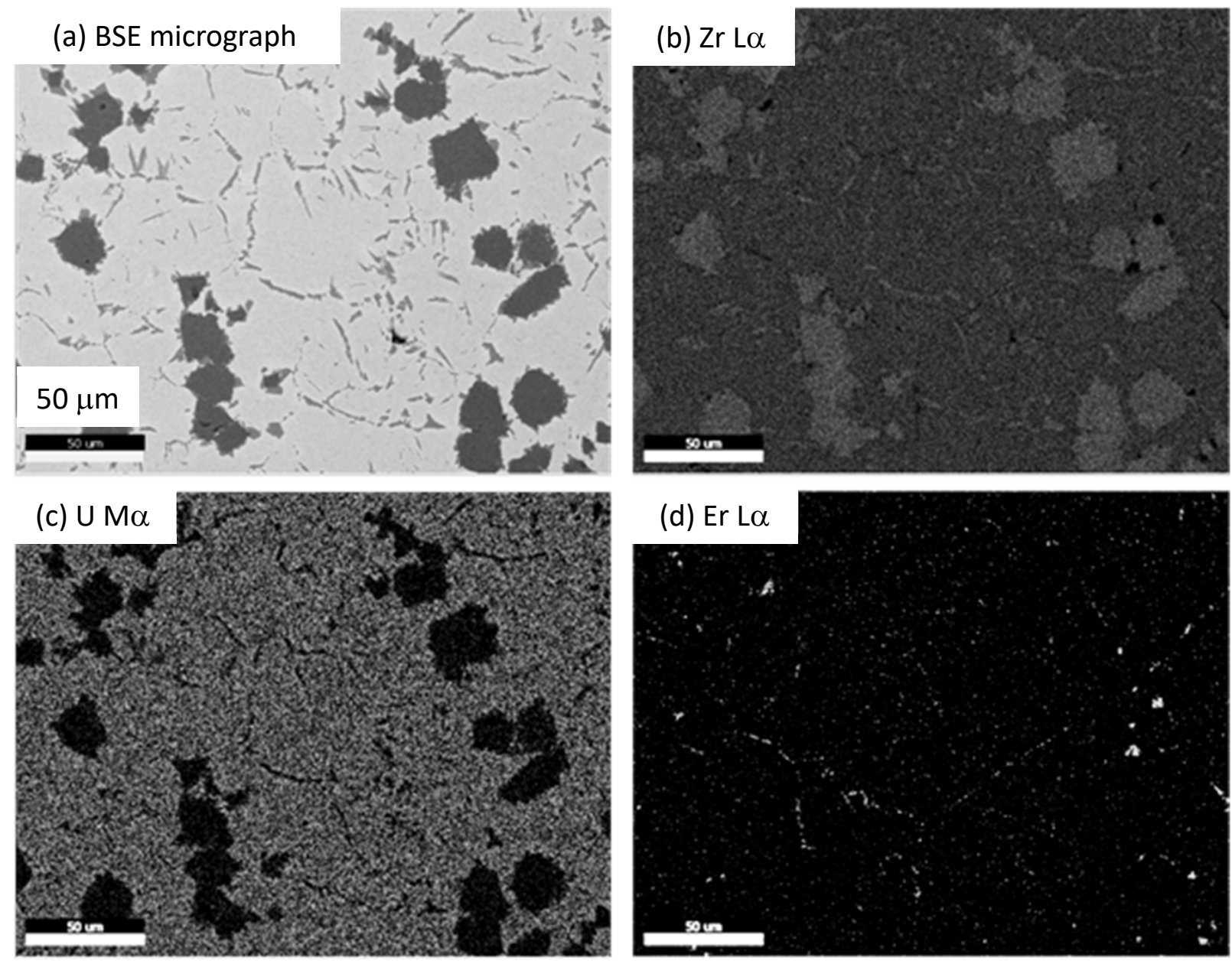

Figure 67. (a) BSE micrograph of a selected microstructural area of unirradiated TRIGA fuel annealed at $950^{\circ} \mathrm{C}$ for 5 hr. EDS x-ray maps are shown for (b) $\mathrm{Zr}$, (c) U, and (d) Er. 
Table 6. EDS measurements for the concentrations of Er, U, and $\mathrm{Zr}$ in various observed phases in the unirradiated TRIGA fuel specimen annealed at $950^{\circ} \mathrm{C}$ for $5 \mathrm{hr}$.

\begin{tabular}{|c|c|c|c|}
\hline \multirow{2}{*}{ Element } & Bright-Contrast Matrix & Mid-Gray Phase & Dark-Gray Phase \\
\cline { 2 - 4 } & \multicolumn{3}{|c|}{ Concentration (at.\%) } \\
\hline $\mathrm{Er}$ & $1.2 \pm 0.4$ & $0.6 \pm 0.2$ & $0.6 \pm 0.1$ \\
\hline $\mathrm{U}$ & $20 \pm 1.3$ & $0.4 \pm 0.2$ & $0.2 \pm 0.1$ \\
\hline $\mathrm{Zr}$ & $78.8 \pm 1.3$ & $99.0 \pm 0.2$ & $99.2 \pm 0.1$ \\
\hline
\end{tabular}

Figure 68 shows SEM images for a sample annealed at $950^{\circ} \mathrm{C}$ for $16 \mathrm{hr}$, and Table 7 shows the phase compositions.
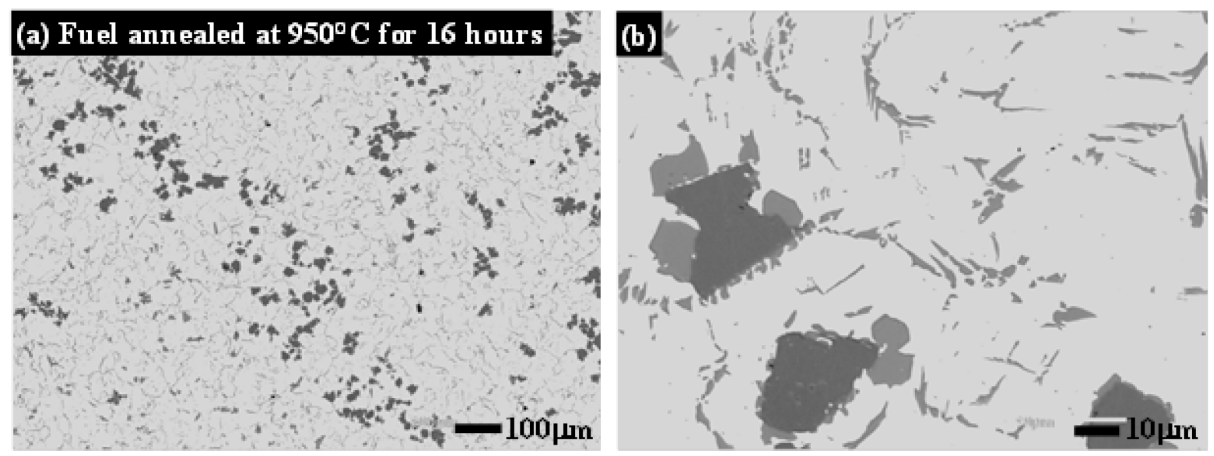

Figure 68. TRIGA fuel microstructure after heat treating at $950^{\circ} \mathrm{C}$ for $16 \mathrm{hr}$ : (a) low and (b) higher magnification BSE micrographs.

Table 7. Measured concentrations using EDS of different observed features in fuel microstructure of sample annealed at $950^{\circ} \mathrm{C}$ for $16 \mathrm{hr}$.

\begin{tabular}{|c|c|c|c|c|}
\hline \multirow{2}{*}{ Element } & Matrix & Mid-Gray Phase & Dark-Gray Phase & Grain Boundaries \\
\cline { 2 - 5 } & \multicolumn{4}{|c|}{ Concentration (at.\%) } \\
\hline $\mathrm{Er}$ & $1.5 \pm 0.7$ & $0.8 \pm 0.3$ & $1.0 \pm 0.1$ & $1.4 \pm 0.6$ \\
\hline $\mathrm{U}$ & $16.0 \pm 2.5$ & $4.8 \pm 0.6$ & $4.0 \pm 0.5$ & $13.3 \pm 2.6$ \\
\hline $\mathrm{Zr}$ & $82.5 \pm 3.1$ & $94.3 \pm 0.7$ & $95.5 \pm 0.5$ & $85.3 \pm 2.5$ \\
\hline
\end{tabular}

Figure 69 shows the microstructure for the $950^{\circ} \mathrm{C}$ sample annealed for $24 \mathrm{hr}$, and Table 8 shows the phase compositions for this sample.
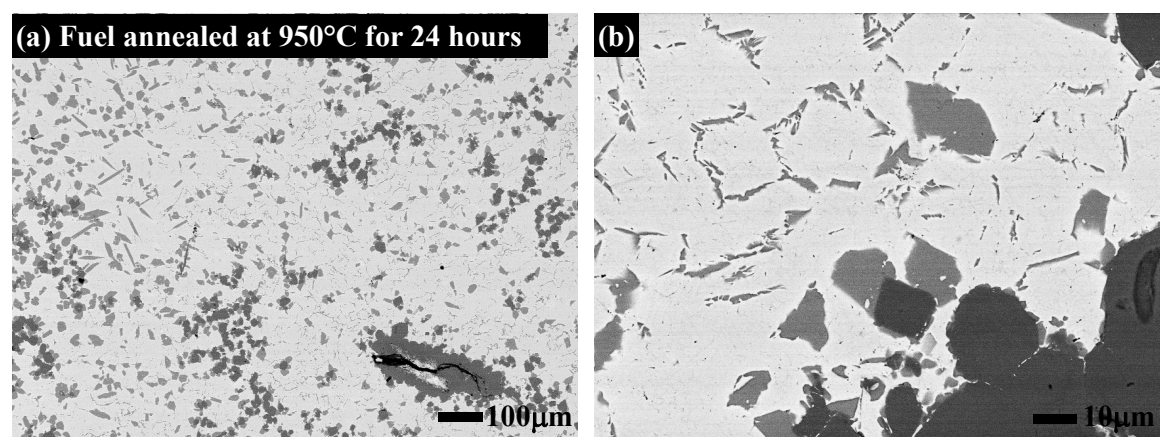

Figure 69. TRIGA fuel microstructure after heat treating at $950^{\circ} \mathrm{C}$ for $24 \mathrm{hr}$ : (a) low and (b) higher magnification BSE micrographs. 
Table 8. Measured concentrations using EDS of different observed features in fuel microstructure of sample annealed at $950^{\circ} \mathrm{C}$ for $24 \mathrm{hr}$.

\begin{tabular}{|c|c|c|c|c|}
\hline \multirow{2}{*}{ Element } & Matrix & Mid-Gray Phase & Dark-Gray Phase & Grain Boundaries \\
\cline { 2 - 5 } & \multicolumn{4}{|c|}{ Concentration (at.\%) } \\
\hline $\mathrm{Er}$ & $2.5 \pm 0.3$ & $2.5 \pm 0.9$ & $1.5 \pm 0.3$ & $3.0 \pm 0.8$ \\
\hline $\mathrm{U}$ & $14.0 \pm 0.1$ & $0.7 \pm 0.3$ & $0.6 \pm 0.3$ & $10.8 \pm 1.1$ \\
\hline $\mathrm{Zr}$ & $81.4 \pm 0.2$ & $94.9 \pm 1.0$ & $95.9 \pm 0.4$ & $84.1 \pm 0.4$ \\
\hline
\end{tabular}

In [2], the results of transmission electron microscope (TEM) characterization of unirradiated TRIGA fuel annealed at $950^{\circ} \mathrm{C}$ for $24 \mathrm{hr}$ have been reported. The results of this work suggest that the fuel microstructure is comprised of a $\mathrm{Zr}$-rich matrix phase(s) (possibly a hexagonal $\mathrm{UZr}_{2}$ or cubic $\mathrm{U}_{0.3} \mathrm{Zr}_{2.13}$ phase) and $\mathrm{Zr}-\mathrm{H}$ phase(s) (possibly a tetragonal $\mathrm{ZrH}_{2}$ or cubic $\mathrm{ZrH}_{1.6}$ phase).

TRIGA fuel Type 304SS diffusion couple experiments have been completed at $1000^{\circ} \mathrm{C}$ for 5 and $24 \mathrm{hr}$ [2]. To investigate the phases that are present in TRIGA fuel after a heat treatment at $1000^{\circ} \mathrm{C}$ for $24 \mathrm{hr}$, XRD was performed. Figure 70 shows the XRD peaks that were observed, along with the identified phases. The dominant phase in the annealed fuel was the hexagonal- $\mathrm{UZr}_{2}$ phase $(\mathrm{hP} 3, \mathrm{P} 6 / \mathrm{mmm}) . \mathrm{XRD}$ indicates that upon heat treating, the $\mathrm{ZrH}$-matrix and the U-particles in the fuel interacted to develop the $\mathrm{UZr}_{2}$ phase. The cubic $\mathrm{ZrC}_{0.67} \mathrm{H}_{0.33}$ phase (cF8, Fm-3m) was observed in the XRD pattern of the annealed fuel. Figure 66, Figure 68, and Figure 69 show that a dark-contrast phase remains in the samples after heat treating at relatively high temperatures, and a mid-contrast phase observed in the figures appears to increase in volume fraction in the material with increased heat treating time. The $\mathrm{ZrC}_{0.67} \mathrm{H}_{0.33}$ phase may be the mid- or dark-contrast phase. Further analysis is needed to determine which of the features observed in the microstructure of the sample is the $\mathrm{ZrC}_{0.67} \mathrm{H}_{0.33}$ phase. Low-intensity peaks in the XRD pattern tentatively identified the $\mathrm{H}_{1.6} \mathrm{Zr}$ and $\mathrm{H}_{2} \mathrm{Zr}$ phases. This suggests that even after heat treating at $1000^{\circ} \mathrm{C}$ for $24 \mathrm{hr}$, some of the $\mathrm{Zr}-\mathrm{H}$ phases remain in the fuel.

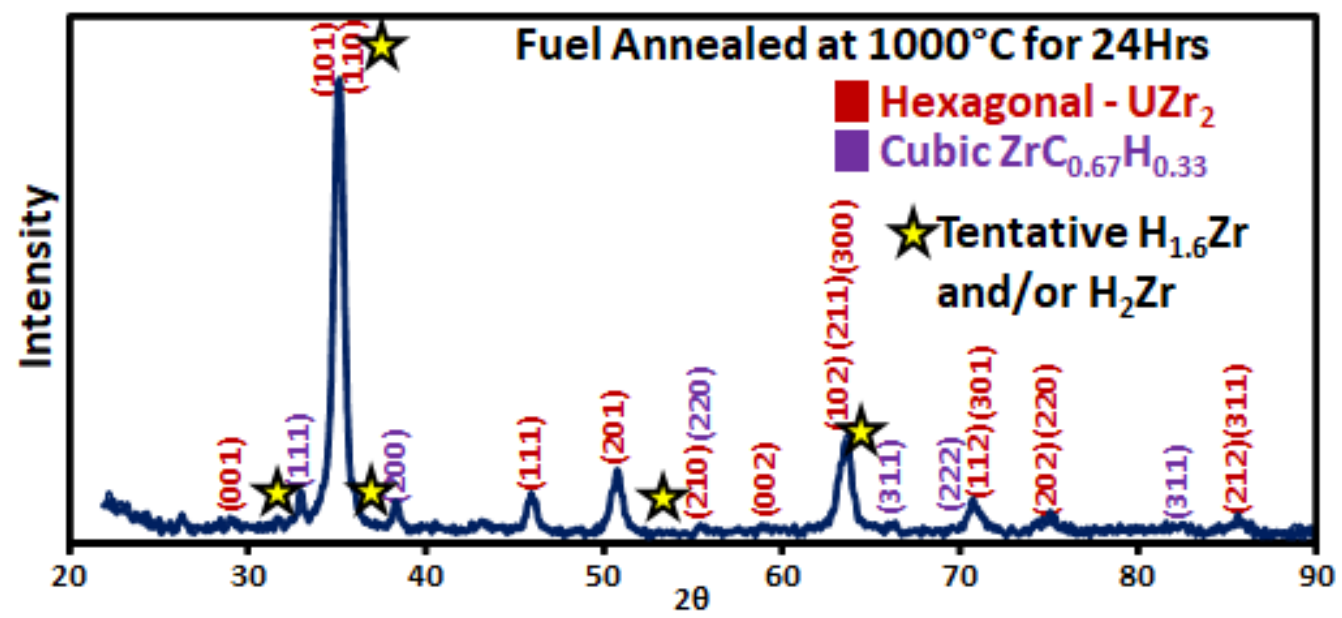

Figure 70. XRD pattern obtained from the TRIGA fuel annealed at $1000^{\circ} \mathrm{C}$ for $24 \mathrm{hr}$.

The diffusion couple annealed for $5 \mathrm{hr}$ was characterized using SEM and TEM, and Figure 71 shows SE and BSE images of the diffusion structures that developed, where some interaction was observed into the cladding, a gap developed at the fuel and cladding interface, and pores were observed on the TRIGA fuel side of the interaction zone. 

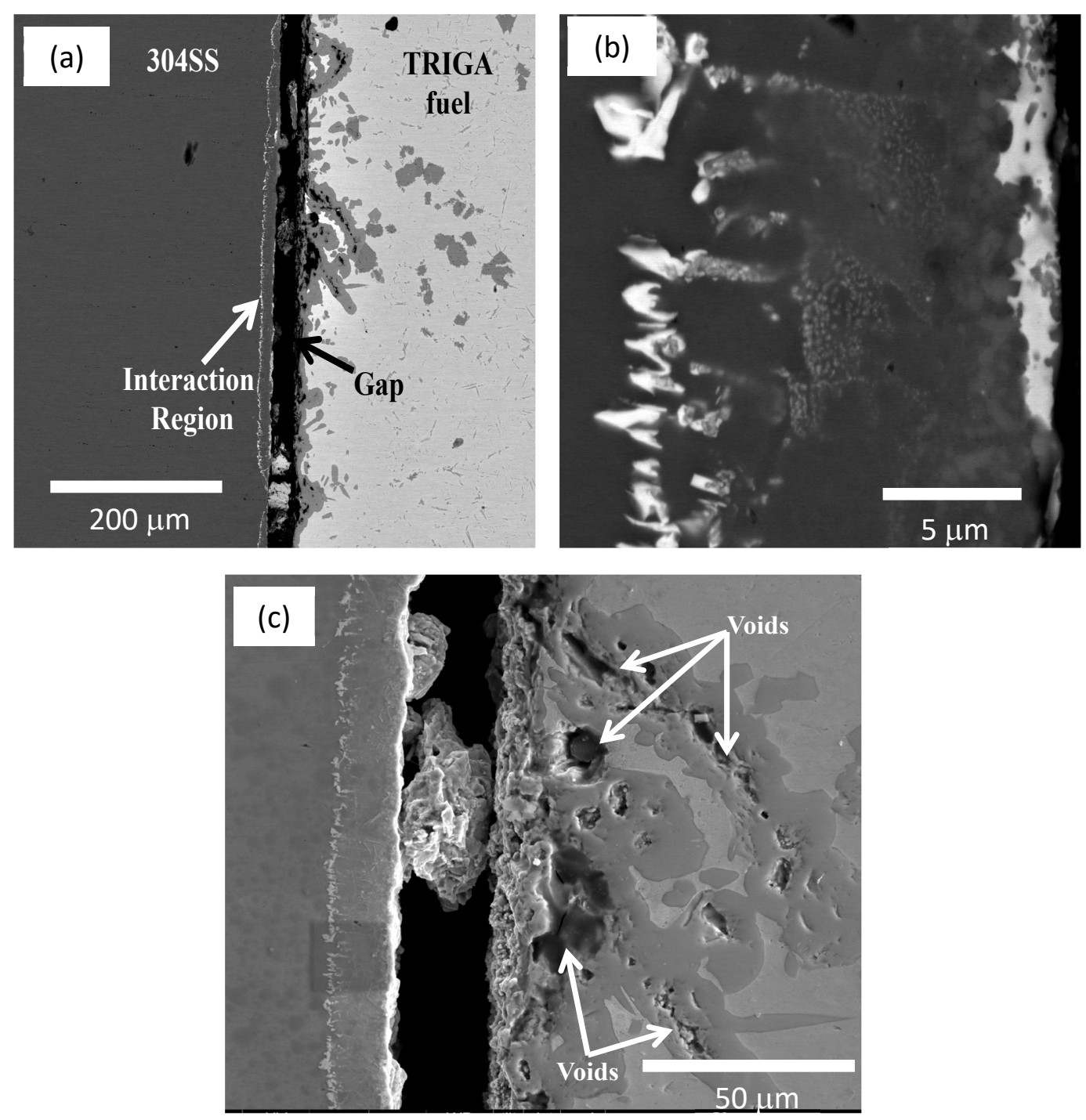

Figure 71. BSE image (a) of a diffusion couple annealed at $1000^{\circ} \mathrm{C}$ for $5 \mathrm{hr}$ where a gap near the fuel and cladding interface is present, along with the presence of a microns-thick FCCI zone that extends into the cladding, and (b) is a higher magnification image of this interaction zone, (c) is an SE image showing voids moving towards the TRIGA fuel.

The TEM micrograph in Figure 72 shows an area of the diffusion couple where specific phases were analyzed using electron diffraction, and the $\mathrm{Fe}_{2} \mathrm{U}$ phase (cF24, SG:Ff-3m) was identified, and it appears as a bright-contrast phase in Figure 72. 


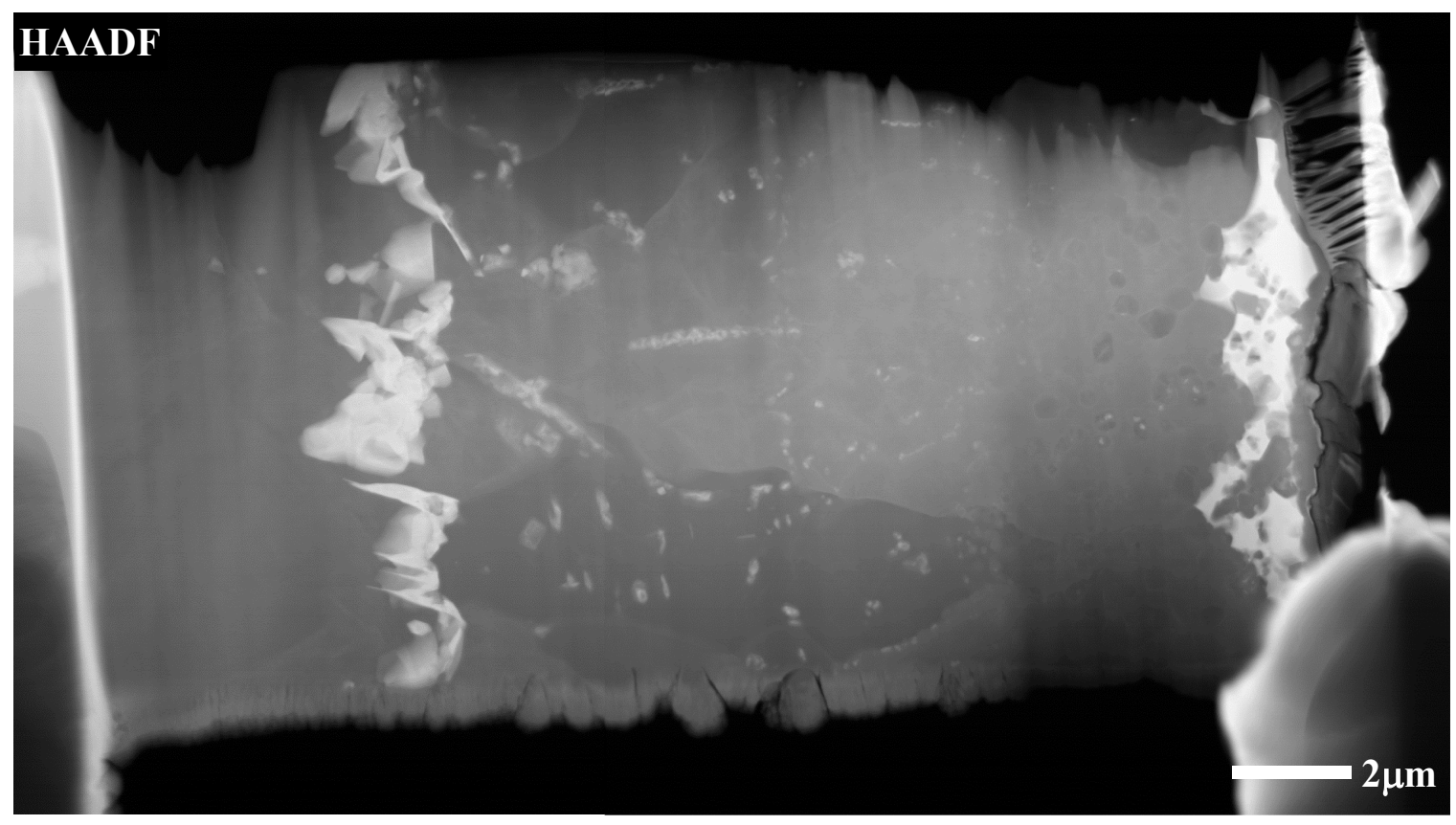

Figure 72. High-angle annular dark-field micrograph of the TEM sample obtained from the interaction region of the diffusion couple of TRIGA fuel versus Type $304 \mathrm{SS}$ annealed at $1000^{\circ} \mathrm{C}$ for $5 \mathrm{hr}$. The sample encompasses the entire thickness of the interaction region present on the cladding side of the gap depicted in Figure 71.

Figure 73 shows a low-magnification BSE image of the interaction zone observed for the diffusion couple annealed at $1000^{\circ} \mathrm{C}$ for $24 \mathrm{hr}$, along with a higher magnification image of the interaction layer nearest the unreacted cladding. A gap can be observed within the interaction zone. It looks very similar to the $1000^{\circ} \mathrm{C}$ couple ran for $5 \mathrm{hr}$.
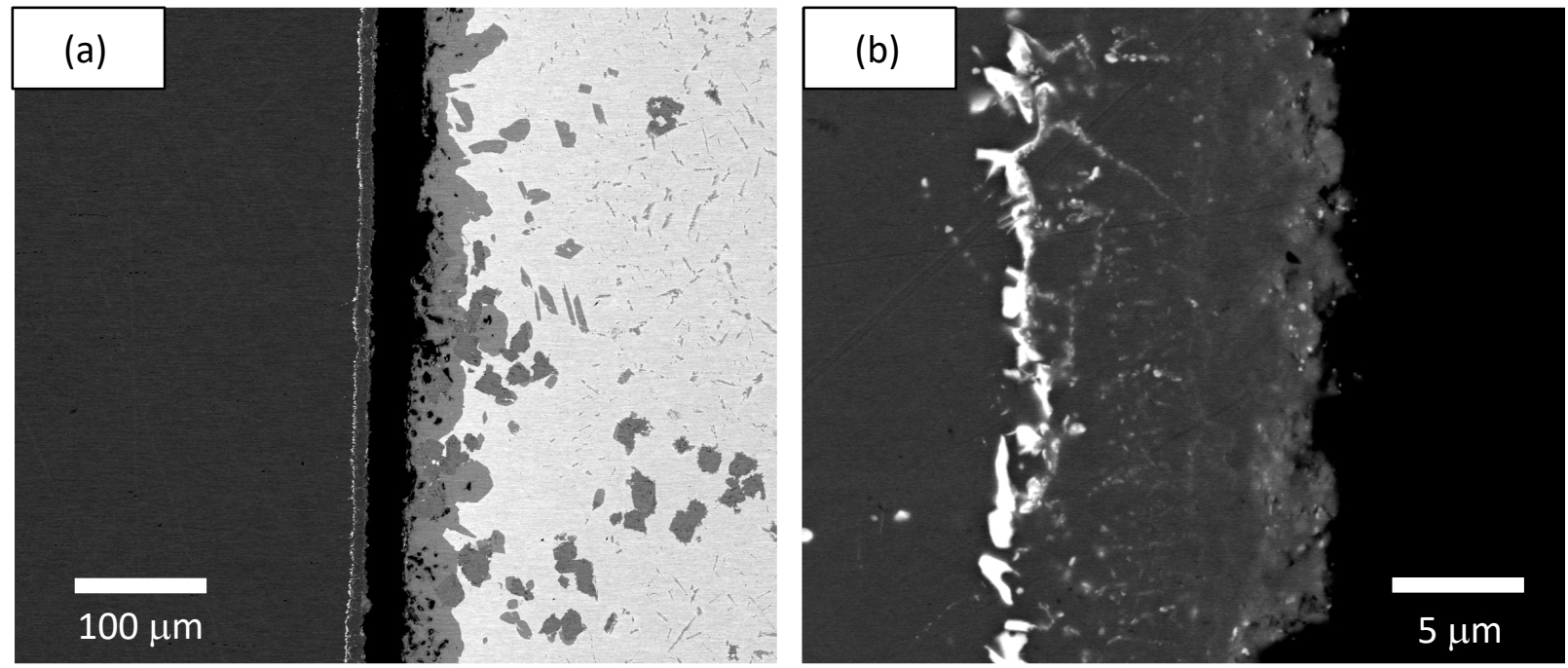

Figure 73. Backscatter electron micrographs of (a) a selected region from the TRIGA fuel versus 304SS diffusion couple annealed at $1000^{\circ} \mathrm{C}$ for $24 \mathrm{hr}$, and (b) a detailed micrograph of the interaction region.

Figure 74 shows a BSE image of the part of the interaction zone that penetrates into the cladding for the $1000^{\circ} \mathrm{C}$ diffusion couples annealed for $24 \mathrm{hr}$, along with WDS x-ray maps for $\mathrm{Er}, \mathrm{U}, \mathrm{Zr}, \mathrm{Cr}, \mathrm{Fe}, \mathrm{Ni}$, $\mathrm{Co}, \mathrm{Cu}, \mathrm{Mn}, \mathrm{Mo}$, and $\mathrm{Si}$ are shown in (b-1), respectively. 

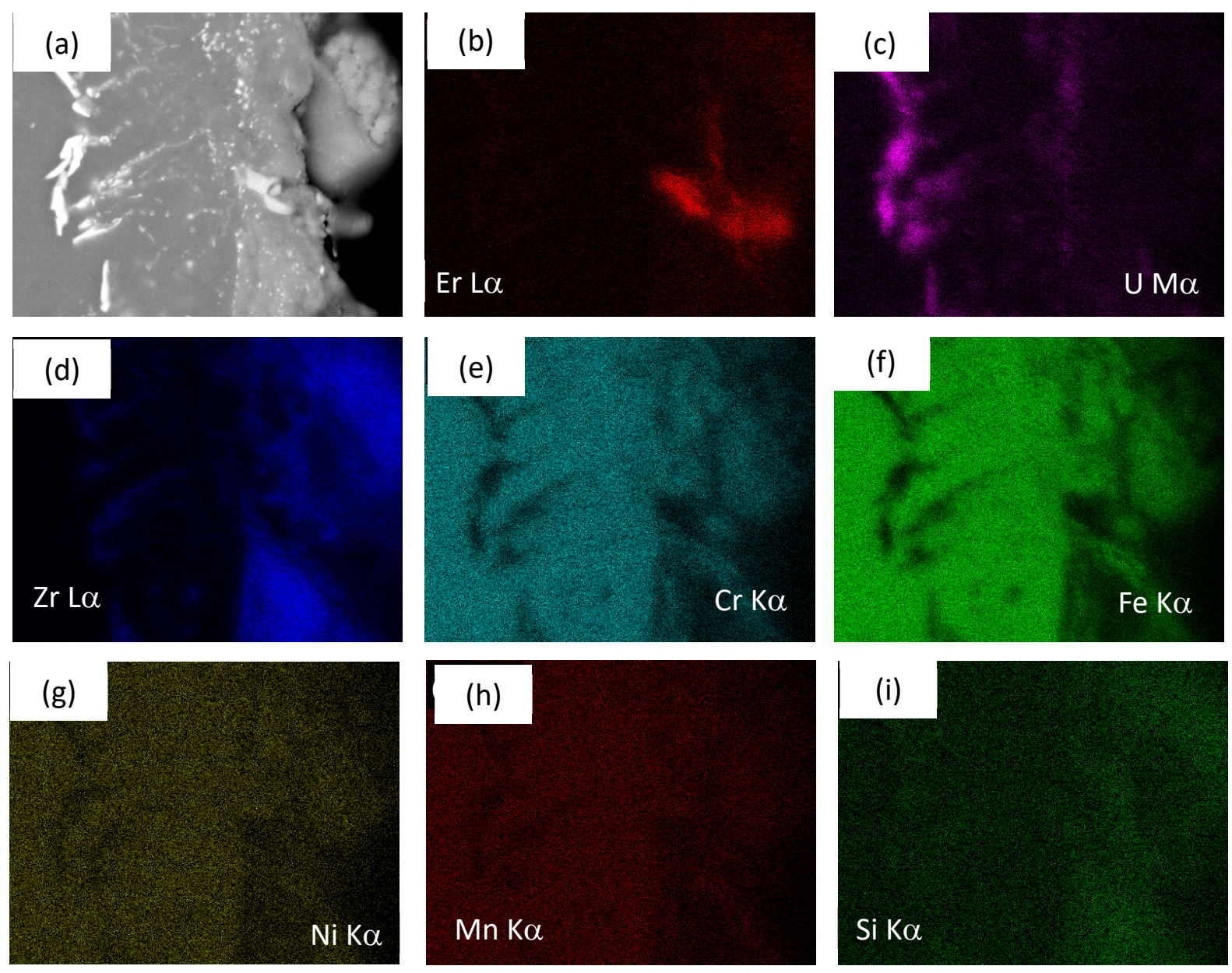

Figure 74. BSE image (a) of the interaction zone penetration into the cladding for the $1000^{\circ} \mathrm{C}$ diffusion couple annealed for $24 \mathrm{hr}$. WDS x-ray maps for (b) Er, (c) U, (d) Zr, (e) Cr, (f) Fe, (g) Ni, (h) Mn, and (i) Si are also presented.

The presence of $\mathrm{H}$ in the TRIGA fuel and any FCCI zones cannot be measured using SEM/EDS or SEM/WDS. Of the techniques that are available, only TEM can identify the presence of $\mathrm{H}$ through the use of electron diffraction where specific hydride phases can be confirmed. TEM has not been employed to characterize any of the irradiated TRIGA fuel specimens that were heat treated. However, it was employed to characterize heat-treated, unirradiated TRIGA fuel $\left(\right.$ at $\left.950^{\circ} \mathrm{C}\right)$ and some phases in the diffusion couple annealed at $1000^{\circ} \mathrm{C}$ for $5 \mathrm{hr}$. The presence of $\mathrm{Zr}-\mathrm{H}$ phases in TRIGA fuel heat treated at $950^{\circ} \mathrm{C}$ was demonstrated, and that was the only case that a hydride phase was confirmed using TEM. At high temperatures approaching $800^{\circ} \mathrm{C}$, the microstructure of the TRIGA fuel dramatically changes as dehydriding of the $\mathrm{ZrH}$ transpires. As hydrogen leaves the fuel, $\mathrm{Zr}$ seems to combine with $\mathrm{U}$ to form a $\mathrm{Zr}$-rich phase that exceeds 80 at.\% $\mathrm{Zr}$ in composition. In terms of the phases that form at the fuel and cladding interface, it is not clear what phases contain H. Conceivably, hydrogen could stabilize some of the phases that develop in the fuel and at the fuel and cladding interface during the interdiffusion process.

Since the diffusion couples run at $1000^{\circ} \mathrm{C}$ for $5 \mathrm{hr}$ and $24 \mathrm{hr}$ had very similar thicknesses, it was assumed that a gap formed at the fuel and cladding interface at about the same time, likely due to shrinkage of the fuel sample. The diffusion couple run for $24 \mathrm{hr}$ should have exhibited a much thicker diffusion zone. The similarity in thickness indicated that during heat treating the bonding interfaces failed at similar time intervals. Because characterization of these couples did not show any indication of oxidation of the interfaces, and because the couples bonded for a time interval to allow diffusion to take 
place, another mechanism was expected to be the cause of the failure of the interface. Shrinkage of the fuel was considered as a candidate. To investigate this possibility, a simple experiment was carried out to determine if the TRIGA fuel experienced shrinkage during heat treating. The Type 304SS was not tested, but shrinkage was not expected. A specimen of the TRIGA fuel was annealed in the furnace at $1000^{\circ} \mathrm{C}$ for $24 \mathrm{hr}$. The specimen was prepared and annealed in the same fashion as those used in the diffusion couple experiments, including wrapping the fuel in Ta to minimize oxidation. The initial specimen weight and dimensions were 0.7058 grams and $2.98 \mathrm{~mm} \times 6.27 \mathrm{~mm} \times 5.10 \mathrm{~mm}$. After heat treating the specimen weight was 0.6987 grams, and the specimen measured $2.84 \mathrm{~mm} \times 6.02 \mathrm{~mm} \times 4.86 \mathrm{~mm}$. The specimen weight loss was 0.0071 grams, indicating a loss of $13 \%$ of its volume. The results indicated that during heat treating under a high-purity Ar cover gas, enough shrinkage of the contact area and thickness of the fuel took place to form a fracture in the interaction zone that was parallel to the fuel and cladding interface. Once a gap had formed, it is unlikely that it would ever close during the remainder of the diffusion anneal. The similar thickness of the interaction regions in the diffusion couples annealed for 5 and $24 \mathrm{hr}$ also suggest that both couples lost bonding prior to $5 \mathrm{hr}$ of heat treating.

Since debonding occurred using a standard diffusion couple jig, a diffusion couple design was developed to maintain a constant pressure on the fuel and cladding interface, where a threaded rod was kept in contact with the diffusion couple throughout the diffusion anneal to ensure that good contact was maintained between the fuel and cladding (see Figure 75). Diffusion couple tests were then run, with the first test being run at $1000^{\circ} \mathrm{C}$ for $24 \mathrm{hr}$. Evidence of melting was observed, with the cladding pieces seeming to be relatively unchanged in dimension. SEM analysis of one of the cladding pieces showed that an interdiffusion zone was observed that was similar to what had been seen in past diffusion experiments (see Figure 76). XRD analysis on the surface of the cladding that exposed interaction zone phases showed the presence of $\mathrm{ZrC}_{0.67} \mathrm{H}_{0.33},\left(\mathrm{Fe}_{0.5} \mathrm{Ni}_{0.5}\right) \mathrm{Zr}_{2}, \mathrm{ZrH}_{1.6}$, and $\mathrm{ZrH}_{2}$ phases (see Figure 77).
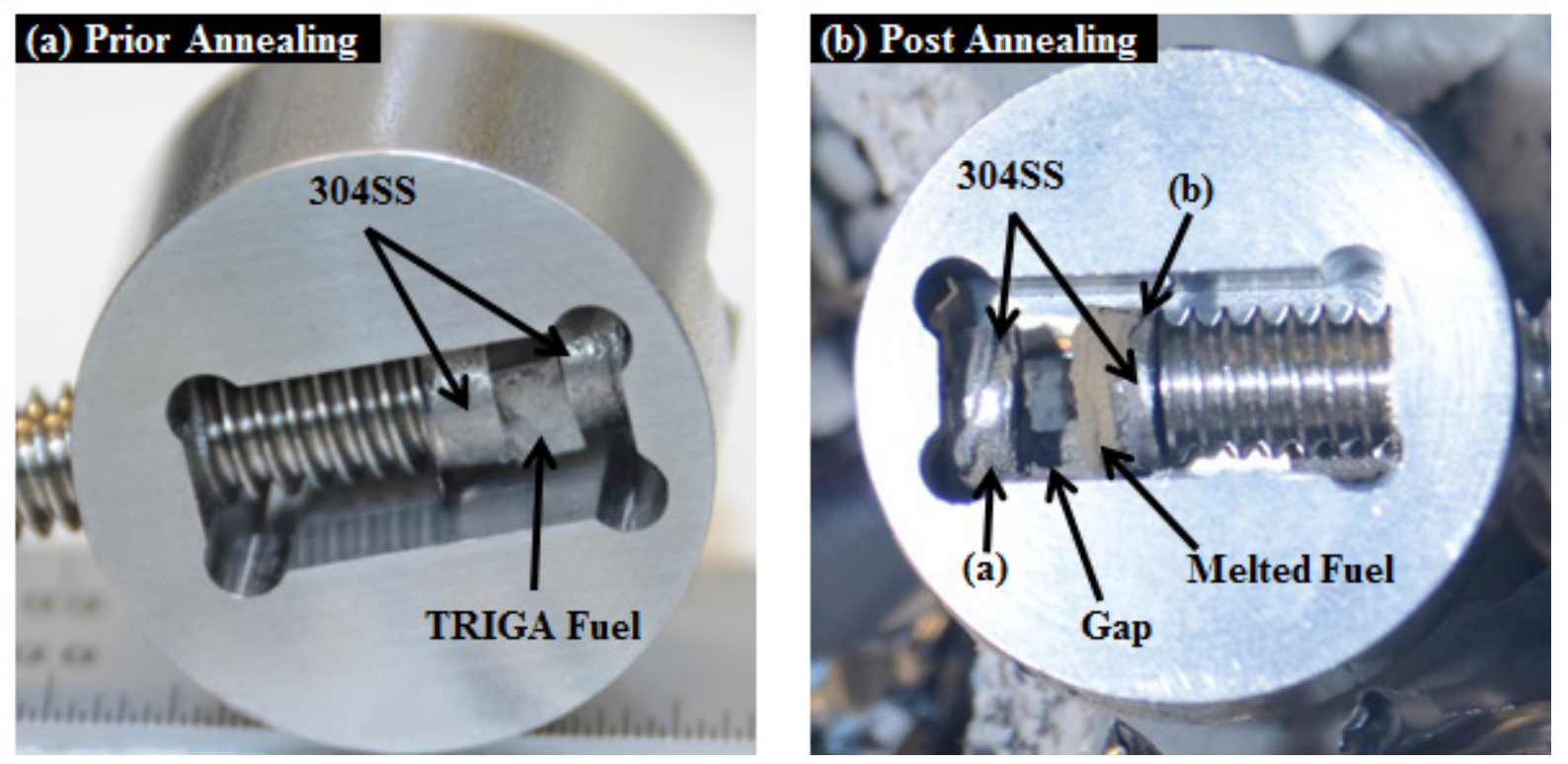

Figure 75. Diffusion couple run at $1000^{\circ} \mathrm{C}$ for $24 \mathrm{hr}$ in the advanced diffusion jig (a) prior to heat treating and (b) post heat treating. A gap is seen in (b) likely due to melting that had occurred. 


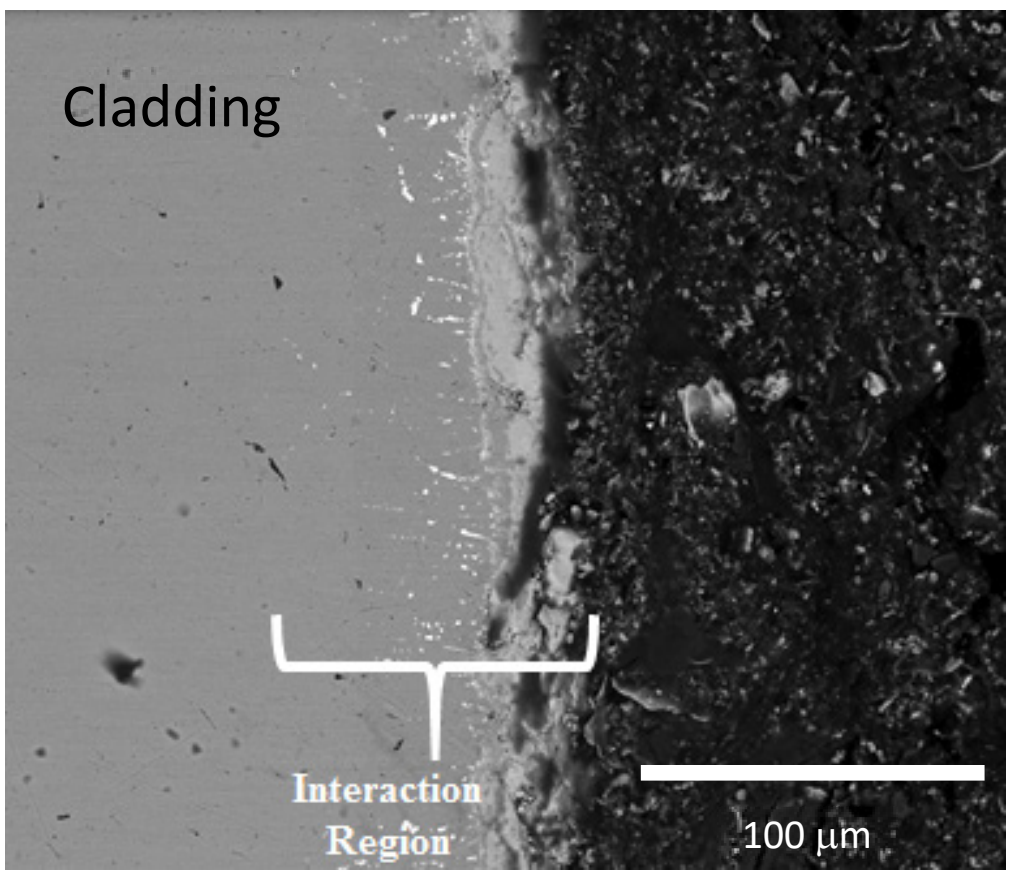

Figure 76. BSE micrograph of a selected area of a cross section of the Type 304SS that was in contact with the re-solidified TRIGA fuel material that was to the right.

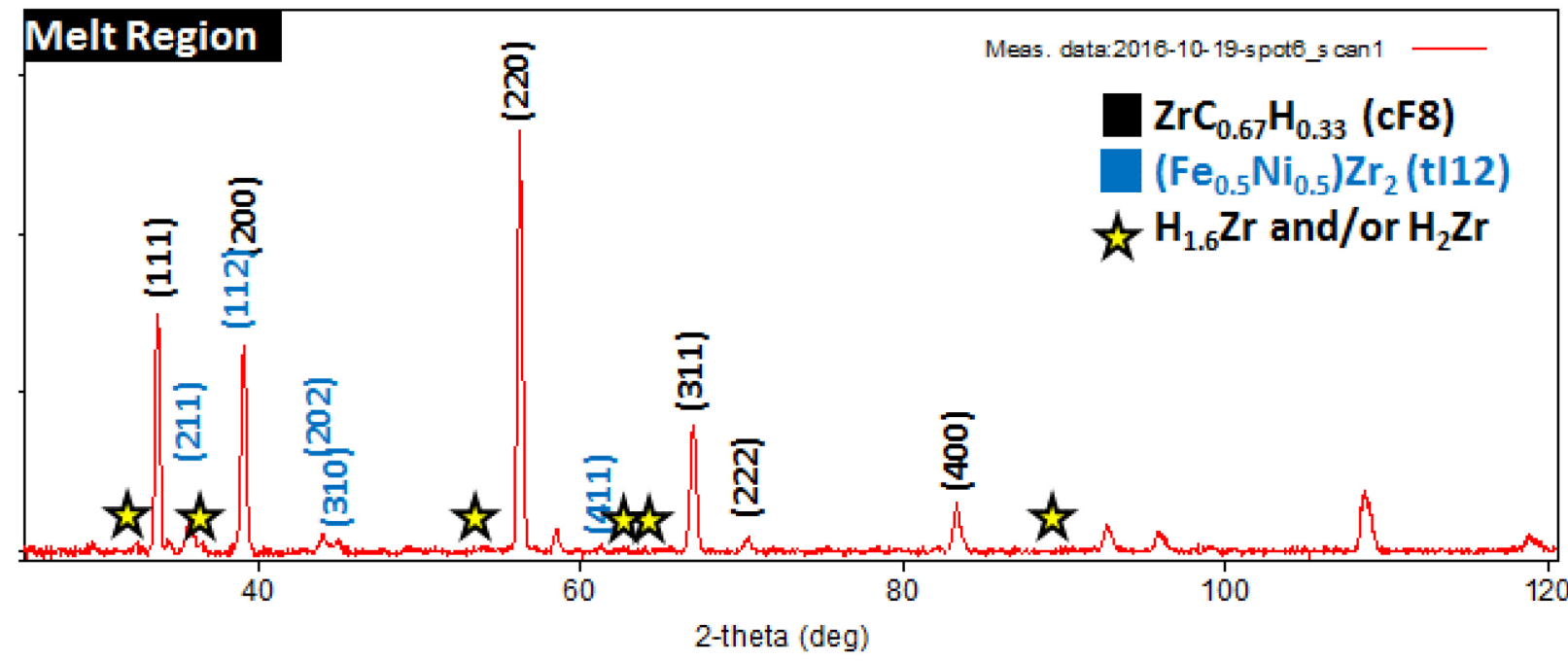

Figure 77. XRD pattern of a selected area in the re-solidified material in a diffusion couple run at $1000^{\circ} \mathrm{C}$ for $24 \mathrm{hr}$ using the advanced diffusion couple jig.

A picture of a diffusion couple run at $900^{\circ} \mathrm{C}$ for $24 \mathrm{hr}$ using the advanced diffusion couple jig is shown in Figure 78. Some evidence of melting was also observed. 


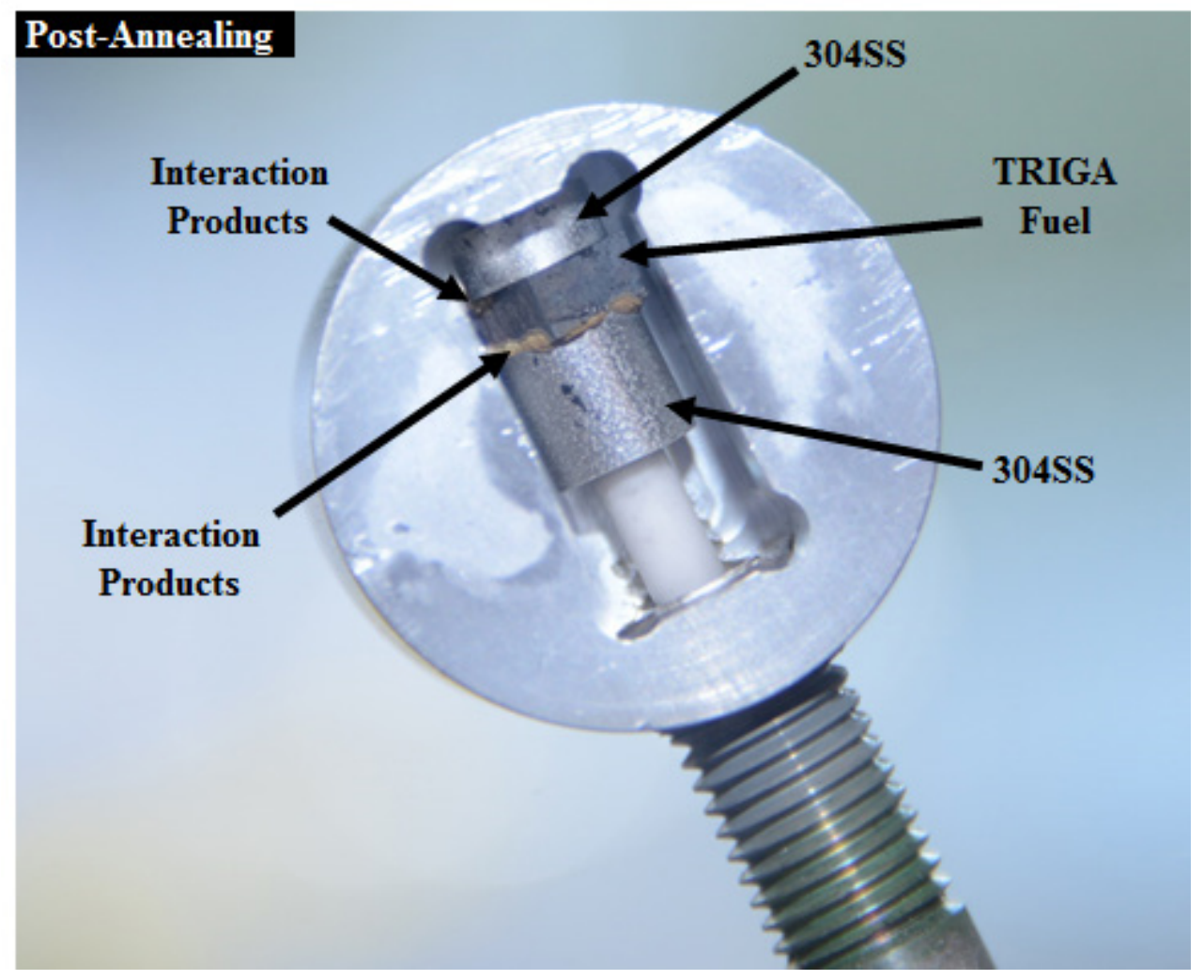

Figure 78. Diffusion couple run at $900^{\circ} \mathrm{C}$ for $24 \mathrm{hr}$ in an advanced diffusion jig in the post heat-treating condition.

BSE images of the fuel and cladding interaction zone for the diffusion couple run at $900^{\circ} \mathrm{C}$ for $24 \mathrm{hr}$ using the advanced diffusion couple jig is shown in Figure 79. Voids were observed on the fuel side of the fuel and cladding interaction zone. 

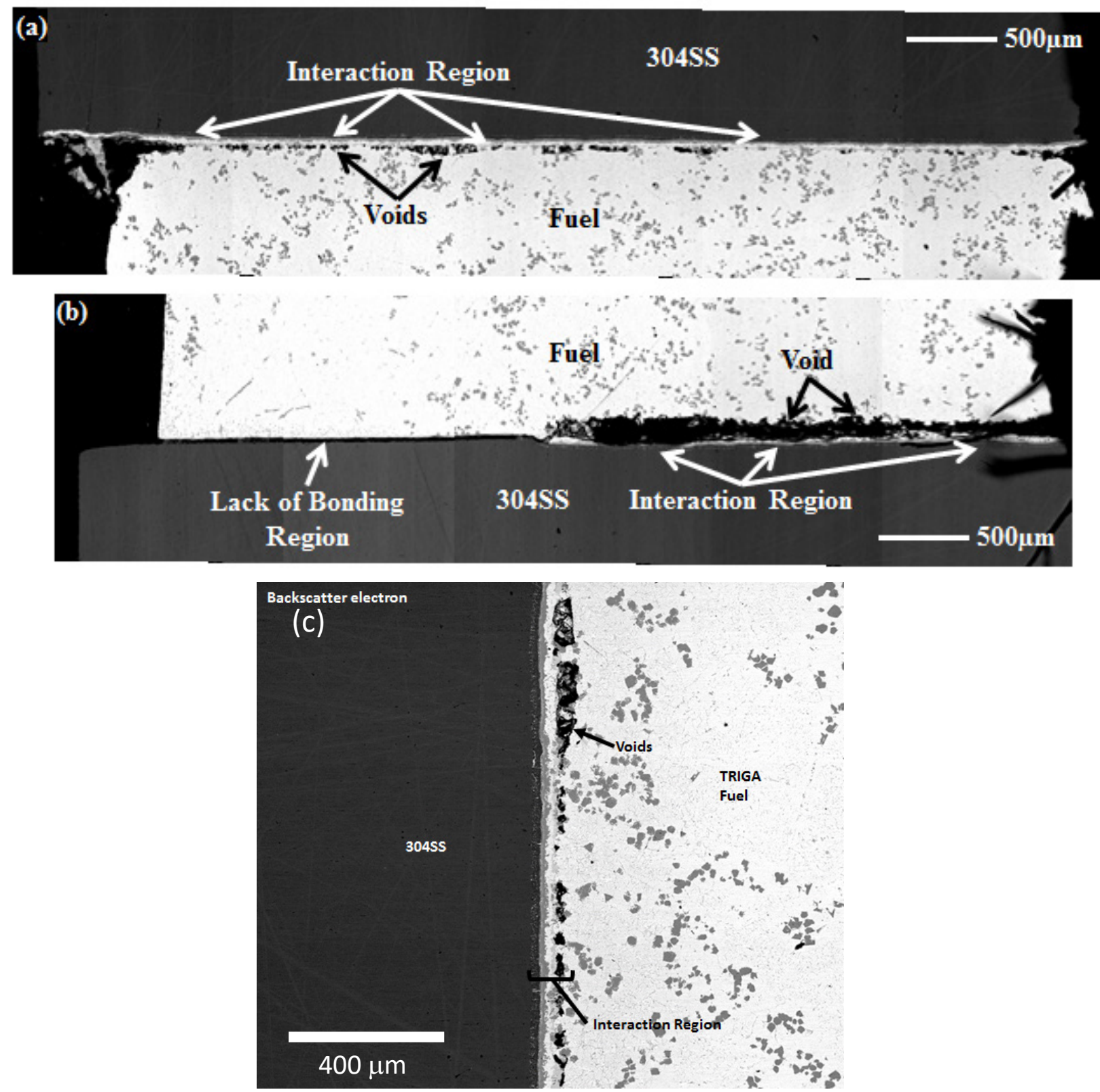

Figure 79. BSE micrographs of the cross sections of the diffusion couple run at $900^{\circ} \mathrm{C}$ for 24 using the advanced diffusion couple jig.

To investigate the different phases that formed during diffusion at $900^{\circ} \mathrm{C}$ for $24 \mathrm{hr}$, an area of the interdiffusion zone along the fuel and cladding interface where melting had not occurred was found (see Figure 80). An EDS line scan was produced in this area (see Figure 81), along with EDS x-ray maps of fuel and cladding constituents (see Figure 82). 


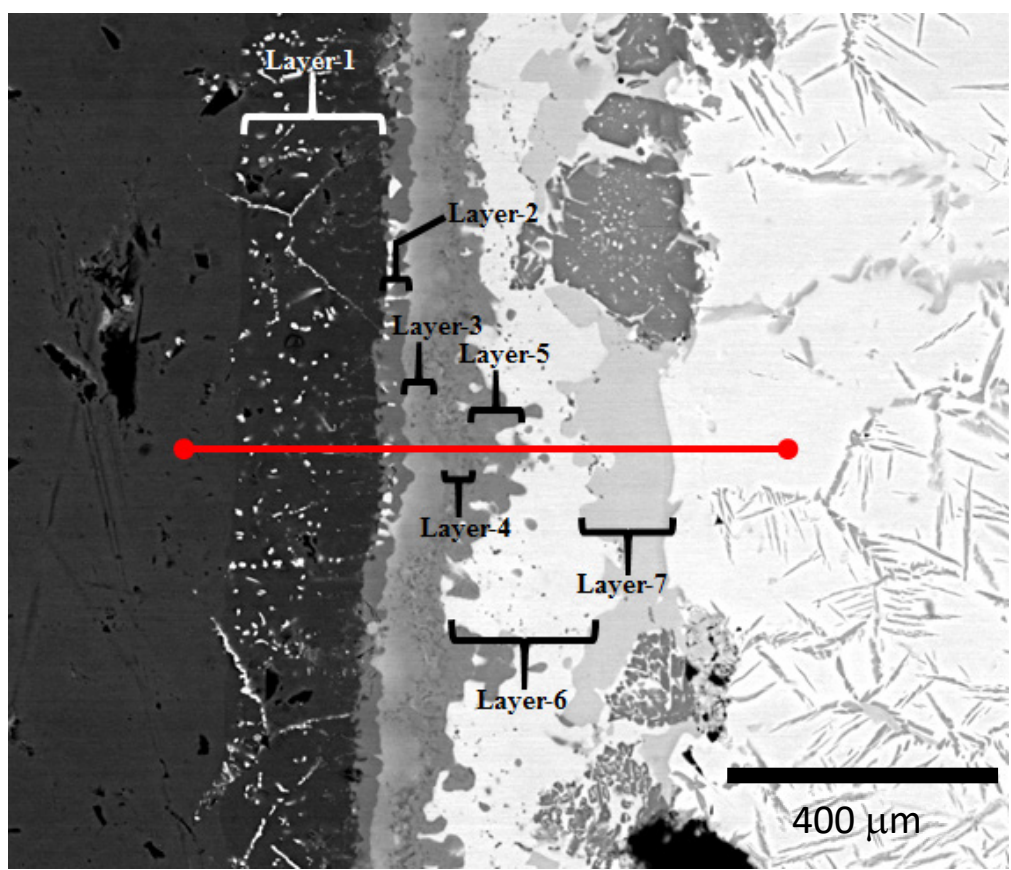

Figure 80. BSE micrograph of a selected region of the fuel and cladding interaction zone. The red line marks the location where the $\mathrm{Zr}, \mathrm{Cr}, \mathrm{Fe}, \mathrm{Ni}$, and $\mathrm{U}$ concentration profiles in Figure 81 were collected. The interaction zone is divided into seven layers of differing composition and phase morphology.

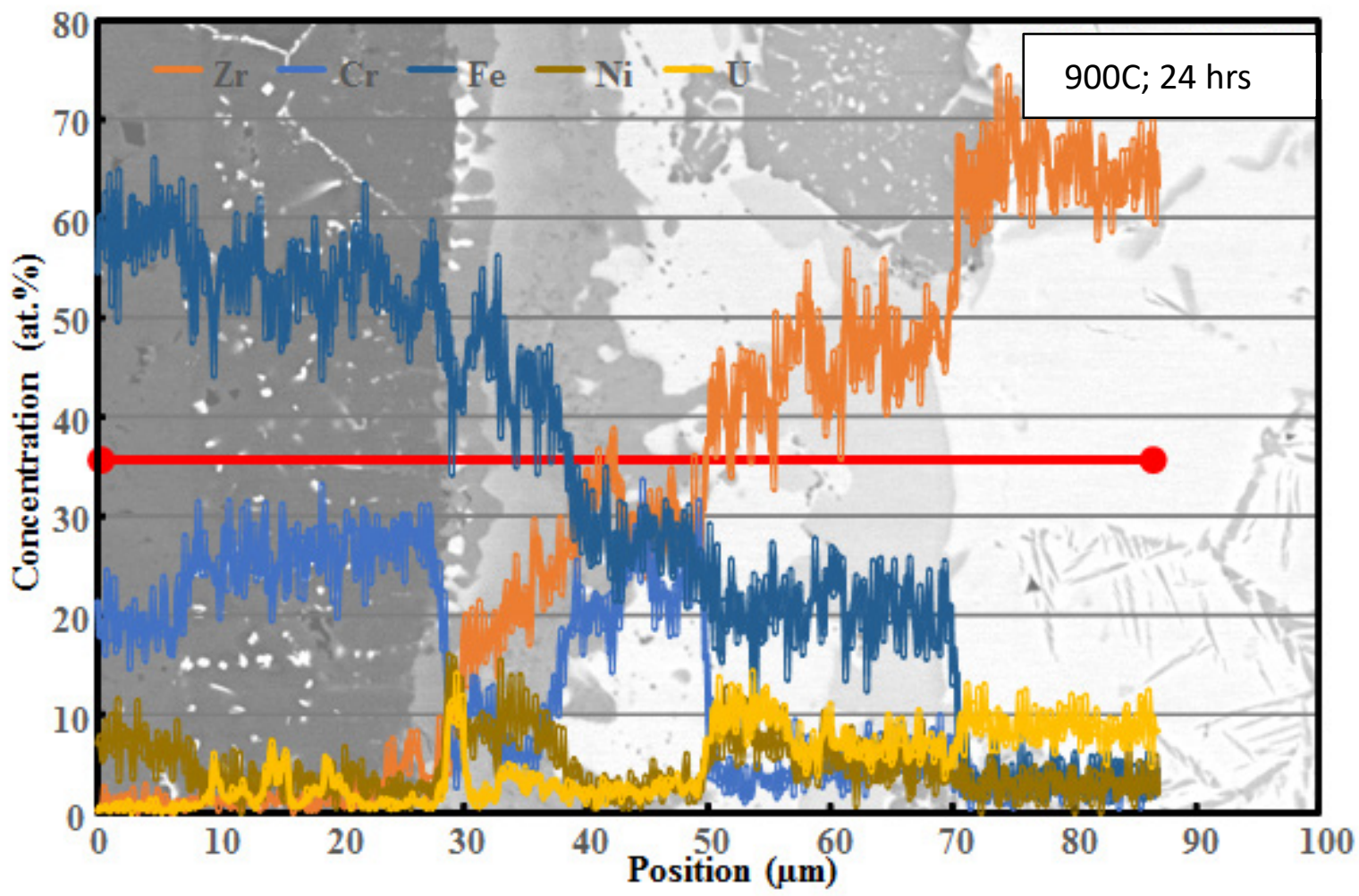

Figure 81. Concentration profiles for $\mathrm{Zr}, \mathrm{Cr}, \mathrm{Fe}, \mathrm{Ni}$, and $\mathrm{U}$ generated from the interaction region of a diffusion couple annealed at $900^{\circ} \mathrm{C}$ for $24 \mathrm{hr}$ using the advanced diffusion couple jig. 

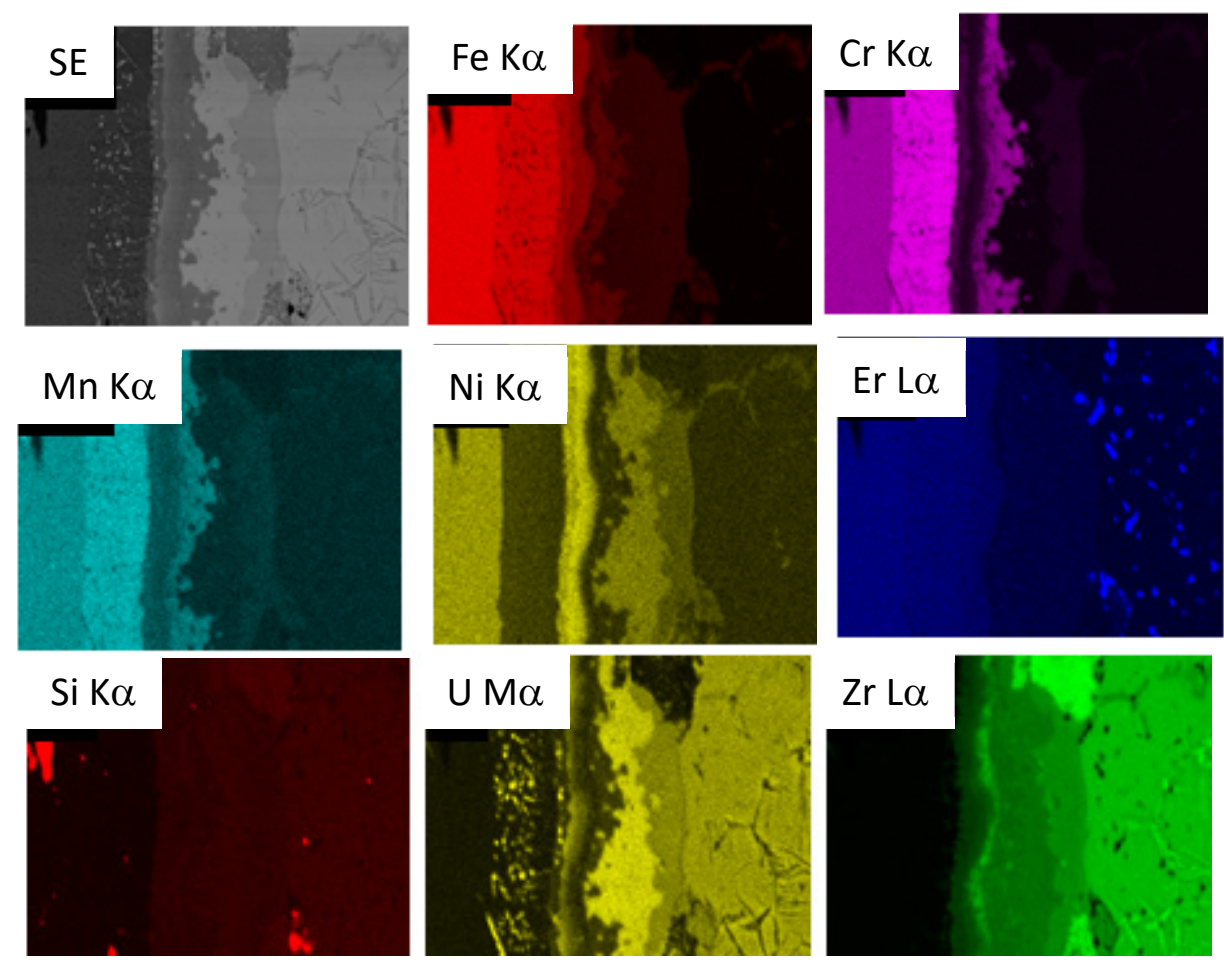

Figure 82. SE image and EDS x-ray maps for $\mathrm{Fe}, \mathrm{Cr}, \mathrm{Mn}, \mathrm{Ni}, \mathrm{Er}, \mathrm{Si}, \mathrm{U}$, and $\mathrm{Zr}$ in the same region along the fuel and cladding interface that was selected for the concentration profile in Figure 81.

Figure 83 shows SE and BSE images in another location along the fuel and cladding interface where voids were observed. Figure 84 shows higher magnification images of the phase present in the vicinity of the voids. Figure 85 shows EDS x-ray maps in an area of the interaction layer with a void.
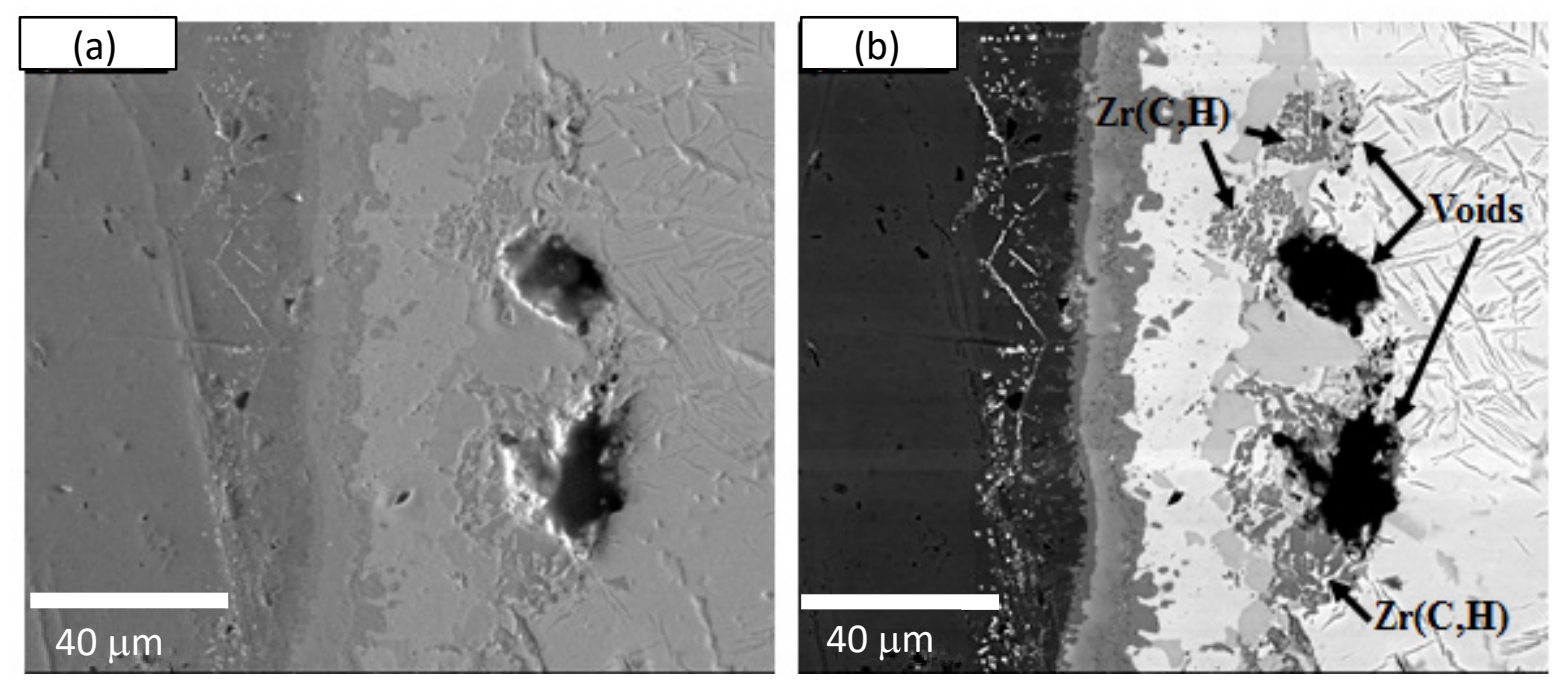

Figure 83. (a) SE and (b) BSE micrographs of a selected region of the interaction zone where voids can be observed. 

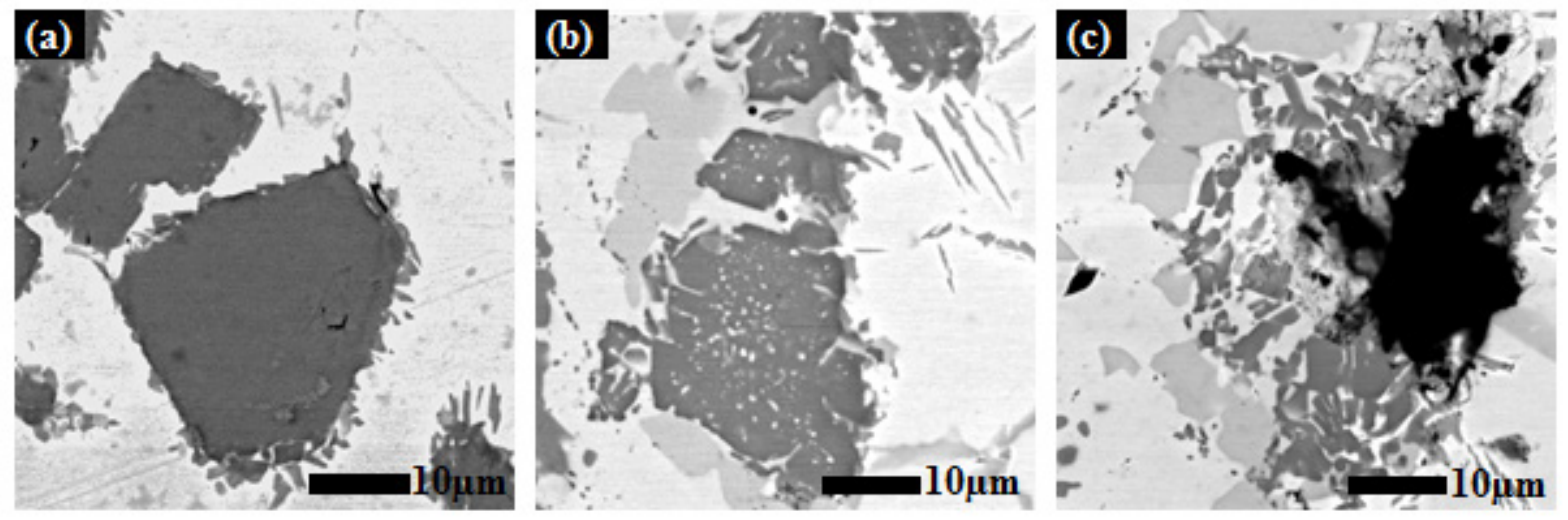

Figure 84. Higher magnification BSE micrographs of the interaction zone region that contains the $\mathrm{Zr}(\mathrm{C}, \mathrm{H})$ phase (a) in the fuel far away from the interaction region, (b) within the interaction region, possibly at an early stage of melting and decomposition, and (c) within the interaction region at a later stage of the melting and decomposition process.
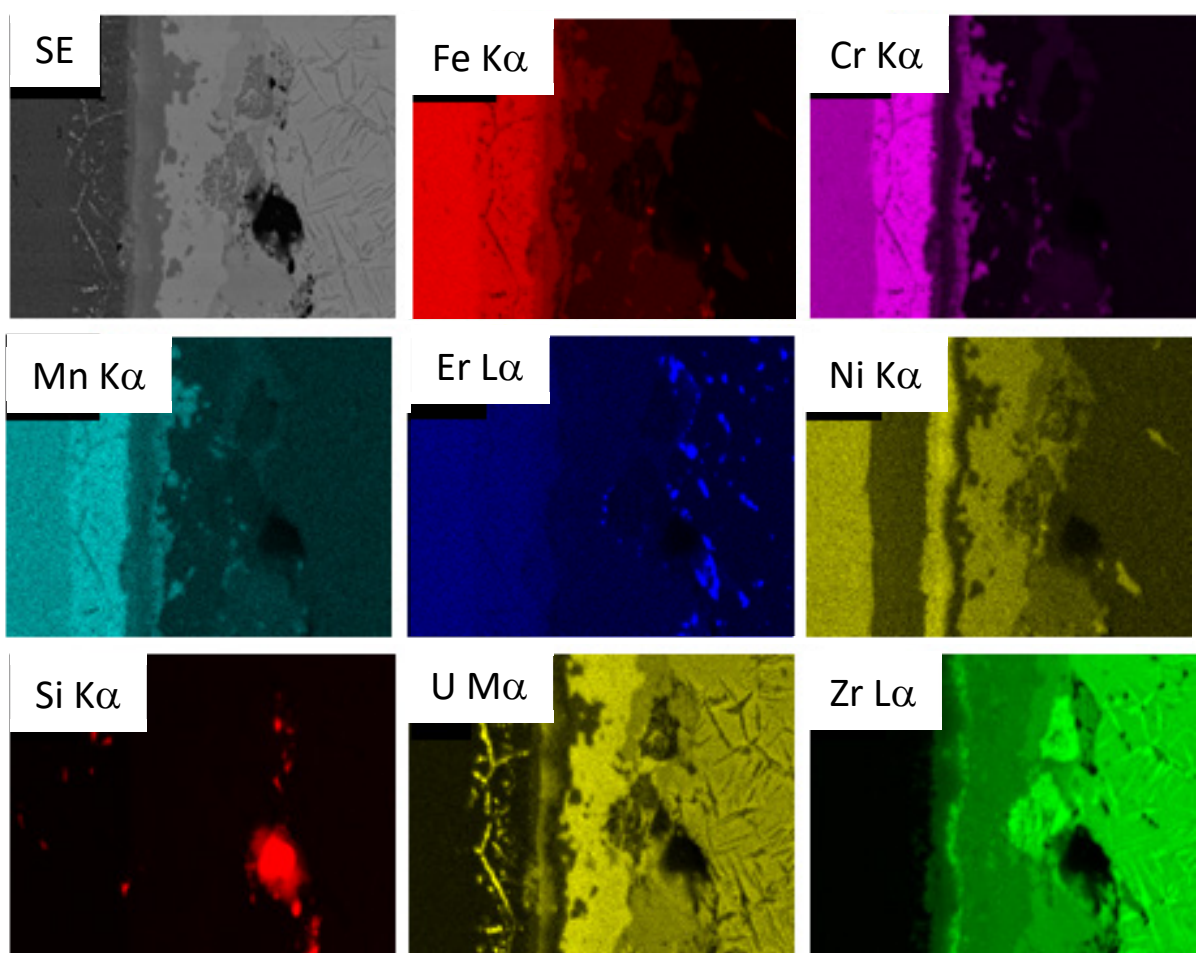

Figure 85. SE image and EDS x-ray maps for $\mathrm{Fe}, \mathrm{Cr}, \mathrm{Mn}, \mathrm{Er}, \mathrm{Ni}, \mathrm{Si}, \mathrm{U}$, and $\mathrm{Zr}$ at a second selected area in the interaction region where a void is present. The high Si concentration in the void is likely due to the presence of polishing material.

If one assumes that the voids are evidence of a phase that had melted during the heat treatment, this melting occurred on the fuel side of the interdiffusion zone and only happened in localized regions.

Examination of the interaction region where voids were located shows that voids typically developed within the same region of the interaction zone. Their location roughly corresponded to the position of Layer-7 in Figure 80. Voids appear to have developed only where the $\operatorname{Zr}(\mathrm{C}, \mathrm{H})$ phase regions were present near or within Layer-7 of the interaction zone. Where voids where observed adjacent to $\operatorname{Zr}(\mathrm{C}, \mathrm{H})$ phase regions, the $\mathrm{Zr}(\mathrm{C}, \mathrm{H})$ phase appeared to have been undergoing decomposition, as shown in 
Figure 84. Figure 84 shows three different $\operatorname{Zr}(\mathrm{C}, \mathrm{H})$ phase regions obtained from the diffusion couple. Figure 84(a) shows a $\mathrm{Zr}(\mathrm{C}, \mathrm{H})$ region within the TRIGA fuel, far away from the interaction region. The $\mathrm{Zr}(\mathrm{C}, \mathrm{H})$ region is continuous and appears to contain a single phase. Figure $84(\mathrm{~b})$ and (c) show $\mathrm{Zr}(\mathrm{C}, \mathrm{H})$ regions within the interaction region. Figure $84(\mathrm{~b})$ shows a $\operatorname{Zr}(\mathrm{C}, \mathrm{H})$ region that seems to contain a secondary bright-contrast phase in the BSE micrograph. Based on general observations of the evolution of the $\mathrm{Zr}(\mathrm{C}, \mathrm{H})$ regions in the interaction region, elements from the interaction products appear to penetrate the $\mathrm{Zr}(\mathrm{C}, \mathrm{H})$ regions through grain boundaries or voids at a rapid pace relative to the rate of interaction of the $\mathrm{Zr}(\mathrm{C}, \mathrm{H})$ with the penetrating elements. The $\mathrm{Zr}(\mathrm{C}, \mathrm{H})$ (see Figure $84[\mathrm{~b}]$ ) within the interaction region was possibly at an early stage of melting and decomposition, and the $\operatorname{Zr}(\mathrm{C}, \mathrm{H})$ phase shown in Figure 84(c) within the interaction region was possibly at a later stage of the melting and decomposition process.

EDS area composition scans (see Figure 86) were also taken in different regions of the interaction zone to give some idea of the compositions of the various layers. Table 9 lists the results of the different area scans. Many of the layers that extended into the fuel contained appreciable $\mathrm{Zr}$, and in these layers the $\mathrm{Zr}$ content was noticeably higher than the U content.

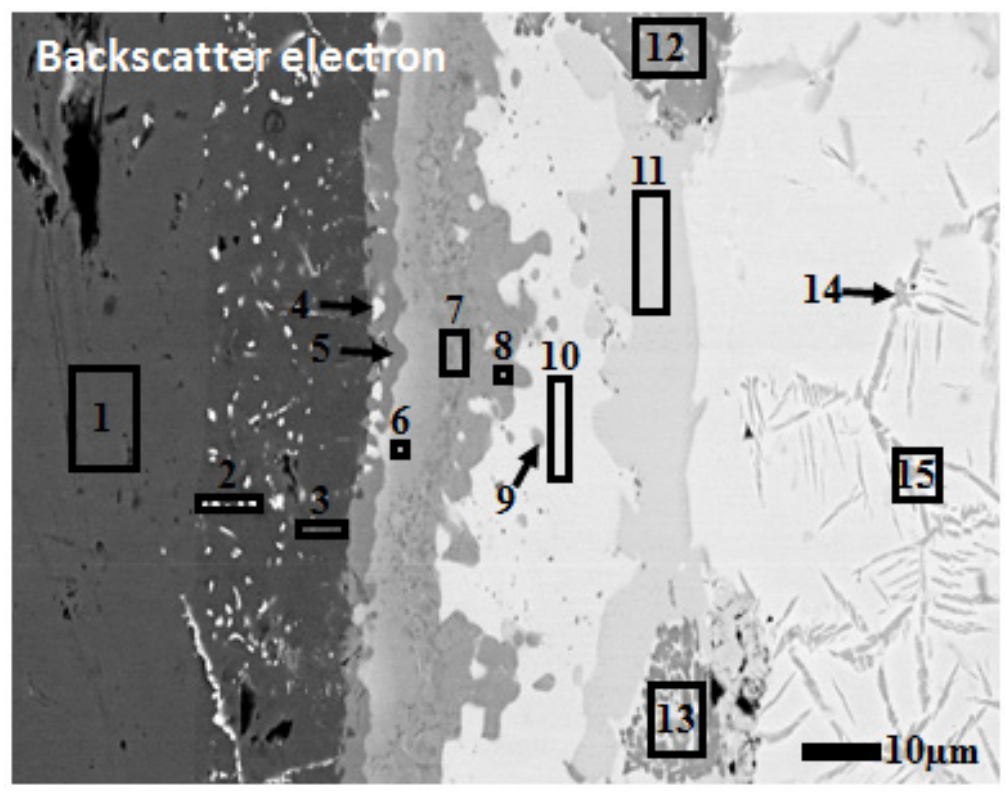

Figure 86. BSE micrograph showing the locations where the EDS compositional data enumerated in Table 9 were collected. 
Table 9. Compositional EDS data collected from the interaction region of a diffusion couple annealed at $900^{\circ} \mathrm{C}$ for $24 \mathrm{hr}$ where the locations are shown in Figure 87.

\begin{tabular}{|c|c|c|c|c|c|c|c|c|}
\hline & 1 & 2 & 3 & 4 & 5 & 6 & 7 & 8 \\
\hline Element & \multicolumn{8}{|c|}{ at. $\%$} \\
\hline $\mathrm{Si}$ & 1.2 & 0.7 & 0.3 & 1.5 & 1.0 & 1.5 & 0.7 & 0.6 \\
\hline $\mathrm{Zr}$ & 0.3 & 0.3 & 2.8 & 10.2 & 17.6 & 21.9 & 30.6 & 31.1 \\
\hline Mo & 0.4 & 1.0 & 0.5 & 0.5 & 0.0 & 0.7 & 0.7 & 0.4 \\
\hline $\mathrm{U}$ & 0.1 & 3.6 & 0.7 & 12.8 & 1.0 & 4.0 & 1.8 & 2.0 \\
\hline $\mathrm{Cr}$ & 19.5 & 27.7 & 28.6 & 6.4 & 12.0 & 5.3 & 19.4 & 26.1 \\
\hline $\mathrm{Mn}$ & 1.9 & 2.1 & 2.1 & 1.9 & 1.7 & 2.2 & 1.7 & 1.6 \\
\hline $\mathrm{Fe}$ & 67.9 & 60.6 & 62.0 & 51.9 & 57.5 & 52.2 & 39.9 & 36.2 \\
\hline Co & 1.0 & 1.0 & 0.4 & 0.0 & 0.8 & 0.0 & 0.6 & 0.3 \\
\hline $\mathrm{Er}$ & 0.0 & 0.0 & 0.0 & 0.7 & 0.0 & 0.5 & 0.1 & 0.1 \\
\hline $\mathrm{Ni}$ & 7.1 & 2.7 & 2.2 & 13.0 & 7.5 & 11.0 & 4.0 & 1.1 \\
\hline $\mathrm{Cu}$ & 0.8 & 0.5 & 0.3 & 1.1 & 0.9 & 0.9 & 0.7 & 0.3 \\
\hline
\end{tabular}

Continued:

\begin{tabular}{|c|c|c|c|c|c|c|c|}
\hline & 9 & 10 & 11 & 12 & 13 & 14 & 15 \\
\hline Element & \multicolumn{7}{|c|}{ at. $\%$} \\
\hline $\mathrm{Si}$ & 0.9 & 1.9 & 0.0 & 0.0 & 0.6 & 0.5 & 0.0 \\
\hline $\mathrm{Zr}$ & 39.8 & 48.2 & 54.5 & 91.7 & 75.8 & 86.6 & 80.0 \\
\hline Mo & 0.8 & 1.1 & 0.8 & 0.6 & 0.9 & 0.6 & 1.0 \\
\hline $\mathrm{U}$ & 7.3 & 12.1 & 7.3 & 1.2 & 5.5 & 4.8 & 9.0 \\
\hline $\mathrm{Cr}$ & 17.2 & 2.2 & 5.7 & 0.7 & 0.8 & 1.3 & 1.3 \\
\hline $\mathrm{Mn}$ & 1.0 & 0.8 & 1.2 & 0.6 & 0.6 & 0.7 & 0.3 \\
\hline $\mathrm{Fe}$ & 27.8 & 24.5 & 25.1 & 3.0 & 11.2 & 2.5 & 4.8 \\
\hline Co & 0.0 & 0.0 & 0.3 & 0.3 & 0.0 & 0.5 & 0.6 \\
\hline Er & 0.5 & 1.1 & 0.5 & 0.5 & 0.7 & 0.7 & 1.2 \\
\hline $\mathrm{Ni}$ & 4.3 & 7.4 & 4.0 & 1.0 & 3.2 & 1.1 & 1.1 \\
\hline $\mathrm{Cu}$ & 0.4 & 0.7 & 0.7 & 0.5 & 0.7 & 0.9 & 0.8 \\
\hline
\end{tabular}


The main conclusions from the diffusion couple work describe above are as follows. During heat treatments at 950 and $1000^{\circ} \mathrm{C}$, there is a strong propensity for the diffusion couples, which started in close contact, to ultimately de-bond near the fuel and cladding interface. At a temperature of $800^{\circ} \mathrm{C}$ or higher, the TRIGA fuel transforms into a microstructure that contains a $\mathrm{Zr}-\mathrm{U}$ matrix phase and $\mathrm{Zr}$-rich phases with $\mathrm{C}$ or $\mathrm{H}$. At $950^{\circ} \mathrm{C}$, it has been confirmed that the TRIGA fuel microstructure is comprised of a $\mathrm{UZr}_{2}$ matrix phase and $\mathrm{Zr}$-rich phases with $\mathrm{C}$ or $\mathrm{H}$. Fuel and cladding interaction zones that develop in diffusion couples annealed at 900,950 , and $1000^{\circ} \mathrm{C}$ contain complex multicomponent phases comprised of different cladding and fuel constituents. The multiphase interaction zone region nearest the unreacted cladding in annealed diffusion couples contains a UFe 2 -type phase and $\mathrm{Fe}_{2} \mathrm{Zr}$ and $\mathrm{FeZr}_{2}$-type phases are present moving towards the fuel. In diffusion couples annealed at 900,950 , and $1000^{\circ} \mathrm{C}$, porosity has been observed near isolated phases at the fuel side of the interaction zone that contain $\mathrm{Zr}$ or $\mathrm{C}$ and $\mathrm{H}$ that could be the result of localized melting. Fe and Ni-containing precipitates have been observed nearest the unreacted fuel with $\mathrm{UZr}_{2}$ as the matrix phase. Fuel shrinkage experiments show that the fuel loses mass (probably due to dehydriding) during heat treatments.

Comparing the results of the diffusion couples described above with those seen for the furnace tests performed using irradiated TRIGA fuel specimens, one can formulate the following conclusions. Due to the similarities seen in the developed microstructures, fission products do not appear to play a big role in dictating phase development, but instead seem to be soluble in the phases that form due to the interaction of fuel and cladding constituents. Fuel and cladding interaction zones observed for the irradiated TRIGA fuel specimen annealed at $950^{\circ} \mathrm{C}$ for $6 \mathrm{hr}$ and the out-of-pile diffusion couples annealed at $900^{\circ} \mathrm{C}$ for $24 \mathrm{hr}$ using an advanced diffusion couple jig and one annealed at $1000^{\circ} \mathrm{C}$ for $5 \mathrm{hr}$ using a standard jig, exhibit similar diffusion layer morphologies and partitioning behavior of various fuel and cladding constituents. Due to the strong similarities in the phases observed nearest the unreacted cladding, TEM analysis available for the annealed diffusion couple at $1000^{\circ} \mathrm{C}$ for $24 \mathrm{hr}$ suggests that the grain boundary phase moving into the cladding is a UFe 2 -type phase for the irradiated TRIGA fuel specimen annealed at $950^{\circ} \mathrm{C}$. The porosity for the annealed irradiated TRIGA fuel specimen and the annealed out-of-pile diffusion couple are only in localized regions on the fuel side of the interdiffusion zone (see Figure 87). This suggests gross melting does not occur in these specimens at temperatures of interest, and some of the porosity could be due to pullout during specimen polishing. 

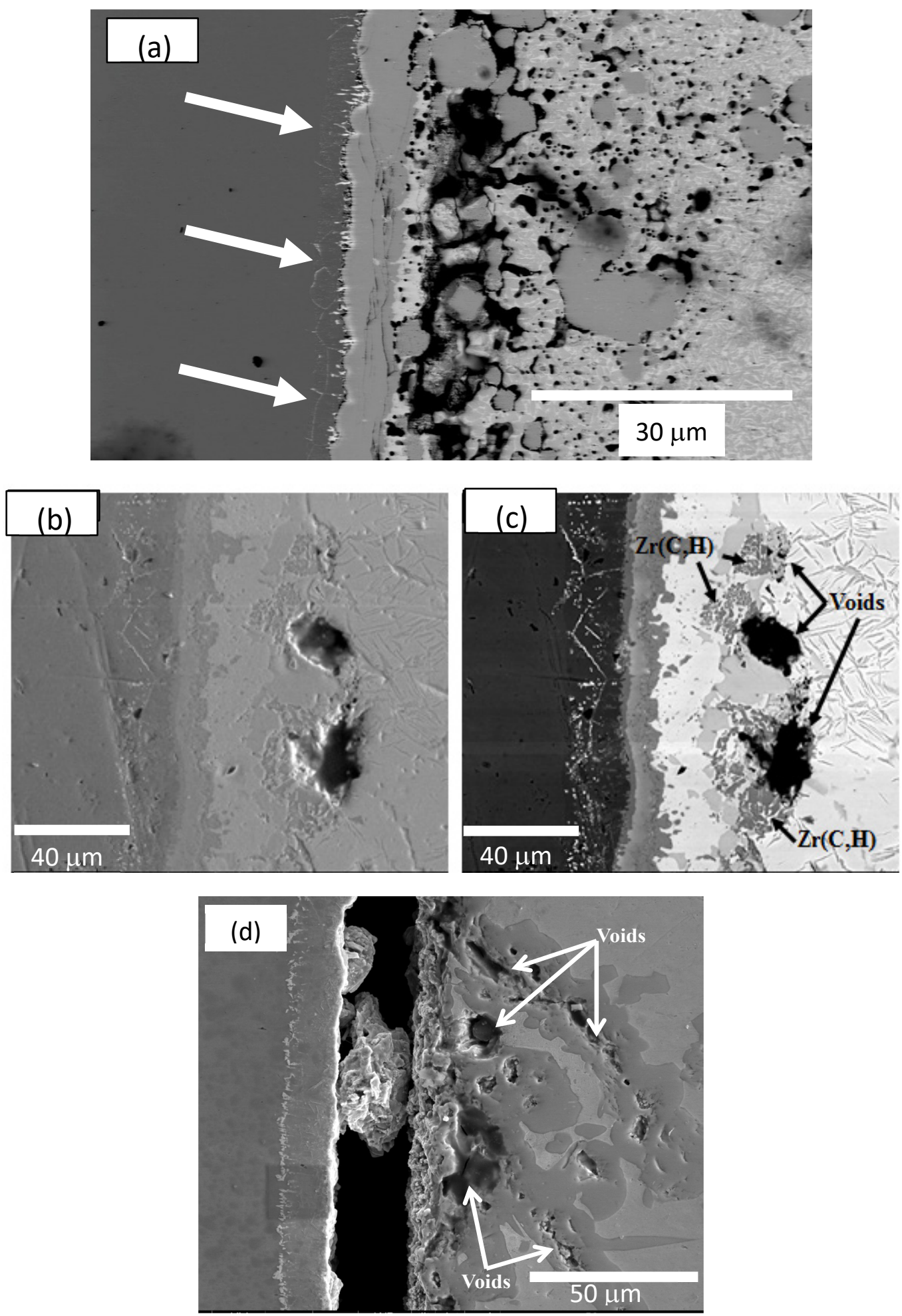

Figure 87. (a) a BSE image of the fuel and cladding interaction zone for the irradiated TRIGA fuel sample annealed at $950^{\circ} \mathrm{C}$ for $6 \mathrm{hr}$ (arrows show presence of bright-contrast phases that form along grain boundaries in the cladding), and an SE image (b) and BSE image (c) for the diffusion couple annealed at $900^{\circ} \mathrm{C}$ for $24 \mathrm{hr}$ using an advanced diffusion couple jig that keeps pressure at the fuel and cladding interface, and (d) BSE image for the diffusion couple annealed at $1000^{\circ} \mathrm{C}$ for $5 \mathrm{hr}$ that used a standard diffusion couple jig where debonding ultimately transpired leaving a gap. 


\subsubsection{Comparison to Phase Diagrams}

The U-Zr phase diagram shown in Figure 88 suggests that at temperatures above $612^{\circ} \mathrm{C}$, a phase with a $\mathrm{Zr}$ content near 80 at.\% should be gamma phase, not $\mathrm{UZr}_{2}$. Yet, this is not the case for high-temperature annealed TRIGA fuel where $\mathrm{UZr}_{2}$ phase has been confirmed to be present at a temperature of $1000^{\circ} \mathrm{C}$, and this is likely due to the hydrogen in the system that seems to be stabilizing this lower temperature phase to high temperature. Laves phases, like $\mathrm{UZr}_{2}$, are known to be stabilized by hydrogen and they accommodate significant hydrogen $[7,8]$.

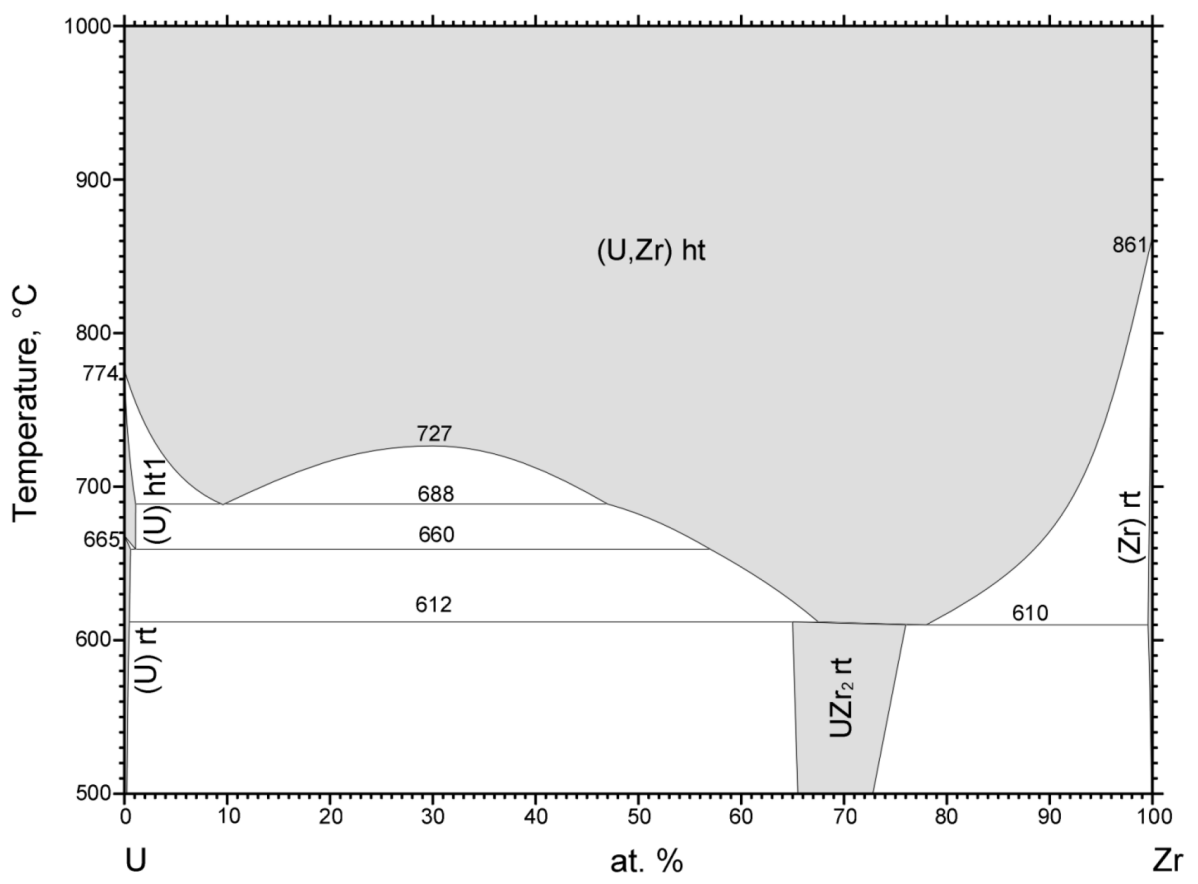

Figure 88. U-Zr equilibrium phase diagram [9].

For a U-bearing fuel that is in contact with an Fe-based cladding, it is common to look at the U-Fe phase diagram (see Figure 89) to get an idea about phases that may be present due to the interaction of a fuel and cladding. However, there are so many other constituents in irradiated fuel and cladding that it is unlikely to see binary phases. The U-Fe phase diagram suggests that, depending on composition, the $\mathrm{UFe}_{2}$ or $\mathrm{U}_{6} \mathrm{Fe}$ can form, and at the eutectic composition between these two phases melting can take place at $725^{\circ} \mathrm{C}$. As it turns out, based on TEM analysis performed on a $1000^{\circ} \mathrm{C}$-annealed TRIGA fuel Type $304 \mathrm{SS}$ diffusion couple a binary UFe $\mathrm{U}_{2}$-type phase may in fact be present, and it is possible that this phase is present when irradiated TRIGA fuel interacts with Type 304SS at high temperatures. This phase is observed along grain boundaries and possibly as fine precipitates nearest the unreacted cladding. As shown in Figure 89, this phase has a melting point of $1230^{\circ} \mathrm{C}$. With respect to the eutectic composition that exists at around $90 \mathrm{U}-10 \mathrm{Fe}$ (wt.\%) or around 65U-35Fe (at.\%), this composition has not been measured to date, and the lamellar microstructure that is typical of such a eutectic region has not been observed. 


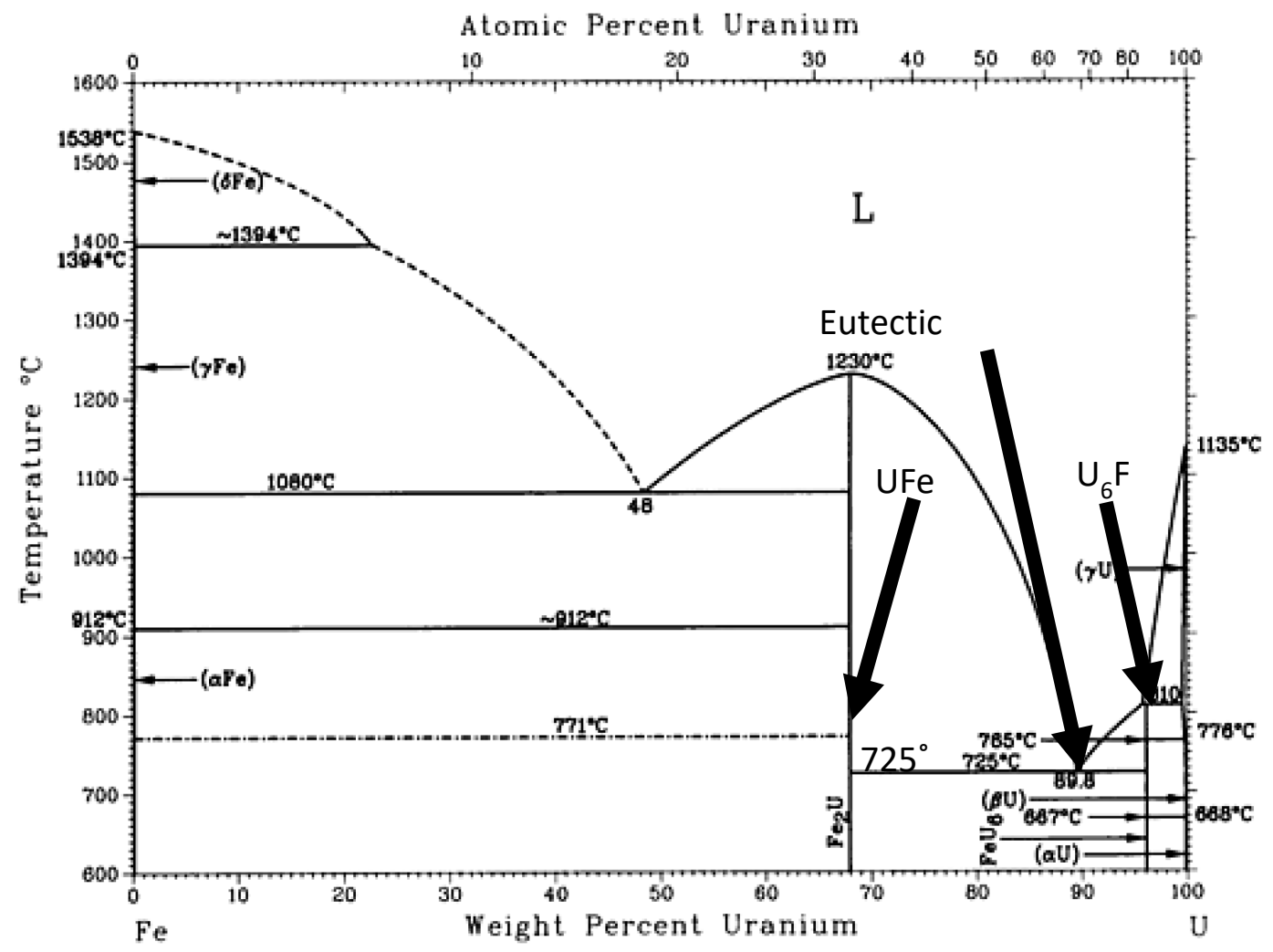

Figure 89. U-Fe equilibrium phase diagram [3].

Zr-rich phases that contain iron have been observed in the fuel and cladding interaction zones for annealed diffusion couples and the irradiated TRIGA fuel specimen annealed at $950^{\circ} \mathrm{C}$ for $6 \mathrm{hr}$. The $\mathrm{Fe}-\mathrm{Zr}$ phase diagram (see Figure 90) indicates that the main phases at the Zr-rich side of the diagram include $\mathrm{FeZr}_{2}$ and $\mathrm{FeZr}_{3}$. At $928^{\circ} \mathrm{C}$, a eutectic composition exists around 75 at.\% $\mathrm{Zr}$ and 25 at.\% Fe.

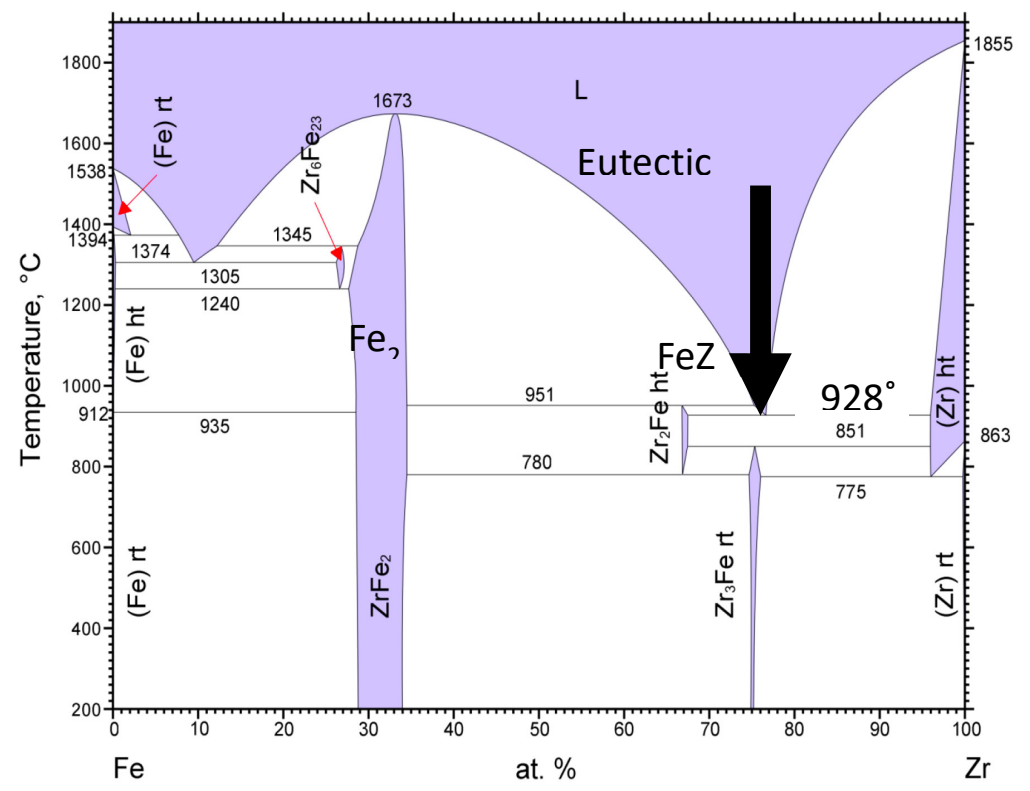

Figure 90. Fe-Zr equilibrium phase diagram [3]. 
As mentioned earlier, most phases that have been identified in the annealed diffusion couples contain many components, and the heat-treated irradiated fuel specimens also contain fission products, and as a result, the benefit of evaluating binary phase diagrams is very limited. It is more beneficial to utilize phase diagrams that contain many more than two components. However, these diagrams are not available. The most prevalent multicomponent diagrams are ternary phase diagrams. U-Zr-Fe phase diagrams are ternary diagrams that could be of interest. Figure 91 presents diagrams at $700^{\circ} \mathrm{C}$ and $800^{\circ} \mathrm{C}$. These are of interest since $\mathrm{U}$ and $\mathrm{Zr}$ are major TRIGA fuel constituents, and $\mathrm{Fe}$ is the most prevalent Type 304SS component. The dashed line in (b) shows a general description of how a diffusion path could be drawn through the phase diagram to describe the observed phases moving from the fuel to the cladding in an annealed diffusion couple, where Fe represents the cladding constituents. Diffusion paths are an accepted way to use ternary diagrams to describe the phases that form in a diffusion couple [10].

(a)
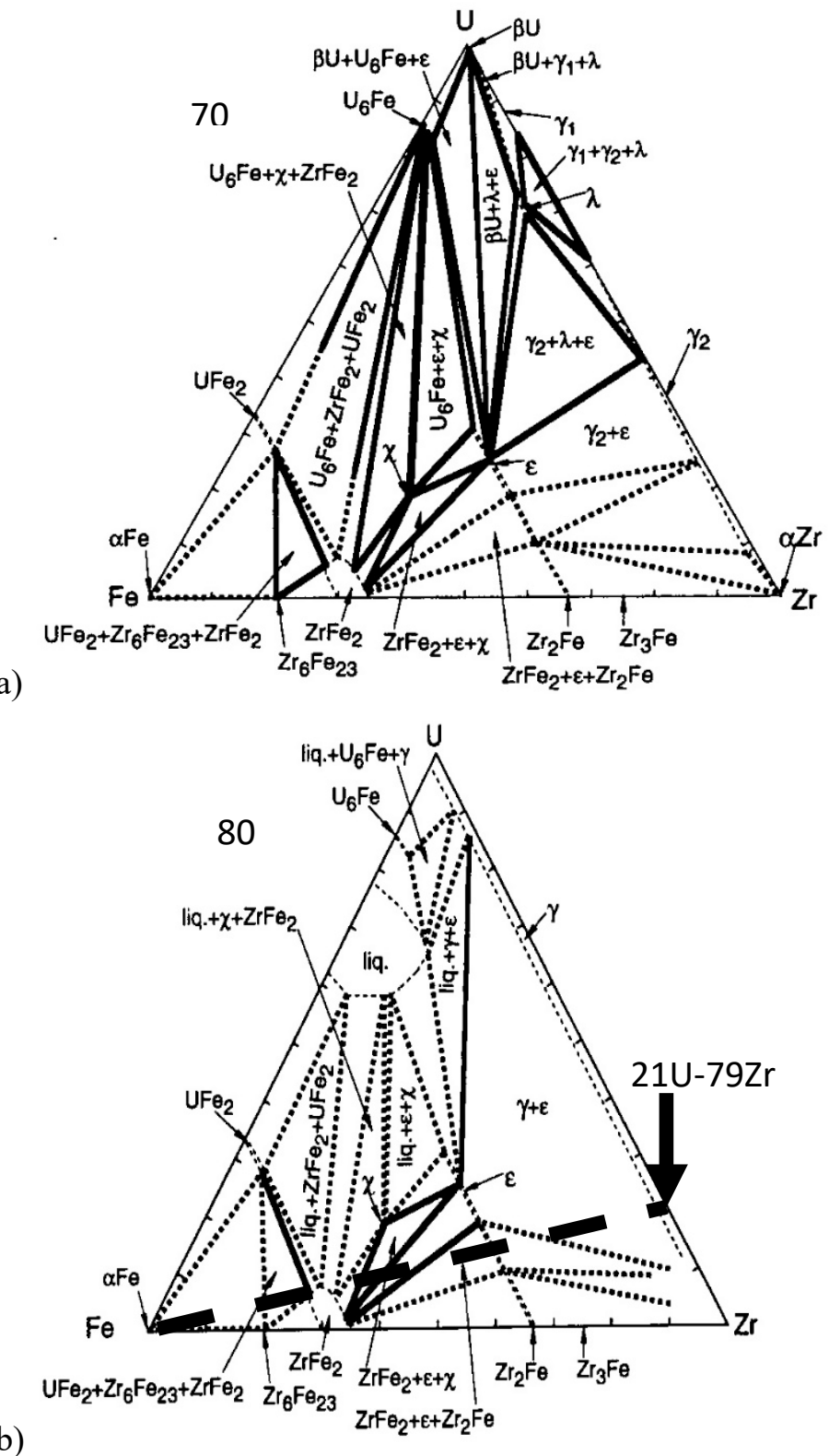

Figure 91. U-Zr-Fe ternary phase diagrams at (a) $730^{\circ} \mathrm{C}$ and (b) $800^{\circ} \mathrm{C}$. The dashed line in (b) shows in a general way how a diffusion path could move through the diagram and various phase regions for a diffusion couple going from the fuel with almost 80 at.\% $\mathrm{Zr}$ to the cladding [11]. 
Based on the $800^{\circ} \mathrm{C} \mathrm{U}-\mathrm{Zr}-\mathrm{Fe}$ phase diagram, multiphase layers would be present for a diffusion couple annealed at $800^{\circ} \mathrm{C}$ nearest the unreacted $\mathrm{UZr}_{2}$ fuel that would contain phases like $\gamma, \varepsilon, \mathrm{X}$, and $\mathrm{FeZr}_{2}$. Depending on how the diffusion path moves through the diagram, it could pass through a threephase region where small amounts of a liquid phase could be present. Nearest the cladding side (as represented by $\mathrm{Fe}$ in the diagram), a layer with $\mathrm{UFe}_{2}, \mathrm{Zr}_{6} \mathrm{Fe}_{23}$, and $\mathrm{Fe}_{2} \mathrm{Zr}$ could be present. A ternary phase region is present in the diagram that contains a liquid phase, $\mathrm{Fe}_{2} \mathrm{Zr}$, and $\mathrm{UFe}_{2}$. The usefulness of this kind of ternary diagram is very limited for describing the actual phases that could be present, since a TRIGA fuel/Type 304SS diffusion couple contains way more than just the three components Fe, U, and Zr. Yet, it does suggest that $\mathrm{UFe}_{2}$ should be the major U-Fe phase one should look for near the cladding, and $\mathrm{Fe}_{2} \mathrm{Zr}$ and $\mathrm{FeZr}_{2}$ are the major $\mathrm{Fe}-\mathrm{Zr}$ phases to look for moving towards the fuel. As it turns out, TEM analysis was used to confirm that $\mathrm{UFe}_{2}$ was present in a TRIGA fuel/Type 304SS diffusion couple annealed at $1000^{\circ} \mathrm{C}$ for $5 \mathrm{hr}$ nearest the unreacted cladding.

Finally, it is of interest to compare the irradiated TRIGA fuel furnace heating results with those reported for fuel segments of other $U$ and $\mathrm{Zr}$-containing fuels. Results have been reported for U-10 wt.\% $\mathrm{Zr}$ fuel irradiated in the Experimental Breeder Reactor-II that were heated in the Fuel Behavior Test Apparatus (FBTA) $[1,11,12]$. Figure 92 compares OM images of $\mathrm{U}-10 \mathrm{Zr}$ segments heated at $750^{\circ} \mathrm{C}$ and $800^{\circ} \mathrm{C}$ for $1 \mathrm{hr}$ with those for fuel segments from irradiated TRIGA fuel heated at $950^{\circ} \mathrm{C}$ for 6 and $12 \mathrm{hr}$ and $1000^{\circ} \mathrm{C}$ for $6 \mathrm{hr}$. There is significant evidence of melting that extends towards the center of the heattreated irradiated U-10Zr fuel and little evidence of melting for the heat-treated irradiated TRIGA fuel. This shows how stabilized $\mathrm{UZr}_{2}$ phase, which comprises much of the irradiated TRIGA fuel segments at relatively high temperatures, is more resistant to liquefaction compared to a fuel without this stabilized phase. This is the case even when there is FCCI with the Type 304SS. 
(a)

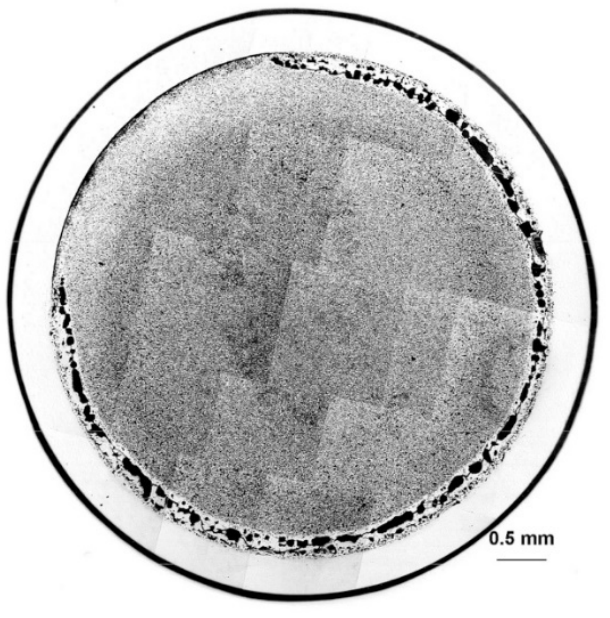

(c)

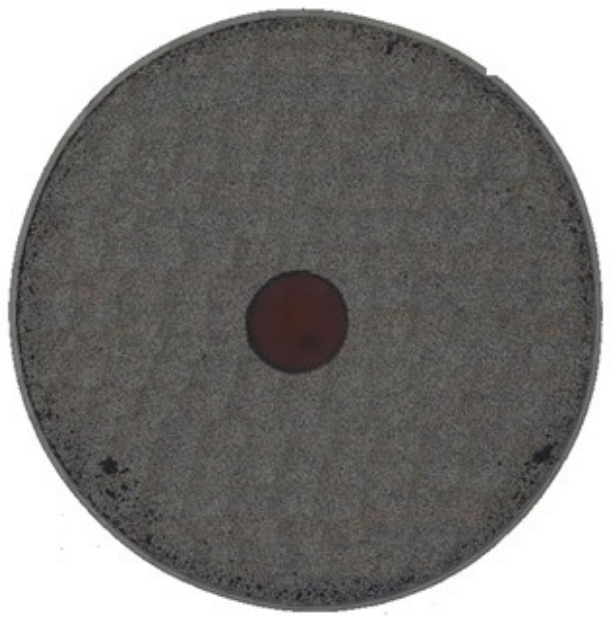

(d)

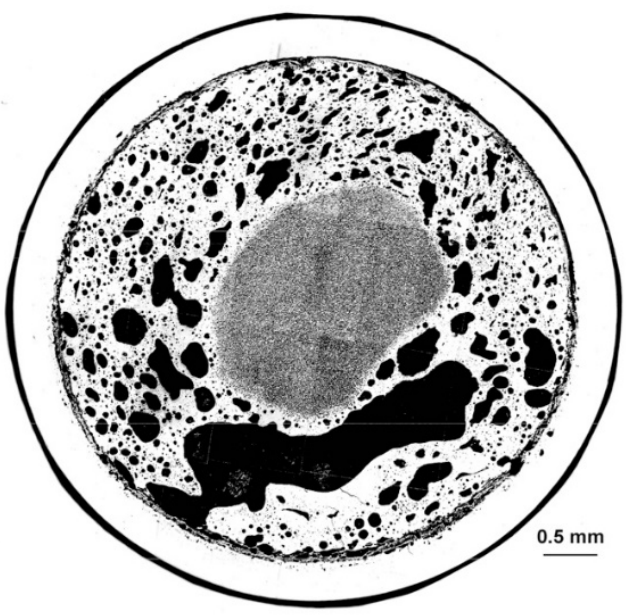

(b)
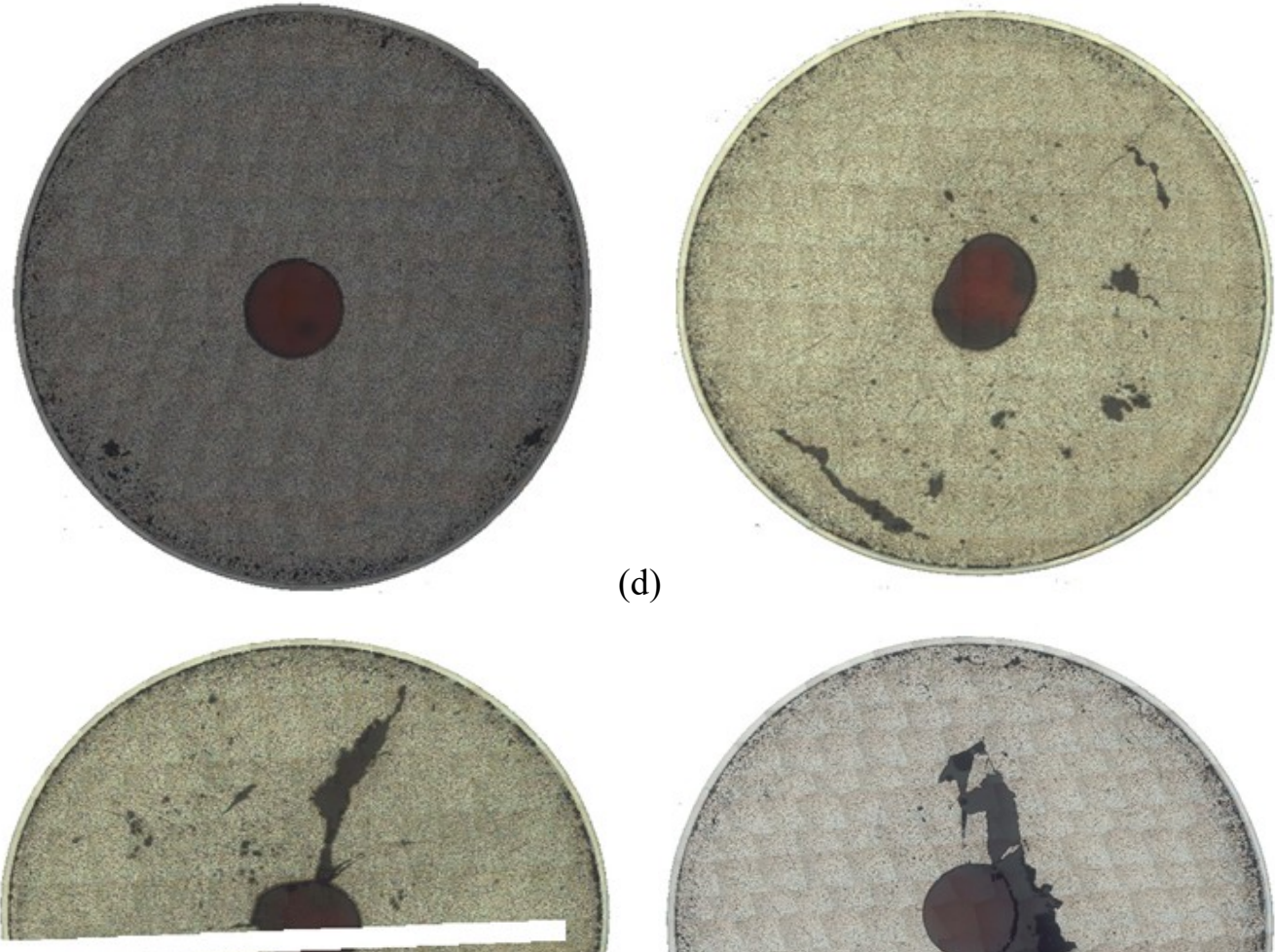

(e)

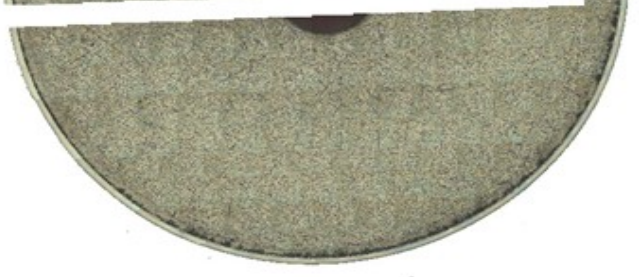

(f)

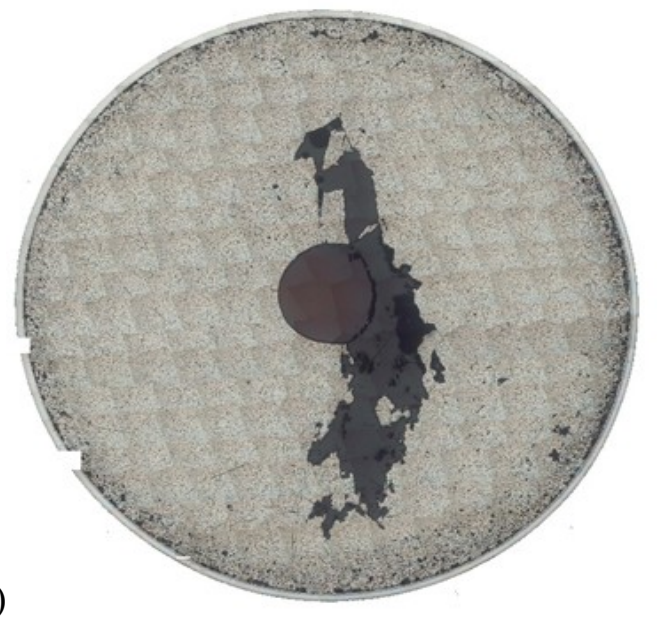

Figure 92. (a) OM image of a FBTA test result showing an HT9-Clad U-10Zr fuel pin segment ( 3 at.\% BU) after being heated at $750^{\circ} \mathrm{C}$ for $1 \mathrm{hr}$ and (b) OM image of a FBTA test result showing an HT9-Clad $\mathrm{U}-10 \mathrm{Zr}$ fuel pin segment ( 3 at.\% BU) after being heated at $800^{\circ} \mathrm{C}$ for $1 \mathrm{hr}$. Note that all but the fuel center has been at least partially melted, and the cladding has not been fully penetrated. (c-f) shows OM images of the microstructures for irradiated TRIGA fuel segments after heating at (c-d) $950^{\circ} \mathrm{C}$ for $6 \mathrm{hr}$, (e) $950^{\circ} \mathrm{C}$ for $12 \mathrm{hr}$, and (f) $1000^{\circ} \mathrm{C}$ for $6 \mathrm{hr}$. 


\section{SUMMARY}

In the Hot Fuel Examination Facility at INL, irradiated TRIGA fuel specimen furnace tests were run for $6 \mathrm{hr}$ at $730,800,900,950$, and $1000^{\circ} \mathrm{C}$, and one test was run for $12 \mathrm{hr}$ at $950^{\circ} \mathrm{C}$, to investigate liquefaction development at high temperatures. Post-test microstructural characterization was performed using OM and selected SEM characterization. The data from these tests were compared to available diffusion couple data and phase diagrams. The following items summarize the major findings of this work:

1. Non-destructive examinations of the as-received TRIGA fuel rods showed that there was only minor cracking and dehydriding in the irradiated fuel-rod fuel pellets such that high-quality specimens could be sectioned from the highest-burnup region of the highest-burnup fuel rod for use in the planned furnace tests.

2. OM and SEM analysis of an as-irradiated specimen before furnace heat treating showed the presence of a gap (around 50-75 $\mu \mathrm{m}$ wide) at the fuel and cladding interface. Intimate contact was not observed, and after careful examination of the outer surface of the fuel pellet and the inner surface of the cladding, no evidence was found to suggest there had been any contact during irradiation.

3. SEM analysis demonstrated that for an irradiated TRIGA fuel specimen annealed at $730^{\circ} \mathrm{C}$ the original fuel and cladding gap is still present. After careful examination of the outer surface of the fuel pellet and the inner surface of the cladding, no evidence was found to suggest there had been any contact during irradiation or the heat treatment that may have resulted in fuel and cladding interaction.

4. The results of OM analysis of irradiated TRIGA fuel specimens annealed at high temperatures, from $730^{\circ} \mathrm{C}$ to $1000^{\circ} \mathrm{C}$, suggest that gross melting had not occurred in any specimens.

5. $\mathrm{OM}$ analysis was used to determine that the specimens annealed at $950^{\circ} \mathrm{C}$ and $1000^{\circ} \mathrm{C}$ had exhibited signs of FCCI, and OM images could not be used to identify any obvious signs of liquefaction. This analysis indicated that even for the specimens that showed interaction, a majority of the cladding was unreacted. The specimen tested at $1000^{\circ} \mathrm{C}$ still had over $75 \%$ of the cladding that was unreacted. For the part of the cladding that was interacted, penetration into the cladding of a grain boundary phase was observed.

6. SEM analysis of samples cut from the specimen heat treated at $950^{\circ} \mathrm{C}$ for $6 \mathrm{hr}$ exhibited a change in the fuel microstructure vis-a-vis what was observed for the as-irradiated specimen. The highertemperature microstructure was found to consist of a $\mathrm{Zr}$-rich (over 80 at.\% $\mathrm{Zr}$ ) $(\mathrm{Zr}, \mathrm{U})$ matrix phase with isolated regions of a $\mathrm{Zr}$-rich phase that contained $\mathrm{C}$ or $\mathrm{H}$.

7. SEM analysis of samples cut from the specimen heat treated at $950^{\circ} \mathrm{C}$ for $6 \mathrm{hr}$ demonstrated that the bulk of the fuel and cladding interaction zone extended into the fuel, and not into the cladding. Only localized porosity was observed into the fuel that might suggest melting, and the majority phases in these regions contained $\mathrm{Zr}, \mathrm{C}$, or $\mathrm{H}$.

8. No Fe-bearing phases with high levels of lanthanide fission products, which could be low melting based on binary phase diagrams, were observed to penetrate into the cladding in the irradiated specimen that was annealed at $950^{\circ} \mathrm{C}$ for $6 \mathrm{hr}$ and then examined using SEM to demonstrate it contained fuel and cladding interaction layers. The most Fe-rich precipitates were observed near the unreacted fuel, and they also contained $\mathrm{Ni}$.

9. The grain boundary phase observed with $\mathrm{OM}$, when examining the specimens heat treated at $950^{\circ} \mathrm{C}$ and $1000^{\circ} \mathrm{C}$, was found to be U-rich when SEM was subsequently employed to examine the $950^{\circ} \mathrm{C}$ sample. 
10. Out-of-pile diffusion experiments have been performed using as-fabricated TRIGA fuel and Type $304 \mathrm{SS}$ at temperatures up to $1000^{\circ} \mathrm{C}$. The fuel and cladding interaction zones observed for the irradiated TRIGA fuel specimen annealed at $950^{\circ} \mathrm{C}$ for $6 \mathrm{hr}$ exhibited similarities with the out-of-pile diffusion couples annealed at $900^{\circ} \mathrm{C}$ for $24 \mathrm{hr}$ using an advanced diffusion couple jig that maintained pressure at the fuel and cladding interface and one annealed at $1000^{\circ} \mathrm{C}$ for $5 \mathrm{hr}$ using a standard jig. The diffusion layers exhibited similar morphologies and partitioning behavior of the various fuel and cladding constituents. Due to the strong similarities in the phases observed nearest the unreacted cladding, TEM analysis available for the annealed diffusion couple at $1000^{\circ} \mathrm{C}$ for $24 \mathrm{hr}$ suggests that the grain boundary phase moving into the cladding is a $\mathrm{UFe}_{2}$-type phase for the irradiated TRIGA fuel specimen annealed at $950^{\circ} \mathrm{C}$.

11. The porosity that develops in the annealed irradiated TRIGA fuel specimen and also in the annealed out-of-pile diffusion couple at high temperatures is only in localized regions on the fuel side of the interdiffusion zone. This suggests that the main fuel and cladding components are dictating the overall interaction behavior, and the eventual localized liquefaction seems to involve the major fuel constituents. The fission products, present only in the irradiated fuel specimen, are not playing a major role.

12. Based on the TEM characterization of unirradiated TRIGA fuel annealed at $950{ }^{\circ} \mathrm{C}$ and the XRD characterization of unirradiated TRIGA fuel annealed at $1000^{\circ} \mathrm{C}, \mathrm{UZr}_{2}$ is the $\mathrm{Zr}$-rich $\mathrm{Zr}-\mathrm{U}$ matrix phase that is observed in TRIGA fuel after heat treating at temperatures from $800^{\circ} \mathrm{C}$ to $1000^{\circ} \mathrm{C}$. This phase is likely stabilized by the hydrogen in the fuel pellet.

13. Based on the results of diffusion couple experiments performed at 950 and $1000^{\circ} \mathrm{C}$, there is a strong tendency for debonding of the fuel and cladding to occur during the interdiffusion process. Dehydriding of the TRIGA fuel can occur at these temperatures, resulting in fuel shrinkage (that was experimentally confirmed), and the result can be debonding and the formation of a gap between the fuel and cladding. Once a gap is present within the interaction zone, the interdiffusion process will stop.

\section{REFERENCES}

1. Dennis D. Keiser, Jr. and Douglas L. Porter, High Temperature Liquefaction at the Fuel/Cladding Interface in Zr-Containing Metallic Nuclear Fuels Clad with Iron- and Nickel-based Alloys, Idaho National Laboratory Report, INL/EXT-09-15598, August 2009.

2. Emmanuel Perez, Dennis D. Keiser, Jr., Bryan Forsmann, Dawn Janney, Jody Henley, Eric C. Woolstenhulme, High Temperature Fuel Cladding Chemical Interactions Between Unirradiated TRIGA Fuels and 304 Stainless Steel, Idaho National Laboratory Report, INL/EXT-15-36708, October 2015.

3. T. B. Massalski, ed. "Binary Alloy Phase Diagrams," $2^{\text {nd }}$ Ed., American Society for Metals, Metals Park, Ohio, 1990.

4. NUREG-1282, "Safety Evaluation Report on High-Uranium Content, Low Enriched UraniumZirconium Hydride Fuels for TRIGA Reactors,” Docket No. 50-163, U.S. Nuclear Regulatory Commission, August 1987.

5. Dennis D. Keiser, Jr., Jan-Fong Jue, Eric Woolstenhulme, Kurt Terrani, and Glenn A. Moore, Hightemperature Chemical Compatibility of As-fabricated TRIGA Fuel and Type 304 Stainless Steel Cladding, INL/EXT-12-27153, September 2012.

6. M. T. Simnad, "The U-ZrH Alloy: Its Properties and Use in TRIGA Fuel," E-117-833 (February 1980) 1-1. 
7. V. Buturlim, L. Havela, S. Sowa, N.-T.H. Kim-Ngan, M. Paukov, D. Drozdenko, M. Dopita, P. Minarik, S. Mašková, "Laves phase UTi2 stabilized by hydrogen and its magnetic properties," Physica B, Vol. 536, 2018, pp. 539-542.

8. Andreas Zuttel, "Materials for Hydrogen Storage," Materials Today, 2003, pp. 24-33. ISSN: 13697021.

9. ASM Alloy Phase Diagram Center. Eds: H. Okamoto and K. Cenzual. "U-Zr Phase Diagram." T. Ogawa, 1991, ASM International, Materials Park, Ohio, 2010.

10. D. D. Keiser, Jr. and M. A. Dayananda, "Interdiffusion Between U-Zr Fuel vs Selected Cladding Steels," Metall. Trans. A, 25A, 1994, pp. 1-5.

11. T. Hanchung, "Fuel/Cladding Compatibility in Irradiated Metallic Fuel Pins at Elevated Temperatures," Proceedings of the 1990 International Fast Reactor Safety Meeting, August 12-16, 1990, Snowbird, Utah: American Nuclear Society.

12. H. Tsai, D. Y. Wang, F. E. Savoie, and A. G. Hins, Fuel/Cladding Compatibility in Low-Burnup U-26Pu-10Zr/HT9 Fuel at Elevated Temperatures, Argonne National Laboratory, ANL-IFR-152, September 1991. 